DOE/WIPP 93-1001

Revision 3, December 1999

\title{
TRUPACT-II Operating and Maintenance Instructions
}

Robert A. Stroud, DOE

Acting Assistant Manager, Office of National TRU Waste Programs

Processing and final preparation of this paper was performed by Westinghouse Electric Corporation, Waste Isolation Division, the management and operating contractor for the Waste Isolation Pilot Plant under US Department of Energy contract number DE-AC04-86AL31950. This document has been submitted as required to:

\author{
Office of Scientific and Technical Information \\ P.O. Box 62 \\ Oak Ridge, TN 37831 \\ (615) 576-8401
}

Additional Information about this document may be obtained by calling (800) 336-9477. Copies may be obtained by contacting the National Technical Information Service, US Department of Commerce, 5285 Port Royal Road, Springfield, VA 22101. 


\section{RECORD OF REVISION}

Revision Reason for Revision/Change

$0 \quad$ New Procedure for TRUPACT-II Operations and Maintenance

1 This document revision is to incorporate changes and requirements for TRUPACT-II Operations and Maintenance. All TRU Waste sites will implement the instructions included in this revision. This document supercedes Revision 0

Rev 1, Chg. 1 This change incorporates changes in OCV lid removal procedures, addition of O-rings for leak check tools, and changes to TRUPACT-II Work Instructions.

\section{Record of Revision DOE/WIPP 93-1001 \\ Revision 2}

Section 1.7.3 added guidance for maintenance and calibration on the ACGLF Table 1.1 added Helium Leak detector and specifications as a required tool Table 1.2 added various instructions for use of miscellaneous tools and equipment

Section 1.7.5 added additional instructions for completing Table 1.3: TRUPACT-11 Spare Parts

Table 1.3 added two new columns: On Hand and Needed Spare Parts

Section 2.4 expanded instructions for material control

Section 2.10 new section explaining the TRUPACT - 11 Shipment Schedule

Section 3.0 added note

Section 4.3.7 clarified caution statement

Section 4.3 added note

Section 4.3.8 new section on rotating the locking ring

Section 4.4.9 clarified caution statement

Section 4.7.2 added steps when using nitrogen bottle

Section 4.7.3 added a warning and two caution statements

Section 4.9 added note

Section 4.11.8 clarified caution statement

Section 4.11.15 added note

Section 4.12.8 clarified caution statement

Section 4.12.13 added note

Attachment $\mathrm{H}$ new attachment "TRUPACT-II O-Ring Exchange Form" 


\begin{tabular}{|c|c|}
\hline \multirow[b]{2}{*}{ Section 1.1} & $\begin{array}{c}\text { Record of Revision } \\
\text { DOE/WIPP 93-1001 } \\
\text { TRUPACT-II Operating and Maintenance Instructions } \\
\text { Revision } 3\end{array}$ \\
\hline & $\begin{array}{l}\text { Deleted statement allowing users to prepare an independent document } \\
\text { and submitting it to WID for approval as being equivalent to these } \\
\text { instructions. }\end{array}$ \\
\hline Section 1.3 & $\begin{array}{l}\text { Added definitions of Annual Maintenance, Five-Year Maintenance, Leak } \\
\text { Check Due Tag, Out-of-Service. }\end{array}$ \\
\hline Section 1.5 .1 & Clarification of TRUPACT-II description. \\
\hline Section 1.7 .3 & Clarification of maintenance/calibration recommendations for the ACGLF. \\
\hline Table 1.1 & $\begin{array}{l}\text { Added TRUPACT-II "shadow board" as a required tool for a Fixed Loading } \\
\text { Facility. Revised various quantities. }\end{array}$ \\
\hline Table 1.2 & $\begin{array}{l}\text { Added Tamper Indicating Device as a user supplied recommended item } \\
\text { for operations. }\end{array}$ \\
\hline Section 1.7 .5 & Editorial clarification for figures 1.13 and 1.14 \\
\hline Section 2.6 & Clarification of training requirements. \\
\hline Section 2.9 & Editorial changes \\
\hline Section 3.0 & $\begin{array}{l}\text { Added guide chart for establishing total payload weight for drums and } \\
\text { Standard Waste Boxes. }\end{array}$ \\
\hline Section 3.1 .2 & Added note on diameter of drums in the payload. \\
\hline Section 3.1 .5 & Reword text to provide more explicit guidance. \\
\hline Section 3.1 .6 & Deleted \\
\hline Section 3.1 .9 & Reword text to provide more explicit guidance. \\
\hline Section 3.2.7 & $\begin{array}{l}\text { Added section for ensuring all Standard Waste Boxes are properly } \\
\text { labeled. }\end{array}$ \\
\hline Section 4.0 & Entire Section and subsections were revised. \\
\hline $\begin{array}{l}\text { Attachment H } \\
\text { Requirements }\end{array}$ & O-ring Exchange form - Deleted, replaced by TRUPACT-II Qualification \\
\hline
\end{tabular}




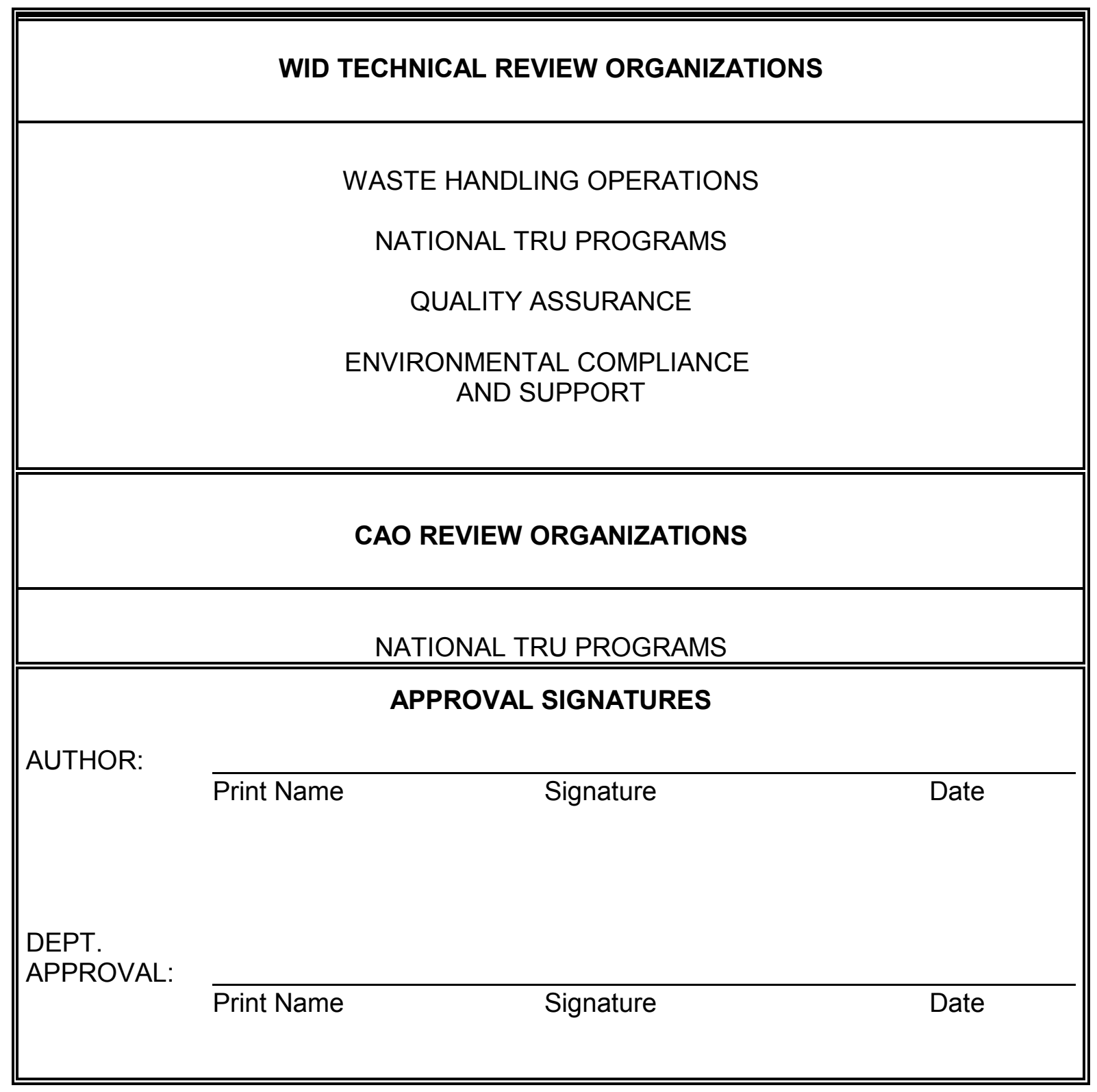




\section{TABLE OF CONTENTS}

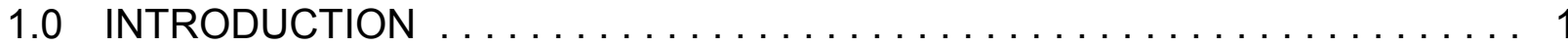

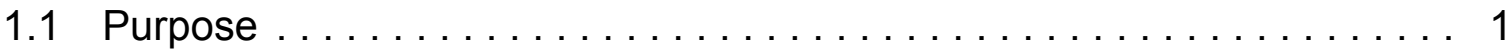

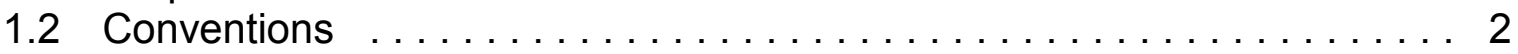

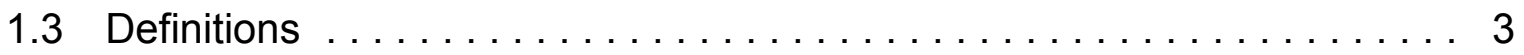

1.4 Preshipment Requirements $\ldots \ldots \ldots \ldots \ldots \ldots \ldots \ldots \ldots \ldots \ldots \ldots$

1.5 Equipment Description $\ldots \ldots \ldots \ldots \ldots \ldots \ldots \ldots \ldots \ldots \ldots$

1.6 TRUPACT-II Mobile Loading Unit $\ldots \ldots \ldots \ldots \ldots \ldots \ldots \ldots \ldots$

1.7 Seal-Test-Port and Vent-Port Tools $\ldots \ldots \ldots \ldots \ldots \ldots \ldots \ldots \ldots$

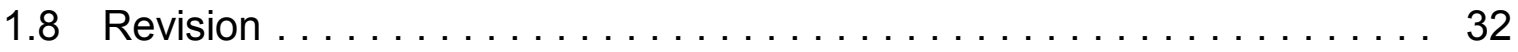

2.0 GENERAL REQUIREMENTS $\ldots \ldots \ldots \ldots \ldots \ldots \ldots \ldots \ldots \ldots \ldots \ldots \ldots \ldots \ldots$

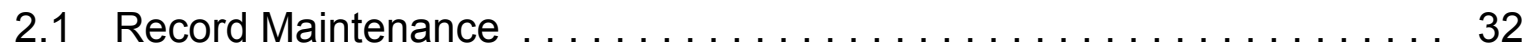

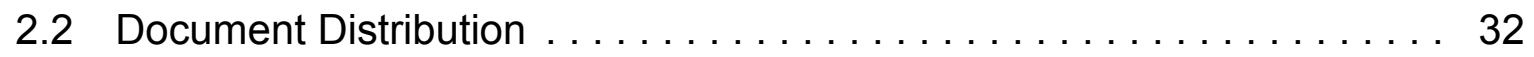

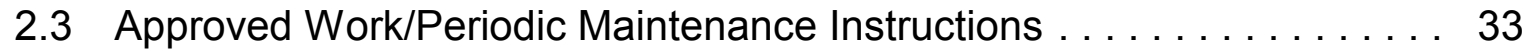

2.4 Material Control . . . . . . . . . . . . . . . . . . . . . . 33

2.5 Quality Assurance Requirements $\ldots \ldots \ldots \ldots \ldots \ldots \ldots \ldots \ldots \ldots$

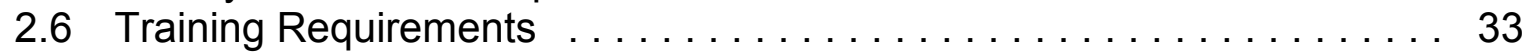

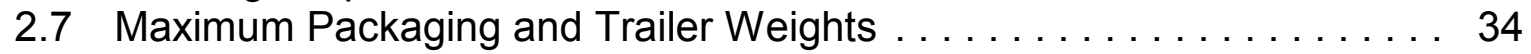

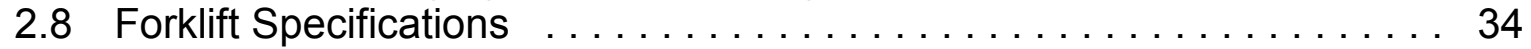

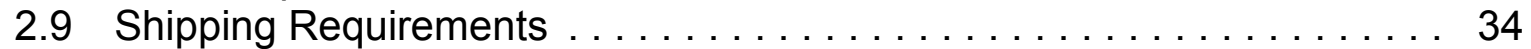

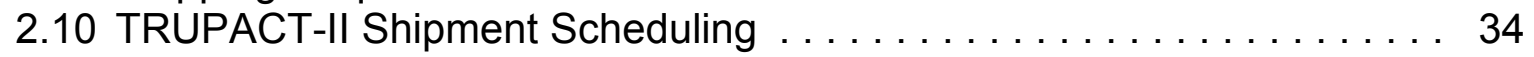

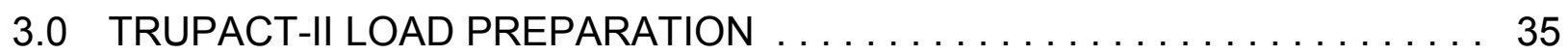

3.1 Preparing a Drum Payload Assembly $\ldots \ldots \ldots \ldots \ldots \ldots \ldots \ldots \ldots \ldots$

3.2 Preparing a SWB Payload Assembly $\ldots \ldots \ldots \ldots \ldots \ldots \ldots \ldots \ldots$

3.3 Preparing a TDOP Payload Assembly $\ldots \ldots \ldots \ldots \ldots \ldots \ldots \ldots$

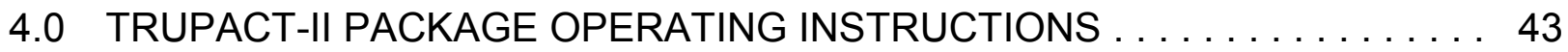

4.1 TRUPACT-II Operating Tips and Techniques ............... 43

4.1.1 Unloading a TRUPACT-II from a trailer . . . . . . . . . . . 43

4.1.2 Outer Containment Assembly (OCA)/Inner Containment Vessel (ICV)

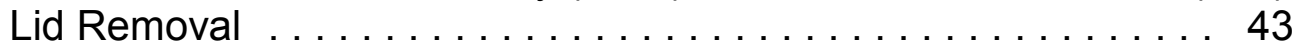

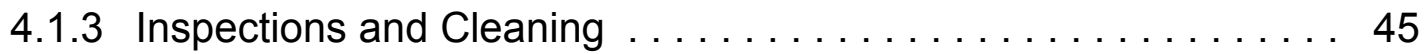

4.1 .4 Loading a Payload ....................... 45

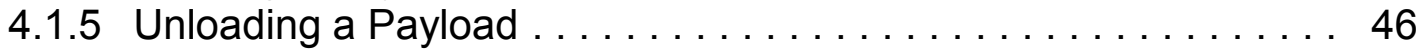

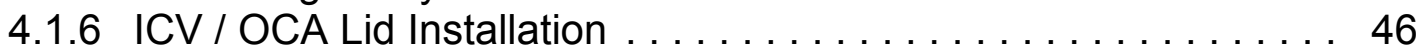

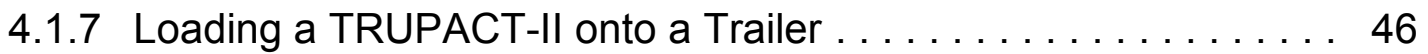

4.1 .8 Lifting A Stuck Lid . . . . . . . . . . . . . . . . 47

4.1.9 Releasing Tiedowns and Removal of a Package from the Trailer 47

4.2 Notes and Cautions Regarding TRUPACT-II Operating Instructions: . . 48

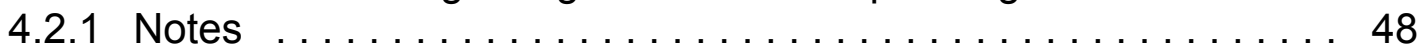

4.2 .2 Cautions .......................... 49

4.3 TRUPACT-II Package Operating Instructions $\ldots \ldots \ldots \ldots \ldots \ldots \ldots 50$

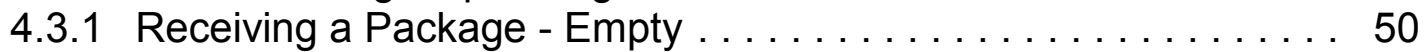

4.3.2 Releasing Tie-downs and Removal of a Package from the Trailer 51

4.3 .3 OCA Lid Removal . . . . . . . . . . . . . . . . . 51 


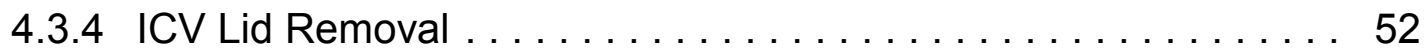

4.3.5 Preloading/Shipping Operational Checks and Examinations ... 53

4.3.6 Outer Containment Assembly (OCA) Lid Inspection and Preparation

4.3.7 Inner Containment Vessel (ICV) Lid Inspection and Preparation . 54

4.3.8 OCA Body Inspection and Preparation . . . . . . . . . . . 55

4.3.9 OCA components preparation and inspection .......... 55

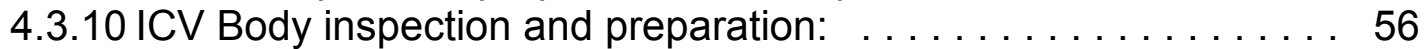

4.3.11 ICV Components Preparation and Inspection $\ldots \ldots \ldots \ldots \ldots .57$

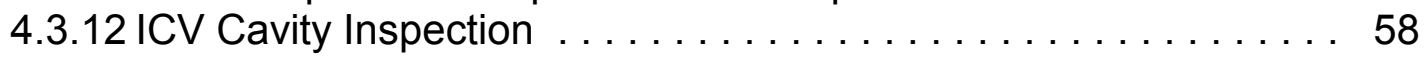

4.3.13 Pre-loading Operations $\ldots \ldots \ldots \ldots \ldots \ldots \ldots \ldots \ldots . \ldots \ldots$

4.3.14 TRUPACT-II Receipt and Inspection Data Sheet Validation ... 58

4.3.15 Loading a Payload Assembly . . . . . . . . . . . . . . . 58

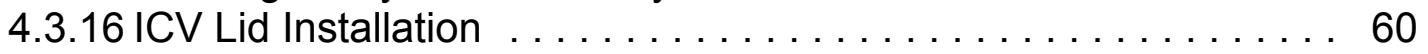

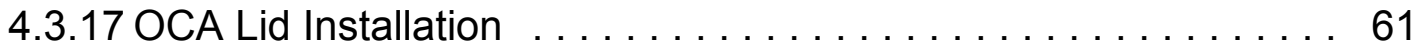

4.3.18 Installation of the Package onto the Transport Trailer . . . . . 62

4.3.19 Receiving a Package - Loaded .................. 64

4.3.20 Releasing Tie-downs and Removal of a Package from the Trailer 64

4.3 .21 OCA Lid Removal . . . . . . . . . . . . . . . . . . . 65

4.3.22 ICV Lid Removal . . . . . . . . . . . . . . . . . . . . 66

4.3.23 Unloading a Payload Assembly . . . . . . . . . . . . 67

4.3.24 TRUPACT-II Shipment Operational Checks and Examinations . 68 4.3.25 Outer Containment Assembly (OCA) Lid Inspection and Preparation

4.3.26 Inner Containment Vessel (ICV) Lid Inspection and Preparation . 70

4.3.27 OCA Body Inspection and Preparation . . . . . . . . . . . 70

4.3.28 OCA Components Preparation and Inspection . . . . . . . . . 71

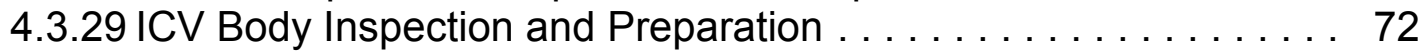

4.3.30 ICV Components Preparation and Inspection . . . . . . . . 72

4.3.31 ICV Cavity Inspection . . . . . . . . . . . . . . . . 73

4.3 .32 ICV Lid Installation $\ldots \ldots \ldots \ldots \ldots \ldots \ldots \ldots \ldots \ldots \ldots \ldots \ldots$

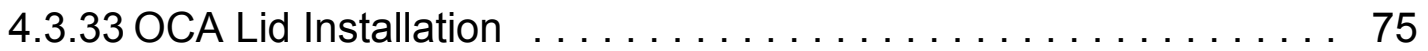

4.3.34 Installation of the Package onto the Transport Trailer . . . . . 76

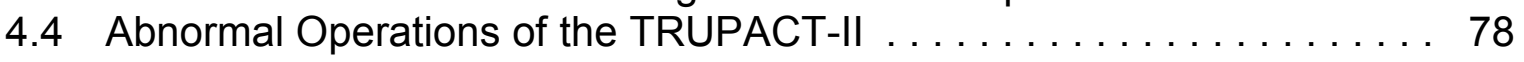

4.4.1 Empty ICV Assembly Removal - (If Water Found in ICV or Annual

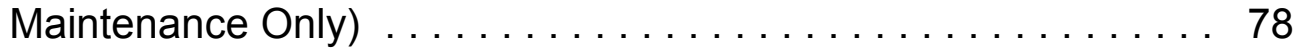

4.4 .2 Using Heat Guns $\ldots \ldots \ldots \ldots \ldots \ldots \ldots \ldots \ldots \ldots \ldots$

4.4.3 Pressurizing with Nitrogen or Compressed Air . . . . . . . . . 79

5.0 TRUPACT-II PACKAGE MAINTENANCE INSTRUCTIONS $\ldots \ldots \ldots \ldots 82$

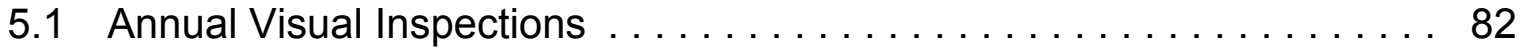

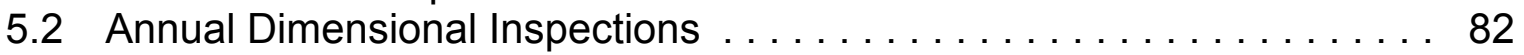

5.3 Annual ICV Interior Surfaces Inspection $\ldots \ldots \ldots \ldots \ldots \ldots \ldots . \ldots 3$

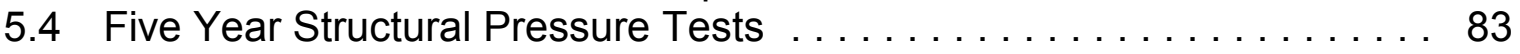

5.5 Packaging Component Replacement Schedule .............. 83

5.6 Periodic Transport Trailer Inspections and Component Replacement Schedule .............................. 84

5.7 Periodic Lift Fixture Inspections and Component Replacement Schedule 84 
5.8 TRUPACT-II Maintenance Records (Form 1709) . . . . . . . . . . . 84

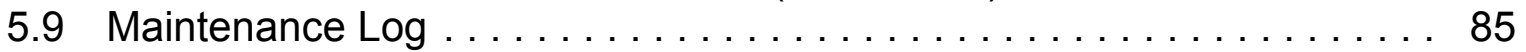

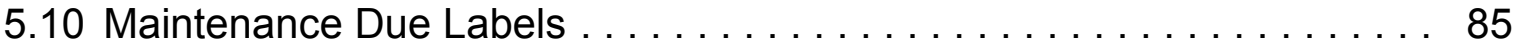

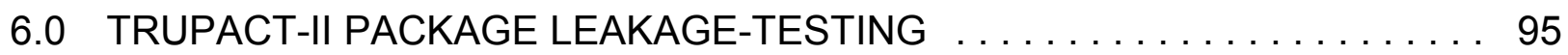

6.1 Assembly Leak-Testing the ICV Containment Seals ............... 95

6.2 Assembly Leak-Testing the OCV Containment Seals . . . . . . . . . . . 97

6.3 Leak-Testing the ICV Containment Seals and Structure ........... . 99

6.4 Assembly Leak-Testing the OCV Containment Seals and Structure . . 102

7.0 TRUPACT-II PACKAGE STRUCTURAL PRESSURE-TESTING $\ldots \ldots \ldots 112$

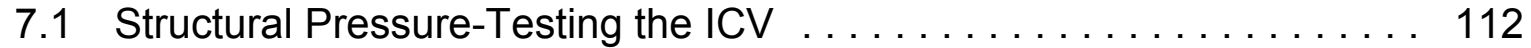

7.2 Structural Pressure-Testing the OCV $\ldots \ldots \ldots \ldots \ldots \ldots \ldots \ldots 113$

Attachment A - TRUPACT-II Data Sheet $\ldots \ldots \ldots \ldots \ldots \ldots \ldots \ldots \ldots \ldots$ A-1

Attachment B - TRUPACT-II Leakage and Pressure-Test Data Sheets . . . . . . . . . B-1

Attachment C - TRUPACT-II Work Instruction Format $\ldots \ldots \ldots \ldots \ldots \ldots$ C-1

Attachment D - TRUPACT-II Approved Work Instructions .............. D-1

Attachment E - Miscellaneous System Interface and Tool Drawings ......... E-1

Attachment F - TRUPACT-II Certificate of Compliance

(NRC Docket No. 71-9218) . . . . . . . . . . . . . . . . . . . . F-1

Attachment G - TRUPACT- II Safety Analysis Report for Packaging (SARP General Arrangement Drawings) $\ldots \ldots \ldots \ldots \ldots \ldots \ldots \ldots \ldots \ldots$ G-1

Attachment H - TRUPACT- II Qualification Requirements .............. H-1 


\section{LIST OF FIGURES}

Figure $1.1 \quad$ TRUPACT-II Mobile Loading Unit $\ldots \ldots \ldots \ldots \ldots \ldots \ldots \ldots$

Figure 1.2 TRUPACT-II Shipping Package $\ldots \ldots \ldots \ldots \ldots \ldots \ldots \ldots \ldots$

Figure 1.3 ICV/OCV Vent-Port Cover Removal Tool (2077-092-A1) . . . . . . 17

Figure 1.4 OCV Vent-Port-Plug Removal/Pressure Relief Tool

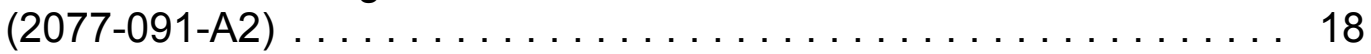

Figure 1.5 OCV Vent-Port-Plug-Leak Check Tool (2077-095-A1) . . . . . . . 19

Figure 1.6 OCV Seal-Test-Port-Plug Removal Tool (2077-094-A2) . . . . . . . 20

Figure 1.7 OCV Seal-Leak Check Tool (2077-093-A2) . . . . . . . . . . . 21

Figure 1.8 ICV Vent-Port-Plug Removal/Pressure Relief Tool

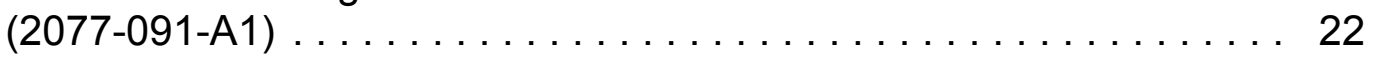

Figure 1.9 ICV Vent-Port-Plug Removal/Pressure Relief Tool with adapter $(2077-091-A 1) \quad \ldots \ldots \ldots \ldots \ldots \ldots \ldots \ldots .23$

Figure 1.10 ICV Vent-Port-Plug Leak Check Tool (2077-095-A2) . . . . . . . 24

Figure 1.11 ICV Seal-Test-Port-Plug Removal Tool (2077-094-A1) . . . . . . . 25

Figure 1.12 ICV Seal-Leak Check Tool (2077-093-A1) . . . . . . . . . . . 26

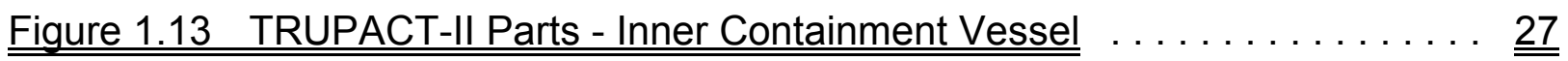

Figure 1.14 TRUPACT-II Parts - Outer Containment Vessel $\ldots \ldots \ldots \ldots \ldots \underline{\underline{28}}$

Figure 3.1 TRUPACT-II Drum Placement $\ldots \ldots \ldots \ldots \ldots \ldots \ldots \ldots \ldots$

Figure 3.2 Fourteen-Pack Assembly, Typical . . . . . . . . . . . . . 39

Figure 3.3 SWB and Adjustable Lifting Slings $\ldots \ldots \ldots \ldots \ldots \ldots \ldots$

Figure 4.1 Flow Diagram for Nitrogen Bottle ICV/OCA Compressed Air Lid Pressurization $\ldots \ldots \ldots \ldots \ldots \ldots \ldots \ldots \ldots \ldots \ldots \ldots$

Figure 5.1 Example TRUPACT-II Maintenance Record . . . . . . . . . . 86

Figure 6.1 O-Ring Seal Leak-Test Setup Support Arrangement for Assembled ICV . . . . . . . . . . . . . . . . . . . . . 106

Figure 6.2 Vent-Port-Plug Seal-Test Setup Support 


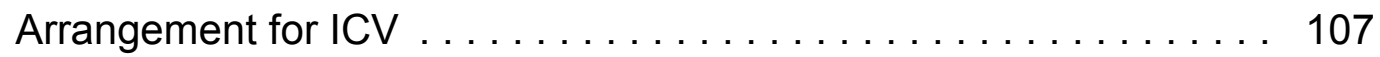

Figure 6.3 O-ring Seal Leak-Test Setup Support Arrangement

For Assembled OCV . . . . . . . . . . . . . . . . . . . . . . . . . . . 108

Figure 6.4 Vent-Port-Plug Seal-Test Setup Support

Arrangement for OCV . . . . . . . . . . . . . . . . . . . . 109

Figure 6.5 Vessel Weld Leak-Test Setup Support Arrangement for

Assembled ICV . . . . . . . . . . . . . . . . . . . . . . 110

Figure 6.6 Vessel Weld Leak-Test Setup Support Arrangement for

Assembled OCV

Figure 7.1 Verification Pressure-Test Support Arrangement for Assembled ICV . . . . . . . . . . . . . . . . . . . . . . . . . . . 115

Figure 7.2 Verification Pressure-Test Support Arrangement for Assembled OCV . . . . . . . . . . . . . . . . . . . . . . 116 


\section{LIST OF TABLES}

Table 1.1 Required Equipment for TRUPACT-II Fixed Loading Facility $\ldots \ldots 12$

Table 1.2 Recommended Miscellaneous User Provided Tools, Equipment, and Consumables ........................... 13

Table 1.3 TRUPACT-II Spare Parts (Bench stock) $\ldots \ldots \ldots \ldots \ldots \ldots$

Table $3.1 \quad$ TRUPACT-II Packaging Component Weights (Pounds) . . . . . . 41

Table 3.2 TRUPACT-II Trailer Identification Data and Weights . . . . . . . . 42

Table 5.1 Routine ICV Visual Inspections, Acceptance Criteria, and Corrective

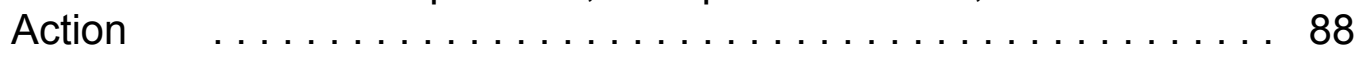

Table 5.2 Routine OCA Visual Inspections, Acceptance Criteria, and Corrective Action .............................. 90

Table 5.3 Annual Component Inspection, Acceptance Criteria, and Corrective

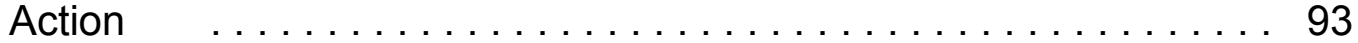

Table 5.4 Component Replacement Schedule and Work Instruction . . . . . . 94 


\section{$1.0 \quad$ INTRODUCTION}

\subsection{Purpose}

The purpose of this document is to provide the technical requirements for preparation for use, operation, inspection, and maintenance of a Transuranic Package Transporter Model II (TRUPACT-II) Shipping Package and directly related components. This document complies with the minimum requirements as specified in the TRUPACT-II Safety Analysis Report for Packaging (SARP) and Nuclear Regulatory Commission (NRC) Certificate of Compliance (C of C) 9218. In the event there is a conflict between this document and the TRUPACT-II SARP, the TRUPACT-II SARP shall govern. TRUPACT-II C of $C$ number 9218 states, "... each package must be prepared for shipment and operated in accordance with the procedures described in Chapter 7.0, Operating Procedures, of the application." It further states, "... each package must be tested and maintained in accordance with the procedures described in Chapter 8.0, Acceptance Tests and Maintenance Program of the application." Chapter 9 of the TRUPACT-II SARP charges the Westinghouse Electric Corporation Waste Isolation Division (WID) with assuring that the TRUPACT-II is used in accordance with the requirements of the $C$ of $C$. To meet this requirement and verify consistency of operations when loading and unloading the TRUPACT-II on the trailer, placing a payload in the packaging, unloading the payload from the packaging, or performing maintenance, the U.S. Department of Energy Carlsbad Area Office (U.S. DOE/CAO) finds it necessary to implement the changes that follow.

This TRUPACT-II maintenance document represents a change to previous philosophy regarding site specific procedures for the use of the TRUPACT-II.

This document details the instructions to be followed to consistently operate and maintain the TRUPACT-II. The intent of these instructions is to ensure that all users of the TRUPACT-II follow the same or equivalent instructions. Users may achieve this intent by any of the following methods:

1. Utilizing these instructions as is, or

2. Attaching a site-specific cover page/letter to this document stating that these are the instructions to be used at their location, or

3. Sites may prepare their own document using the steps in this document word-for-word, in-sequence, including Notes and Cautions. Site specific information may be included as deemed necessary. Submit the document to WID National TRU Programs for approval. Any revision made subsequent to WID TRU Program's approval shall be reviewed and approved by WID TRU Programs. A copy of the approval letter from WID National TRU Programs should be available for audit purposes.

Users shall develop site-specific procedures addressing leak testing, preoperational activities, quality assurance, hoisting and rigging, and radiation health physics to be used in conjunction with the instructions contained in this document. 
Users desiring to recommend changes to this document may submit their recommendations to the WID National TRU Programs for evaluation. If approved, the change(s) will be incorporated into this document for use by all TRUPACT-II users. User sites will be audited to this document to ensure compliance within one year from the effective date of this revision.

This document discusses operating instructions, required inspections and maintenance for the following:

- $\quad$ TRUPACT-II packaging, and

- Miscellaneous packaging, special tools, and equipment.

Packaging and payload handling equipment and transport trailers have been specifically designed for use with the TRUPACT-II Packaging. This document discusses the required instructions for use of the following equipment in conjunction with the TRUPACT-II Packaging:

- $\quad$ TRUPACT-II Mobile Loading Unit (MLU),

- $\quad$ Adjustable Center-of-Gravity Lift Fixture (ACGLF), and

- $\quad$ TRUPACT-II Transport Trailer.

Attachment E contains the various TRUPACT-Il packaging interface control drawings, leak-test and vent-port tool drawings, ACGLF drawings, and tie-down drawings that identify the various system components.

\subsection{Conventions}

The following conventions are used to standardize the language used in these instructions:

- The words "will" and "shall" and "must" denote requirements.

- $\quad$ The word "should" denotes a recommendation.

- $\quad$ The word "may" denotes permission, neither a requirement nor a recommendation.

- $\quad$ The word "check" is used to determine the condition or status.

- The word "verify" is used to confirm a condition.

- $\quad$ Parts shall be identified with the part number and name as listed in the TRUPACT-II Work Instructions. 
- $\quad$ Standard abbreviations (not symbols) will be written out to express measurements and dimensions. For example, use 10 feet or $10 \mathrm{ft}$, but not 10'.

- Acronyms will be identified fully in the first usage in the instructions.

- Cautions and notes, if used, shall always precede the pertinent step(s).

- $\quad$ Cautions and notes shall not be used as instruction steps.

\subsection{Definitions}

- Annual Maintenance is Periodic Maintenance that is performed at one year intervals, not to exceed a 30 day grace period.

- $\quad$ Assembly Verification Leak-Test includes all leak-tests performed during assembly of a loaded TRUPACT-II package.

- Bench stock is the on-hand supply of TRUPACT-II components sufficient to cover anticipated needs for one calendar year of operation. Stockage levels are based on historical data of component replacement required to complete a given number of shipments.

- $\quad$ Carlsbad Area Office (CAO) is the U.S. Department of Energy (DOE) office responsible for managing the packaging and transportation activities associated with defense-generated contact handled $(\mathrm{CH})$ and remote handled $(\mathrm{RH})$ transuranic (TRU) materials.

- Certificate of Compliance (C of $\mathbf{C}$ ) is issued by the NRC, approving the design of a specific radioactive materials packaging for use with specified payload limitations.

- $\quad$ Certified waste is waste that has been confirmed under a formal program to comply with acceptance criteria under an approved waste certification program.

- $\quad$ Contact handled transuranic (CH TRU) waste is waste with an external radiation dose rate not exceeding $200 \mathrm{millirem} / \mathrm{hr}$ at the waste container's surface such that shielding beyond that provided by the packaging is not necessary. Containers of $\mathrm{CH}$ TRU waste may be handled directly without the need for remote handling or robotic equipment.

- $\quad$ Containment Integrity Verification Leak-Test includes all leak-tests performed after Structural Pressure-Testing to verify containment boundary integrity (both metallic and elastomeric).

- $\quad$ Five Year Maintenance is Periodic Maintenance that is performed at five (5) year intervals, not to exceed a 30 day grace period. 
- Leak Check Due Tag is a tag that is attached near the OCA vent port. This tag indicates a containment O-ring has been replaced and a maintenance verification leak check is required prior to the next radioactive shipment. The reverse side of the tag will be marked in indelible ink indicating which containment O-ring was replaced.

- Maintenance record is a list of maintenance performed that becomes a permanent part of the TRUPACT-II packaging documentation record.

- Major maintenance consists of all repairs requiring welding or machining to correct a deficiency that affects the integrity of the TRUPACT-II containers or its components. Note: major repairs and major component replacements are the responsibility of the WID. These repairs/replacements will be performed at a TRUPACT-II Maintenance Facility as designated and approved by the WID.

- Minor maintenance consists of all repairs that can be readily accomplished and require no special tools, supplies, equipment, or highly skilled personnel. Minor repairs would include scratches on the sealing surface. Note that minor repairs and minor component replacements shall be performed at sites that have the necessary equipment and qualified personnel to perform these tasks.

- Non-Conforming Condition Report (NCR) is a document that identifies and records a nonconforming condition, and the action taken for the disposition of the nonconformance. Disposition of nonconforming items include review, accept, reject, rework, use-as-is, or repair in accordance with approved instructions. All occurrences of NCRs require formal disposition by WID National TRU Programs.

- Out-of-Service is an administrative condition of the TRUPACT-II that denotes it is not useable for radioactive shipments. When a TRUPACT-II is determined to be out-of-service, a tag shall be attached to the OCA near the vent port. The tag shall state the out-of-service condition.

- Owner is the organization to which the NRC C of C is issued (e.g., for the TRUPACT-II Shipping Package, the U.S. Department of Energy Headquarters).

- $\quad$ Mobile Loading Unit (MLU) consists of trailer mounted equipment necessary to load/unload a TRUPACT-II at locations where fixed loading/unloading facilities do not exist.

- Nuclear Regulatory Commission (NRC) is the federal agency that certifies the design, manufacture, and quality assurance (QA) of TRU materials shipment packaging by certifying that all packaging meet the design requirements specified in 10 CFR 71.

- $\quad$ Package consists of the TRUPACT-II shipping package WITH its contents or payload. 
- $\quad$ Packaging consists of the TRUPACT-II shipping package WITHOUT its contents or payload (empty).

- $\quad$ Periodic maintenance (PM) consists of all maintenance activities performed annually or other periodic time interval. Periodic maintenance activities listed in Section 5.0 will normally be performed at a TRUPACT-II maintenance facility as designated and approved by the WID.

- $\quad$ Safety Analysis Report for Packaging (SARP) is the official application to a packaging licensing agency (DOE or NRC) containing a demonstration of packaging effectiveness and ability in achieving the requirements delineated in 10 CFR 71. The SARP is the controlling document with regards to all packaging operations and maintenance.

- Test and Handling (T\&H) Equipment is that equipment required to be on-hand to load, unload, and test the TRUPACT-II

- Transuranic Content Codes (TRUCON) is a uniform system grouping waste forms with similar characteristics for purposes of shipment in the TRUPACT-II Packaging.

- $\quad$ Transuranic (TRU) Waste Means waste containing more than 100 nanocuries of alpha-emitting transuranic isotopes per gram of waste, with half-lives greater than 20 years, except for: (a) high-level radioactive waste: (b) waste that the Secretary has determined, with concurrence of the Administrator, does not need the degree of isolation required by the disposal regulations: or (c) waste that the Nuclear Regulatory Commission has approved for disposal on a case-by-case basis in accordance with para 61 of title 10, Code of Federal Regulations.

- Transuranic Waste Authorized Methods for Payload Control (TRAMPAC) is the document that provides acceptable methods of preparation and characterization to qualify transuranic waste as payload for transport in the TRUPACT-II Packaging.

- National TRU Programs is the group within the WID that performs all required actions associated with the TRUPACT-II on behalf of the DOE/CAO.

- Users are those organizations, both DOE and commercial, that are authorized by the DOE to use the DOE-owned, NRC-approved TRUPACT-II packaging to ship or receive waste.

- Visual inspection is an inspection of component attributes, usually performed with checklist using the eye only.

- WID is the Waste Isolation Division of Westinghouse Electric Corporation.

- WIPP is the Waste Isolation Pilot Plant. 
- Work instruction is a form containing detailed steps outlining the requirements for performing maintenance activities.

- Work control is the process by which all scheduled and unscheduled maintenance is initiated, prioritized, performed, and documented.

\subsection{Preshipment Requirements}

Prior to making the initial shipment of TRU waste in a TRUPACT-II from a site, the shipper must submit TRUPACT-II Authorized Methods for Payload Control (TRAMPAC) and associated Quality Assurance (QA) plans for review. If needed, additional guidance for these areas may be obtained by contacting WID National TRU Programs at (505) 234-7498. A new TRUPACT-II user must also perform the following:

- $\quad$ Determine whether a fixed facility or a Mobile Loading Unit will be required. Drawings for a fixed facility are available from WID TRU Waste Programs. The facility must meet minimum size and height requirements to accommodate loading operations. Minimum electrical power requirements for operation of a crane and other equipment must be considered.

- Obtain the required amount of test and handling equipment required to sustain operations (see Table 1.1).

- $\quad$ Obtain the required consumables and bench stock of spare parts needed to ensure continuity of TRUPACT-II loading operations (see Table 1.2 and Table 1.3).

- $\quad$ Prepare and approve site procedures (QA, Hoisting and Rigging, Preoperational, and Radiation Health Physics) for use during the loading/unloading of the TRUPACT-II.

- $\quad$ Obtain Authorization to Use, and complete required training to operate the DOE TRANSCOM satellite based shipment tracking system.

- $\quad$ Complete required training and site specific qualification of personnel to perform TRUPACT-II loading operations.

- $\quad$ Successfully complete a certification audit by CAO/WID to ship TRU Waste in the TRUPACT-II. Initial certification will include observation of a "dummy" loading operation and performance of a randomly selected Maintenance Instruction using a TRUPACT-II training unit, to include preparation of associated documentation. (This does not apply to small quantity sites with shipments loaded by other trained personnel).

\subsection{Equipment Description}

\subsubsection{TRUPACT-II Shipping Package}

The TRUPACT-II is a U.S. Department of Transportation (DOT) Type "B" packaging certified by the NRC. The packaging is a stainless steel and polyurethane foam insulated right circular cylinder shipping container. It is designed to provide double 
containment for shipment of Contact Handled Transuranic Waste (CH TRU). A TRUPACT-II packaging assembly is illustrated in Figure 1.2.

The following is a list of typical payload assemblies for the TRUPACT-II:

- $\quad$ Fourteen, 55-gallon drums, or

- $\quad$ Two DOT Type-A Standard Waste Boxes (SWB), or

- $\quad$ One 10 drum overpack (TDOP).

The Outer Containment Assembly (OCA) consists of a lid and body, composed of an inner stainless steel shell which comprises the outer containment vessel (OCV) boundary, approximately ten inches of thermal and impact absorbing polyurethane foam, and an external stainless steel shell. The lid internal and external top surfaces are domed. The body internal surface is domed and the external surface bottom is flat. Three lifting interfaces are supplied on the lid for handling the lid. Two forklift slots in the body base are used for handling the entire loaded OCA. When the lid is installed on the body the overall height is approximately ten $\mathrm{ft}$ and overall diameter is approximately eight $\mathrm{ft}$. A tapered sealing flange on the lid mates with a similar sealing flange on the body. The body sealing flange contains two main O-ring seals. A removable brass plug in a seal test-port allows testing of the upper main O-ring seals during loading operations. The lid is secured to the body with a rotating locking ring located on the lid sealing flange. Six fasteners secure the lock ring from rotating during shipment. A single vent-port comprises the only containment penetration into the OCV cavity. A removable brass plug in the vent-port allows access to the cavity during loading and unloading operations.

The Inner Containment Vessel (ICV) consists of a stainless steel shell lid and body. Both the lid and body ends are domed to mate with the interior cavity of the OCV. Three lifting sockets in the lid provide the lifting interface for the lid or an empty (contents not installed) lid/body assembly. Aluminum honeycomb spacers inside the lid and body domes provide impact protection to the domes and a flat surface on which the packaging contents are installed. A tapered sealing flange on the lid mates with a similar sealing flange on the body. The body sealing flange contains two main O-ring seals. Both a silicone-debris seal and an O-ring wiper seal are contained on the lid sealing flange to preclude debris ingress into the main O-ring seal areas. A removable brass plug in a seal-test-port allows testing of the upper main O-ring seal during loading operations. The lid is secured to the body by a rotating locking ring located on the lid sealing flange. Three fasteners secure the lock ring from rotating during shipment. A single vent-port comprises the only containment penetration into the ICV cavity. A removable inner brass plug in the vent-port allows access to the ICV cavity. A removable outer brass plug in the vent-port allows for helium purging of the ICV upper main O-ring seal and the volume between the inner and outer plug for subsequent leakage-testing.

\subsection{TRUPACT-II Mobile Loading Unit}

The TRUPACT-II MLU is an assembly of equipment, housed and transported on a trailer, and specifically designed for performing the loading and unloading operations associated with the TRUPACT-II (see Figure 1.1; TRUPACT-II Mobile Loading Unit). The MLU consists of the following equipment: 
- Control equipment for the MLU components

- $\quad$ ACGLF

- $\quad$ Leak-testing equipment

- Work platforms and ladders, and

- Tools to remove and secure the ICV and OCA lids

\subsection{Seal-Test-Port and Vent-Port Tools}

Seal-Test-Port and vent-port tools are provided by WID as indicated in Table 1.1 or are furnished with the MLU. Quantities are sufficient for user site requirements with provisions for a limited number of spares. Replacements for defective tools are provided by the WID TRUPACT-II Maintenance Engineer on an exchange basis.

NOTE: $\quad$ The tool drawings listed in Attachment $E$ were designed and used during the fabrication phase of the TRUPACT-Il packaging program. Users may choose to modify these tools to interface with equipment for individual site requirements. However, users shall not modify the TRUPACT-II packaging fittings.

Several tools have been designed specifically for the operation and leakage rate testing of the TRUPACT-II shipping package. Although the OCV and ICV seal-testports and vent-ports are similar in design, the tools are not interchangeable.

The functional description of each tool is as follows:

- $\quad$ OCV seal-test-port-plug removal tool provides for installation and removal of the OCV seal-test-port-plug through the seal-test access port in the OCA upper assembly (see Figure 1.6; Part No. 2077-094-A2).

- $\quad$ OCV seal-leak check tool is used to check the main O-ring seal for all leakagetests (see Figure 1.7; Part No. 2077-093-A2). Access is through the seal-test access port in the OCA upper assembly. This tool is equipped with a quickconnect fitting to interface with the leak-testing equipment.

- $\quad$ ICV/OCV vent-port cover removal tool provides for remote removal and installation of the vent-port covers. (See Figure 1.3; Part No. 2077-092-A1).

- $\quad$ OCV vent-port-plug removal/pressure relief tool provides for the removal and installation of the OCV vent-port-plug, and access to the OCV cavity through the vent access port in the OCA lower assembly (see Figure 1.4; Part

No. 2077-091-A2). This tool is equipped with a quick-connect fitting to interface with gas sampling, vacuum, and helium backfill equipment and is used for the following operations:

- OCV annulus venting and gas sampling,

- vacuum pump interface for OCA upper assembly installation and removal, 
- $\quad$ helium backfill during all OCV leakage-testing, and

- $\quad$ pressure fill during periodic OCV structural pressure-testing and axial play measurements.

- $\quad$ OCV vent-port-plug leak check tool is used to check the OCV vent-port-plug seal for all leakage-tests (see Figure 1.5; Part No. 2077-095-A1). Access is through the vent-access port in the OCA lower assembly. This tool is equipped with a quick-connect fitting to interface with the leak-testing equipment.

- $\quad$ OCV seal-test-port-plug removal tool provides for installation and removal of the OCV seal-test-port-plug through the seal-test access port in the OCA upper assembly (see Figure 1.6; Part No. 2077-094-A2).

- $\quad$ OCV seal-leak check tool is used to check the main O-ring seal for all leakagetests (see Figure 1.7; Part No. 2077-093-A2). Access is through the seal-test access port in the OCA upper assembly. This tool is equipped with a quickconnect fitting to interface with the leak-testing equipment.

- $\quad$ ICV vent-port-plug removal/pressure relief tool provides for the removal and installation of the ICV inner vent-port-plug (see Figure 1.8; Part

No. 2077-091-A1), removal and installation of the ICV outer vent-port-plug, with an adapter (see Figure 1.9; Part No. 2077-091-A1), thereby gaining access to the ICV cavity. This tool is equipped with a quick-connect fitting to interface with gas sampling, vacuum, and helium backfill equipment and is used for the following operations:

- $\quad$ ICV cavity venting and gas sampling (with the adapter),

- $\quad$ vacuum pump interface for ICV lid installation and removal,

- $\quad$ helium backfill during all ICV leakage-testing, and

- $\quad$ pressure fill during periodic ICV structural pressure-testing and axial play measurements.

- $\quad$ ICV vent-port-plug leak check tool is used to check the ICV vent-port-plug seal for all leakage-tests (see Figure 1.10; Part No. 2077-095-A2). This tool is equipped with a quick-connect fitting to interface with the leak-testing equipment.

\subsubsection{Lock-Ring Tools}

The lock-ring tools are designed for rotating the lock-ring assemblies to either the locked or unlocked position (Part Nos. 2077-156-A6 for the ICV lock-ring and 2077-156-A7 for the OCA lock-ring). These locking-ring tools are furnished with the MLU. These tools are illustrated on sheet 3 of drawing 2077-300 listed in Attachment E.

NOTE: Lock-ring tools are furnished by the WID.

\subsubsection{Lower Spacer Removal Sling}


One lower spacer removal sling is designed for installation and removal of the lower spacer (Part No. SK-1104).

\subsubsection{Adjustable Center-of-Gravity Lift Fixture (ACGLF)}

NOTE: The ACGLF is furnished with the MLU. Users that do not use the MLU are responsible for procurement and maintenance of an ACGLF. Furnished for information in Attachment $E$ are the latest "as-built" drawings of the ACGLF procured by the WID. Drawings for the SWB and TDOP adapters are available from the WID.

The ACGLF is used for loading and unloading payloads when the center-of-gravity is not on the vertical centerline of the payload. With an adaptor, the ACGLF may be used for loading and unloading SWBs and TDOPs.

The ACGLF is used in conjunction with a 5-ton crane (minimum) and is designed for the following general requirements:

- $\quad$ maximum rated capacity of the lift fixture is 10,000 pounds;

- $\quad$ system power is $115 \mathrm{VAC}, 60 \mathrm{~Hz}, 20$ amperes;

- $\quad$ minimum crane hook height is $20.5 \mathrm{ft}$;

- $\quad$ maximum 7.5 ton Crosby hook size interface;

- $\quad$ one, 14 drum payload assembly, two SWB payload assemblies, or one TDOP may be lifted at one time; and

- a 3.6-inch maximum lateral offset in the payload assembly center-of-gravity may be accommodated.

The ACGLF is designed to handle the weight of the following configurations:

- $\quad$ an OCA lid assembly

- $\quad$ an ICV lid

- $\quad$ an empty ICV assembly

- $\quad$ a loaded payload (i.e., 14 drums), two SWBs, or one TDOP

The ACGLF is NOT designed to lift the weight of the following configurations:

- $\quad$ a loaded or empty TRUPACT-II package

- a loaded or empty OCA

- a loaded ICV 
WID recommends the following maintenance/calibration intervals. Users may vary intervals based on site requirements:

- Semi-annual lubrication and inspection

- Semi-annual electrical inspection

- Annual calibration

Guidance in the development of site specific procedures for the above can be obtained from the WID TRUPACT-II Maintenance Engineer.

\subsubsection{Required Tools, Equipment, and Consumables for TRUPACT-II Loading}

Table 1.1 lists the tools required for the loading and unloading of a TRUPACT-II. Quantities listed are for a fixed facility with a limited number of spares. Tools are provided by the WID through the TRUPACT-II Maintenance Engineer. The MLU is equipped with the required quantities of tools. Table 1.2 lists user provided tools, equipment, and consumables used in TRUPACT-II operation. 
Table 1.1 Required Equipment for TRUPACT-II Fixed Loading Facility

\begin{tabular}{|c|c|c|c|}
\hline Tool & Quantity & Spares & $\checkmark$ \\
\hline $\begin{array}{l}\text { ICV/OCV vent-port cover removal tool } \\
\text { (2077-092-A1), (Figure 1.3) }\end{array}$ & $\begin{array}{l}1 \\
\begin{array}{l}\text { common hand tool } \\
\text { (user supplied) }\end{array}\end{array}$ & 0 & \\
\hline $\begin{array}{l}\text { OCV vent-port-plug removal/pressure relief tool } \\
\text { (2077-091-A2), (Figure 1.4) }\end{array}$ & 3 & 1 & \\
\hline $\begin{array}{l}\text { OCV vent-port-plug leak check tool } \\
\text { (2077-095-A1), (Figure 1.5) }\end{array}$ & 3 & 1 & \\
\hline $\begin{array}{l}\text { OCV seal-test-port-plug removal tool } \\
\text { (2077-094-A2), (Figure 1.6) }\end{array}$ & $\begin{array}{c}1 \\
\text { common hand tool } \\
\text { (user supplied) }\end{array}$ & 0 & \\
\hline $\begin{array}{l}\text { OCV seal-leak check tool (2077-093-A2), } \\
\text { (Figure 1.7) }\end{array}$ & 3 & 1 & \\
\hline $\begin{array}{l}\text { ICV vent-port-plug removal/pressure relief tool \& } \\
\text { adapter (2077-091-A1), (Figure } 1.8 \text { and } 1.9) . \\
\text { "Proto" brand extension should be used to } \\
\text { ensure proper fit. }\end{array}$ & 3 & 1 & \\
\hline $\begin{array}{l}\text { ICV vent-port leak Check tool (2077-095-A2) } \\
\text { (Figure 1.10) }\end{array}$ & 3 & 1 & \\
\hline $\begin{array}{l}\text { ICV seal-test-port-plug removal tool } \\
(2077-094-A 1) \text { (Figure 1.11) }\end{array}$ & $\begin{array}{l}1 \\
\begin{array}{l}1 \\
\text { common hand tool } \\
\text { (user supplied) }\end{array}\end{array}$ & 0 & \\
\hline $\begin{array}{l}\text { ICV seal-leak check tool (2077-093-A1) } \\
\text { (Figure 1.12) }\end{array}$ & 3 & 1 & \\
\hline ICV locking handle (2077-156A6) & 6 & 1 & \\
\hline OCV locking handle (2077-156A7) & 6 & 1 & \\
\hline $\begin{array}{l}\text { Helium leak detector capable of detecting a leak } \\
\text { of } 5 \times 10^{-8}\end{array}$ & 1 (User supplied) & Optional & \\
\hline Calibrated Standard Leak & 1 (User supplied) & Optional & \\
\hline $\begin{array}{l}\text { Calibrated ambient temperature measuring } \\
\text { device }\end{array}$ & 1 (User supplied) & Optional & \\
\hline Tool, lock ring & 2 per site & None & \\
\hline TRUPACT-II "shadow board" & 1 per loading station & None & \\
\hline
\end{tabular}


Table 1.2 Recommended User Supplied Miscellaneous Tools, Equipment, and Consumables

\begin{tabular}{|c|c|c|}
\hline Item* & Application & $\checkmark$ \\
\hline Compressed air "blow gun" & $\begin{array}{l}\text { Clean threads, cavities with } \\
\text { Argon gas }\end{array}$ & \\
\hline 12 inch adjustable wrench $\times 2$ & $\begin{array}{l}\text { Fastening gauges to } \\
\text { compressed gases }\end{array}$ & \\
\hline $\begin{array}{l}3 / 4 \text { inch deep well socket, } 1 / 2 \text { inch ratchet drive } 16 \\
\text { inches or longer }\end{array}$ & $\begin{array}{l}\text { Loosening TRUPACT-II } \\
\text { tiedowns }\end{array}$ & \\
\hline Impact Wrench & $\begin{array}{l}\text { Adjusting TRUPACT-II } \\
\text { tiedowns }\end{array}$ & \\
\hline $1 / 4$ inch flat tip screwdriver & $\begin{array}{l}\text { Hose clamps on leak test } \\
\text { equipment and forklift } \\
\text { pocket cover screws }\end{array}$ & \\
\hline $\begin{array}{l}\text { Torque wrenches, } \\
0-200 \text { inch pounds / } 10-80 \text { foot pounds }\end{array}$ & $\begin{array}{l}\text { Apply correct torque on } \\
\text { components }\end{array}$ & \\
\hline Cotter pin removal tool & Removing small O-rings & \\
\hline Utility knife & Cutting tube for leak testing & \\
\hline Small flashlight & $\begin{array}{l}\text { Inspection of threads and } \\
\text { cavities }\end{array}$ & \\
\hline $\begin{array}{l}\text { Wire/brass brushes, flat and } 1 / 2,3 / 4,1,1-1 / 4 \text { and } \\
1-1 / 2 \text { inch sizes SS or Brass Bottle brushes }\end{array}$ & $\begin{array}{l}\text { Cleaning threads on plugs } \\
\text { and ports }\end{array}$ & \\
\hline $\begin{array}{l}3 / 8 \text { inch T-handle allen wrench } \times 2,3 / 8 \text { inch allen } \\
\text { head socket with } 3 / 8 \text { inch drive }\end{array}$ & Removing locking ring bolts & \\
\hline $\begin{array}{l}\text { Lint free rags (Wilshire Contamination Control, } \\
5922 \text { Farnsworth Court, Carlsbad, CA 92008, } \\
\text { (619) 929-6950, Part Number 5710 "Polywipe" or } \\
\text { Berkshire, P.O. Box 588, Great Garrington, MA, } \\
012301 \text {, "Texwipe", (800) 242-7000 }\end{array}$ & $\begin{array}{l}\text { Cleaning surfaces as } \\
\text { required }\end{array}$ & \\
\hline $\begin{array}{l}1 \text { inch allen wrench, } 1 \text { inch allen head socket with } \\
3 / 8 \text { inch drive }\end{array}$ & $\begin{array}{l}\text { Remove/install TRUPACT-II } \\
\text { plugs }\end{array}$ & \\
\hline Spray bottle - (1 quart) & $\begin{array}{l}\text { Applying alcohol when } \\
\text { cleaning surfaces }\end{array}$ & \\
\hline Argon & Pressure Cleaning Threads & \\
\hline Nitrogen/Compressed air & Lid removal & \\
\hline Helium (with vendor grade certification) & Leak testing & \\
\hline Dow Corning High Vacuum Grease & Lubricate O-rings & \\
\hline Thread locking compound (Locktite 222) & Threaded surfaces & \\
\hline Nickel bearing lubricant (Locktite 767, paste form) & Threaded surfaces & \\
\hline
\end{tabular}




\begin{tabular}{|c|c|c|}
\hline Item* & Application & $\sqrt{ }$ \\
\hline Epoxy adhesive & $\begin{array}{l}\text { Bonding OCA seal test port } \\
\text { and vent port to plug }\end{array}$ & \\
\hline Alcohol, Ethyl & Cleaning surfaces & \\
\hline Stretch wrap, 60 gauge, 18 inch & $\begin{array}{l}\text { Wrap } 55 \text { gallon drum } \\
\text { payload }\end{array}$ & \\
\hline $\begin{array}{l}\text { O-rings: National, Buna-N, \#AS-568-914 \& } \\
\text { \#AS-568-015 \& Parker, Buna-N, \#3-905, } 10 \text { ea } \\
\text { suggested }\end{array}$ & $\begin{array}{l}\text { TRUPACT-II Leak/Seal } \\
\text { Check/Detection Tools }\end{array}$ & \\
\hline $\begin{array}{l}\text { Keensert Installation Tools (PN TD-420L or } \\
\text { PN TD-813L) }\end{array}$ & $\begin{array}{l}\text { Lock-ring bolt insert thread } \\
\text { repair }\end{array}$ & \\
\hline Rubber gloves & Cleaning TRUPACT-II & \\
\hline $\begin{array}{l}\text { Load stabilizing jack (McMaster-Carr \#8817T21 } \\
\text { or equivalent }\end{array}$ & $\begin{array}{l}\text { Stabilize free standing } \\
\text { trailers }\end{array}$ & \\
\hline $\begin{array}{l}\text { Tamper Seal, American Casting and } \\
\text { Manufacturing Corp., } 51 \text { Commercial Street, } \\
\text { Plainview, NY, } 11803 \text { (516-349-7010) }\end{array}$ & $\begin{array}{l}\text { Sealing TRUPACT-II for } \\
\text { shipment }\end{array}$ & \\
\hline $\begin{array}{l}\text { * Standard Waste Boxes, Ten Drum Overpacks, } \\
\text { and Pipe Components have been procured } \\
\text { successfully from the Engineered Products } \\
\text { Department, P.O. Box } 2138 \text {, Carlsbad, NM } \\
88221,(505) \text { 234-5600. This is not to be } \\
\text { construed as an endorsement or recommendation } \\
\text { of this vendor. Current vendor qualifications } \\
\text { should be reviewed prior to placing orders. }\end{array}$ & TRUPACT-II payloads. & \\
\hline
\end{tabular}


Rev. 3

Figure 1.1 TRUPACT-II Mobile Loading Unit
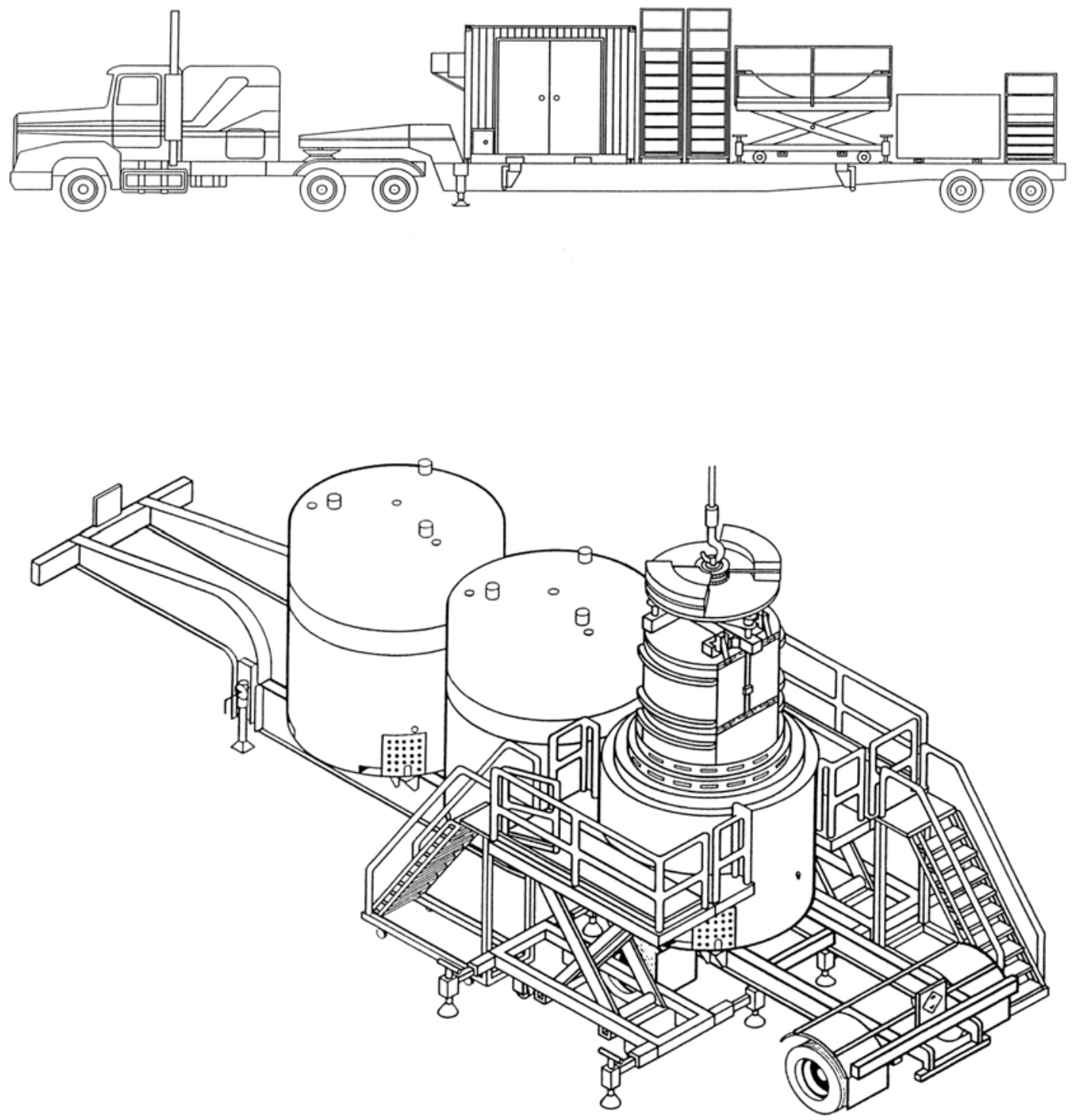


\section{Figure 1.2 TRUPACT-II Shipping Package}

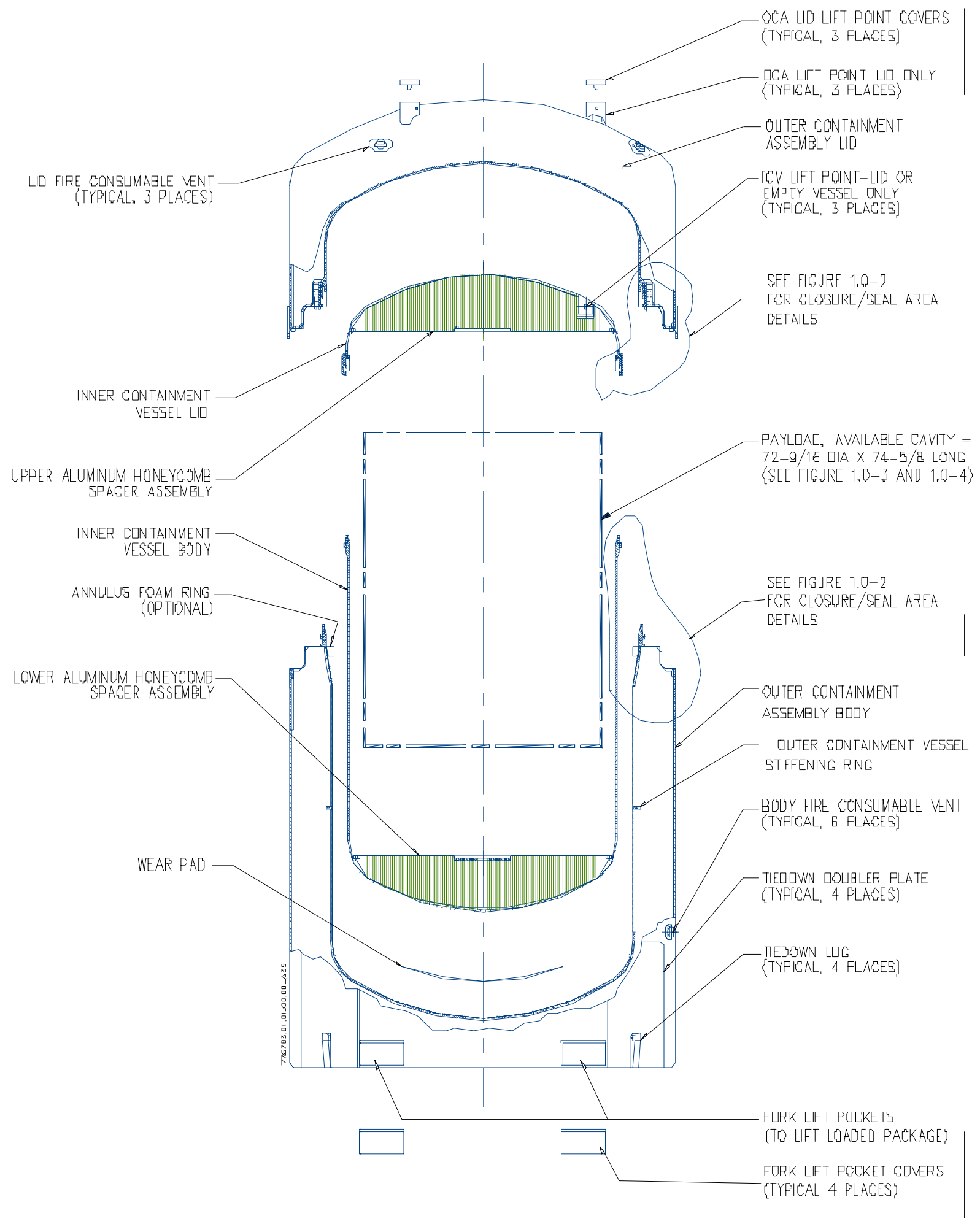

Not to Scale 
Figure 1.3 ICV/OCV Vent-Port Cover Removal Tool (2077-092-A1)

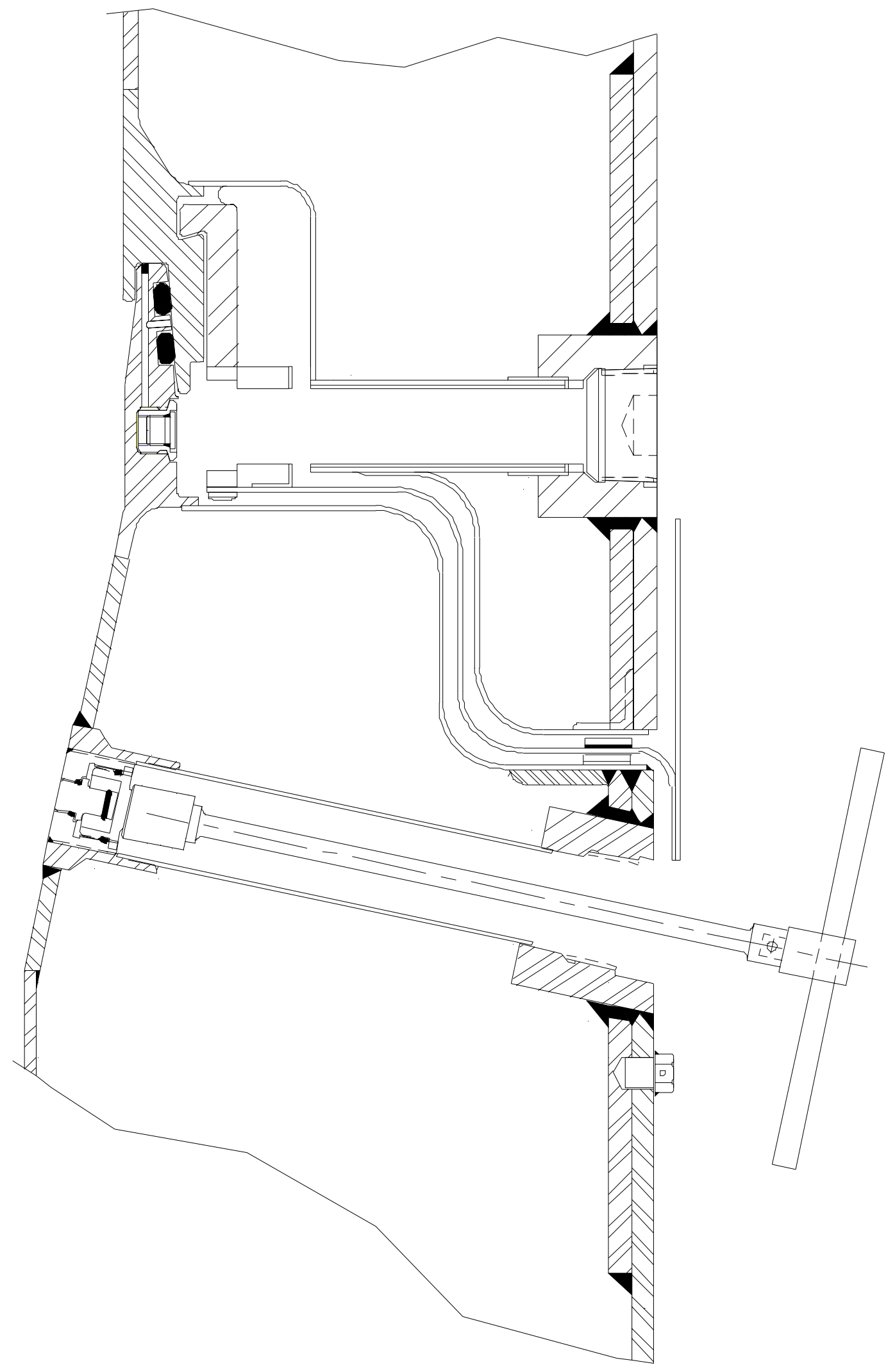

Not to scale 
Figure 1.4 OCV Vent-Port-Plug Removal/Pressure Relief Tool (2077-091-A2)

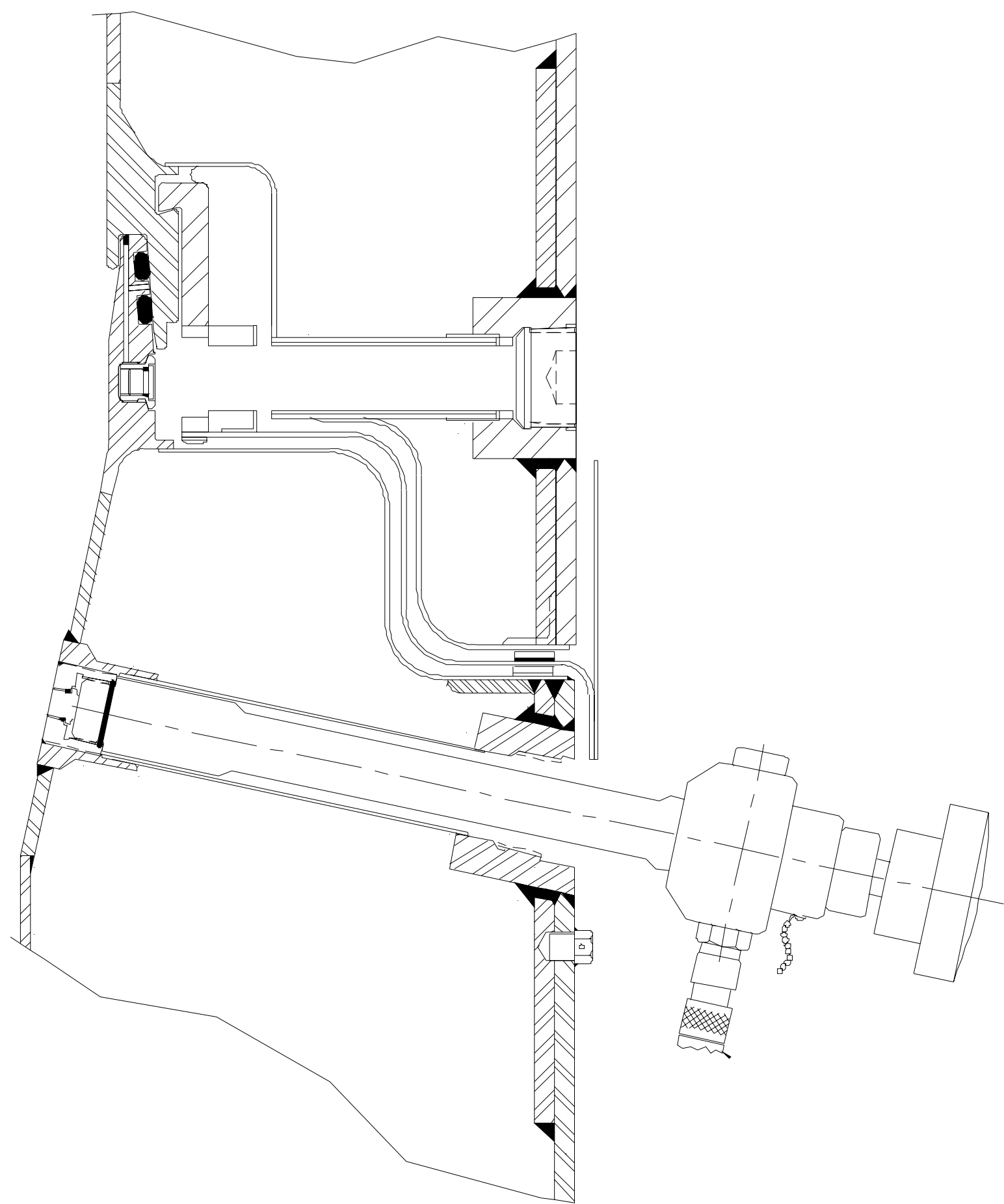

Not to scale

Note: Uses National O-ring, Buna N, Part \# AS-568-914 and\# AS-568-015 
Rev. 3

Figure 1.5 OCV Vent-Port-Plug-Leak Check Tool (2077-095-A1)

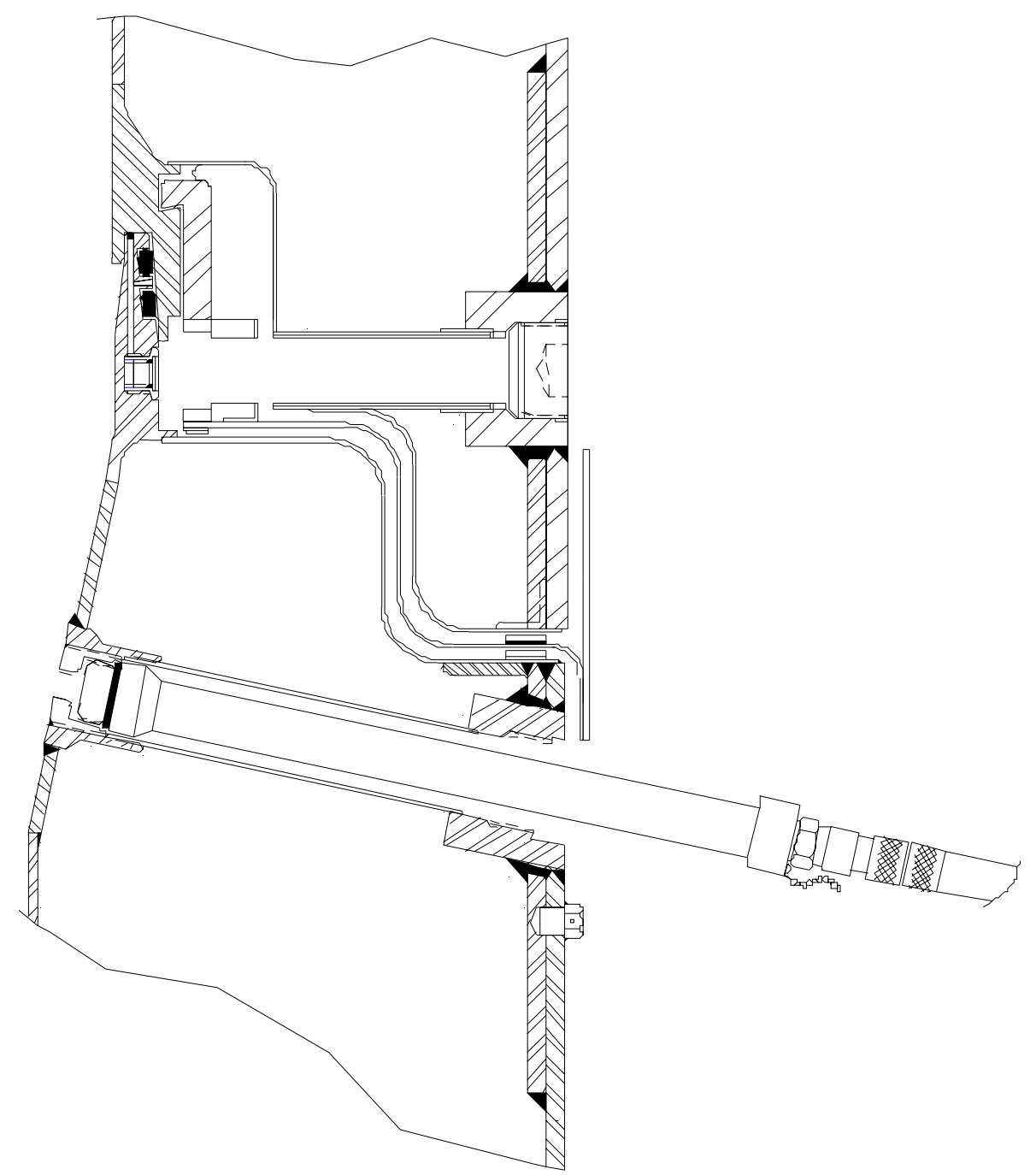

Not to scale

Note: Uses National O-ring, Buna N, part \# AS-568-914 
Figure 1.6 OCV Seal-Test-Port-Plug Removal Tool (2077-094-A2)

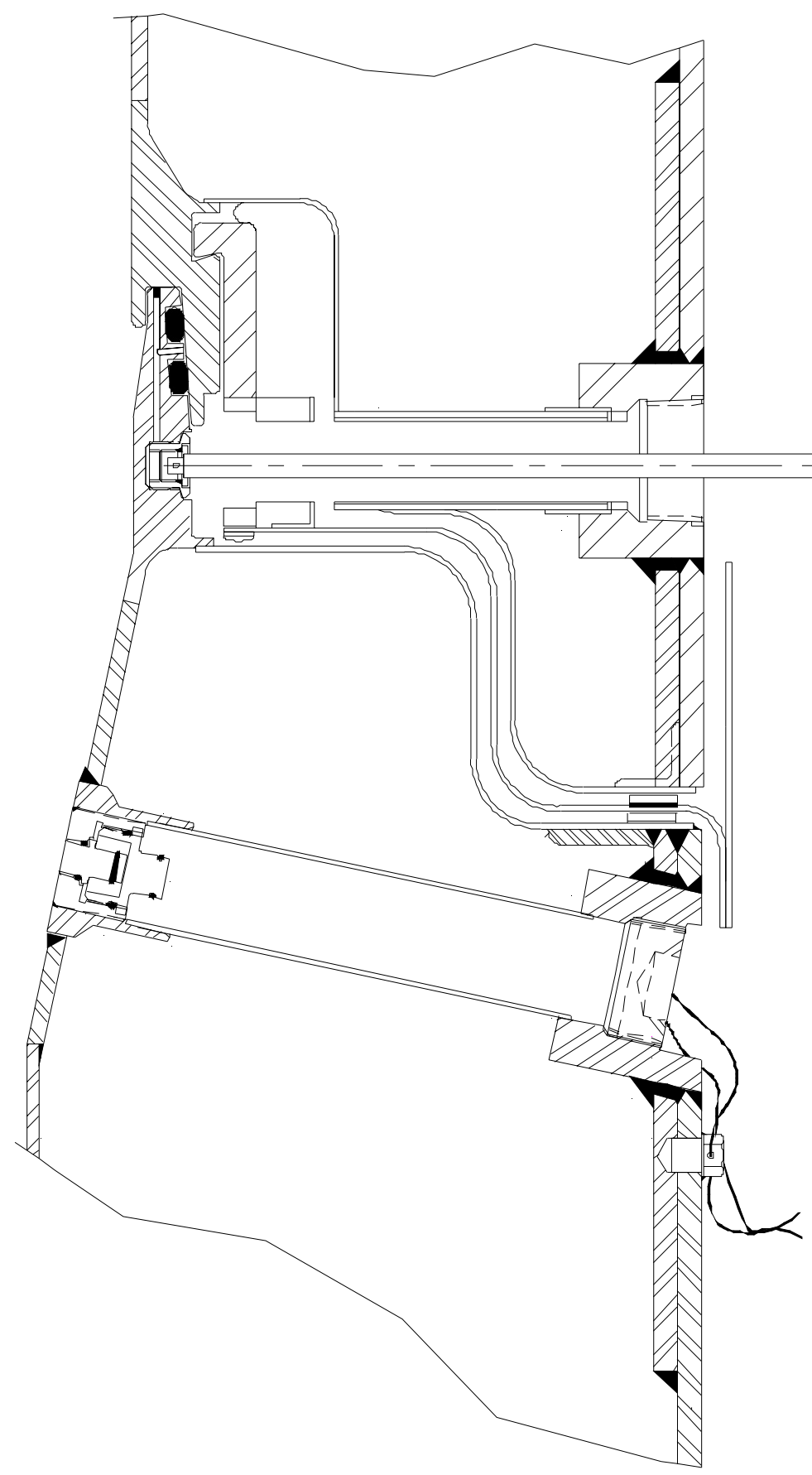

Not to scale 


\section{Figure 1.7 OCV Seal-Leak Check Tool (2077-093-A2)}

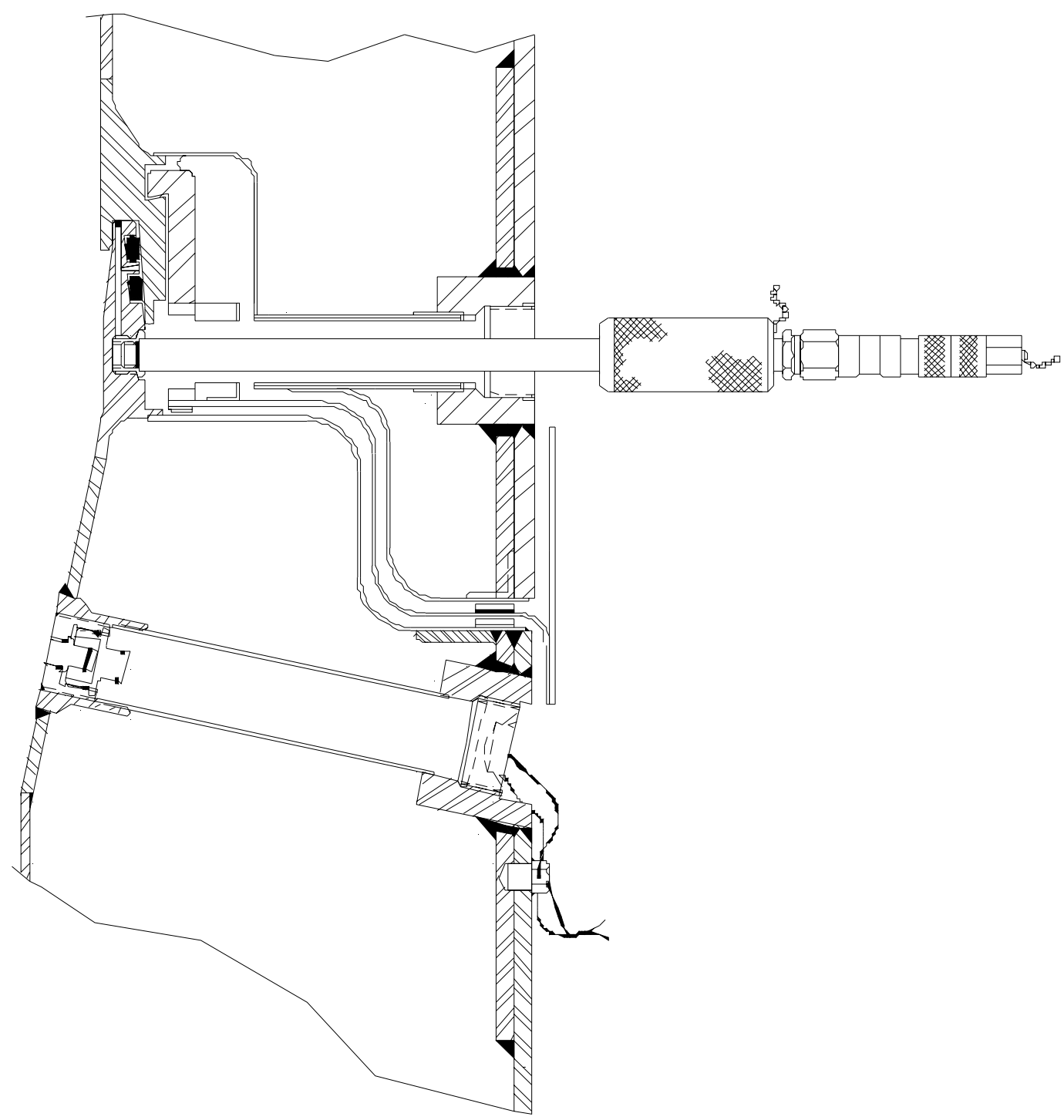

Not to scale

Note: Uses Parker O-ring, Buna N, Part \# 3-905 


\section{Figure 1.8 ICV Vent-Port-Plug Removal/Pressure Relief Tool (2077-091-A1)}

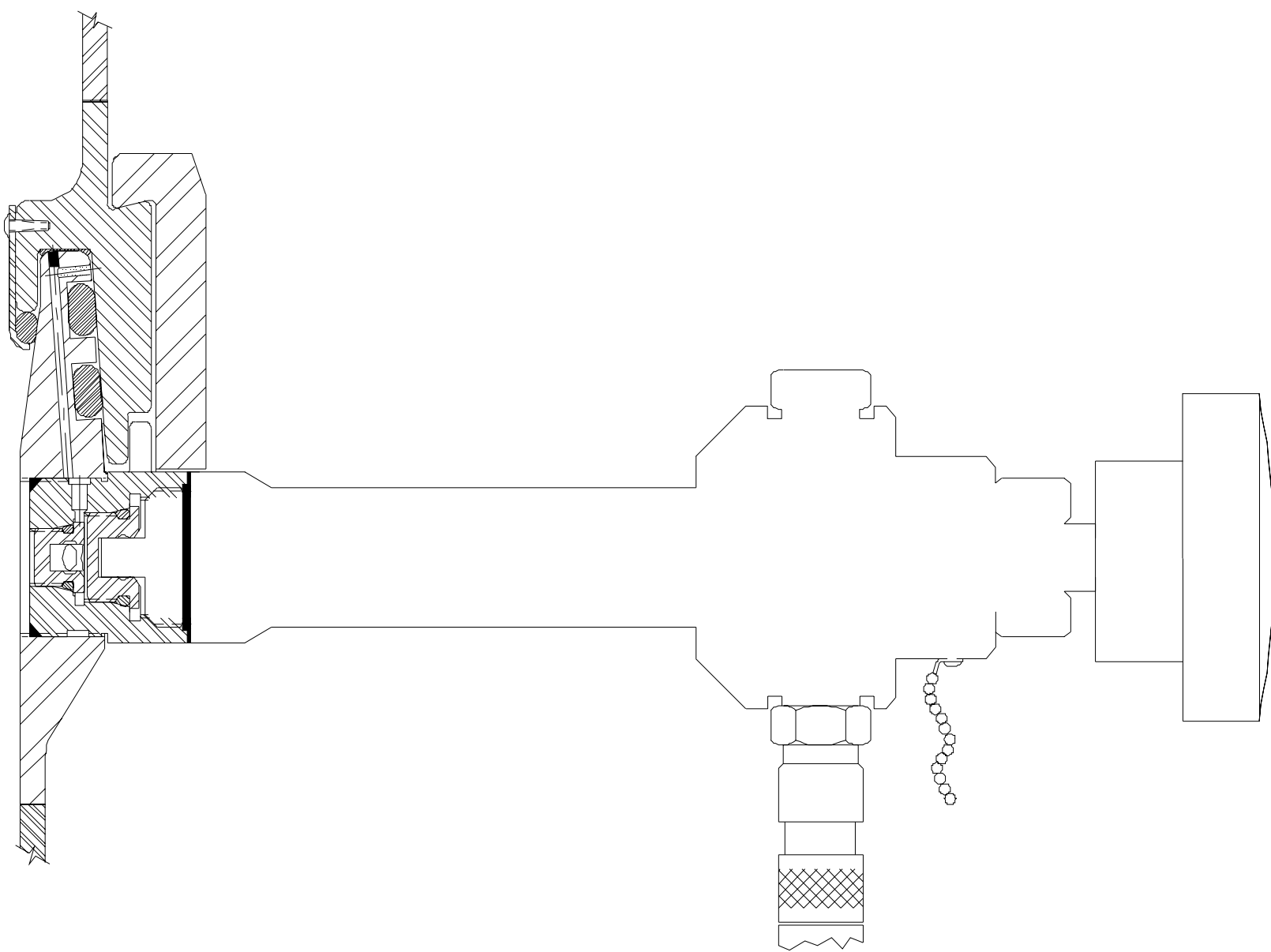

Not to scale

Note: Uses National O-ring, Buna-N, Part \# AS-568-914 and AS-568-015 


\section{Figure 1.9 ICV Vent-Port-Plug Removal/Pressure Relief Tool with adapter} (2077-091-A1 and AS568-015)

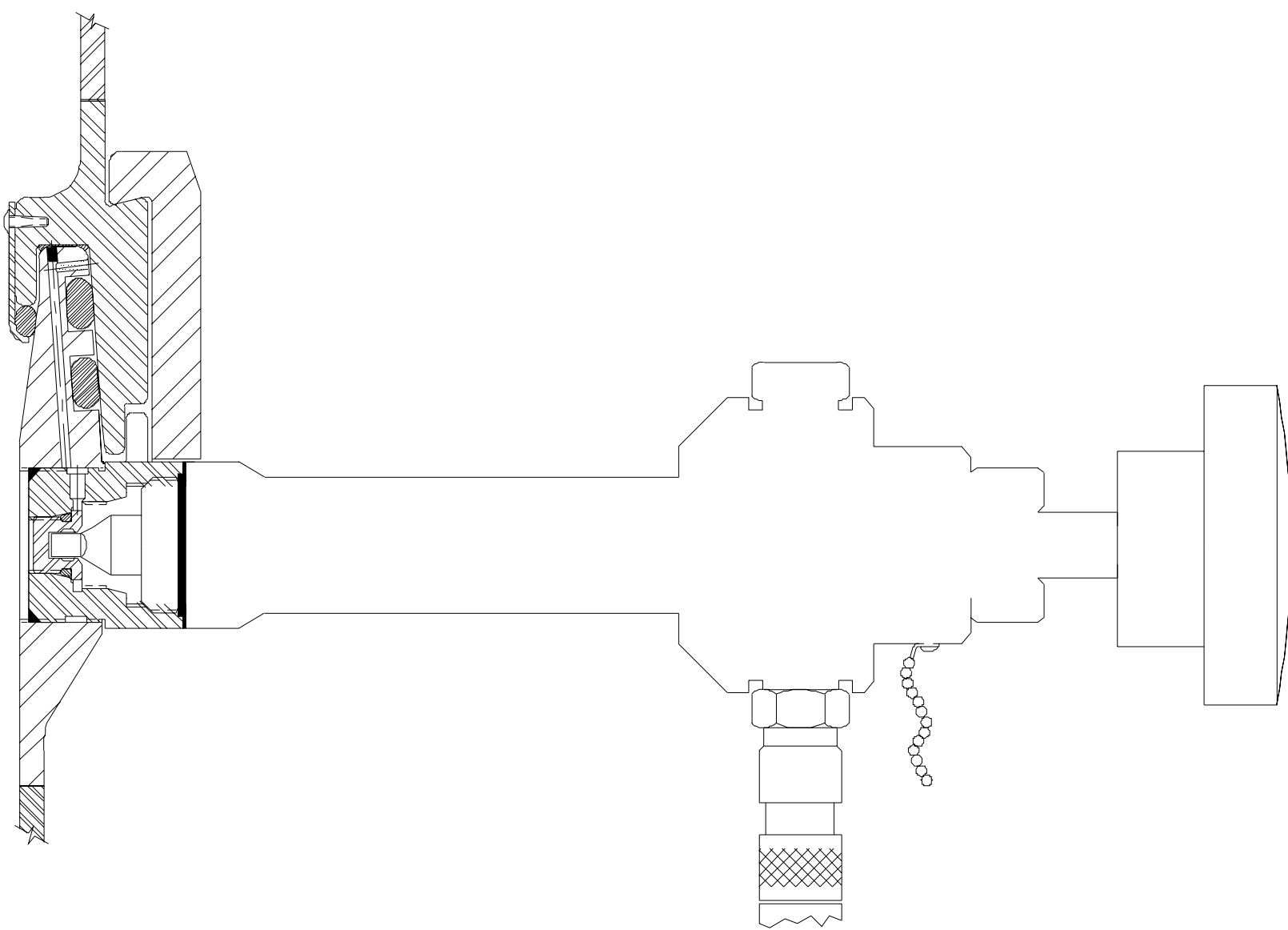

Not to scale

Note: Uses National O-ring, Buna-N, Part \# AS-568-914 and AS-568-015 


\section{Figure 1.10 ICV Vent-Port-Plug Leak Check Tool (2077-095-A2)}

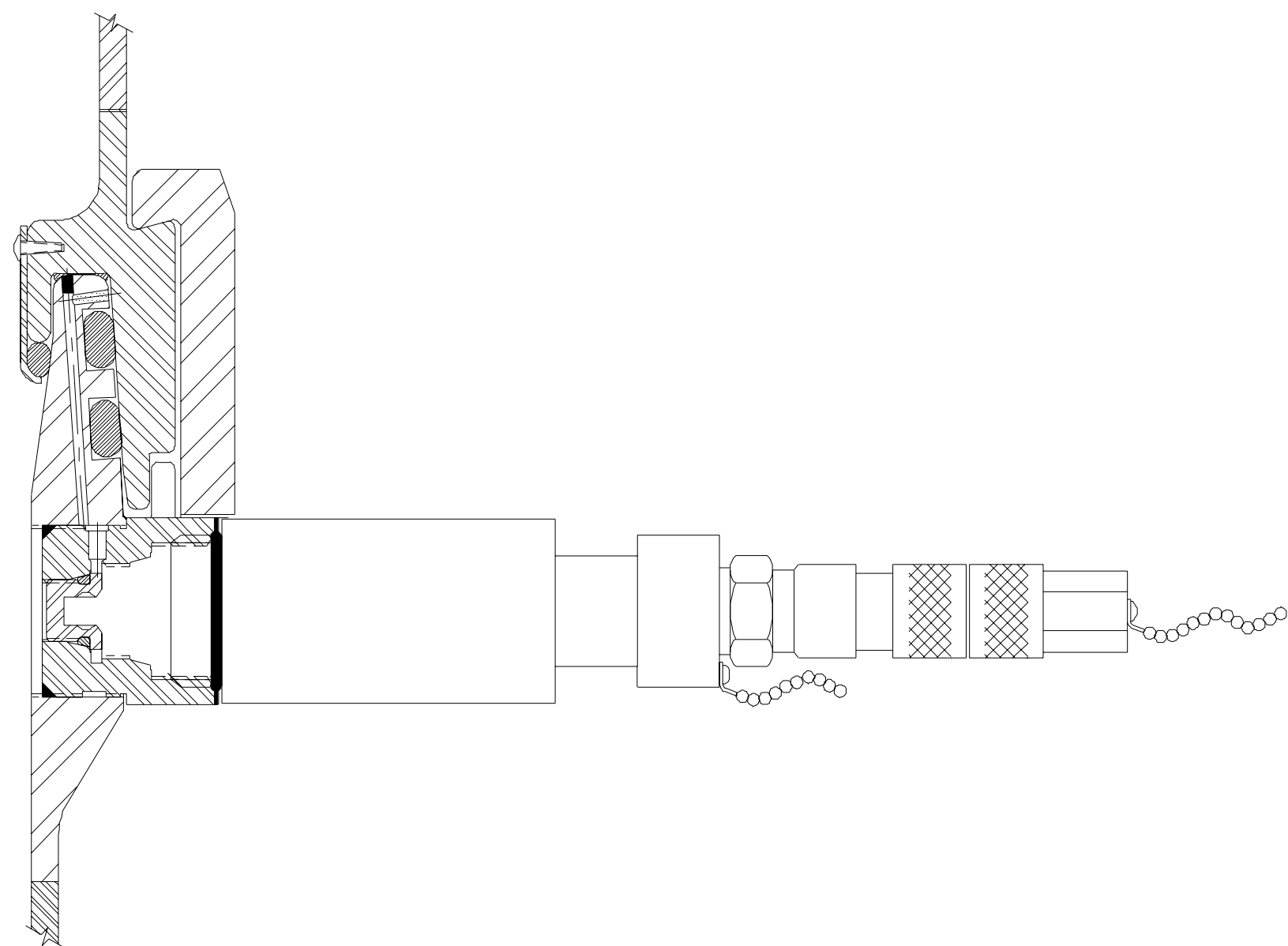

Not to scale

Note: Uses National O-ring, Buna-N, part \# AS-568-914 


\section{Figure 1.11 ICV Seal-Test-Port-Plug Removal Tool (2077-094-A1)}

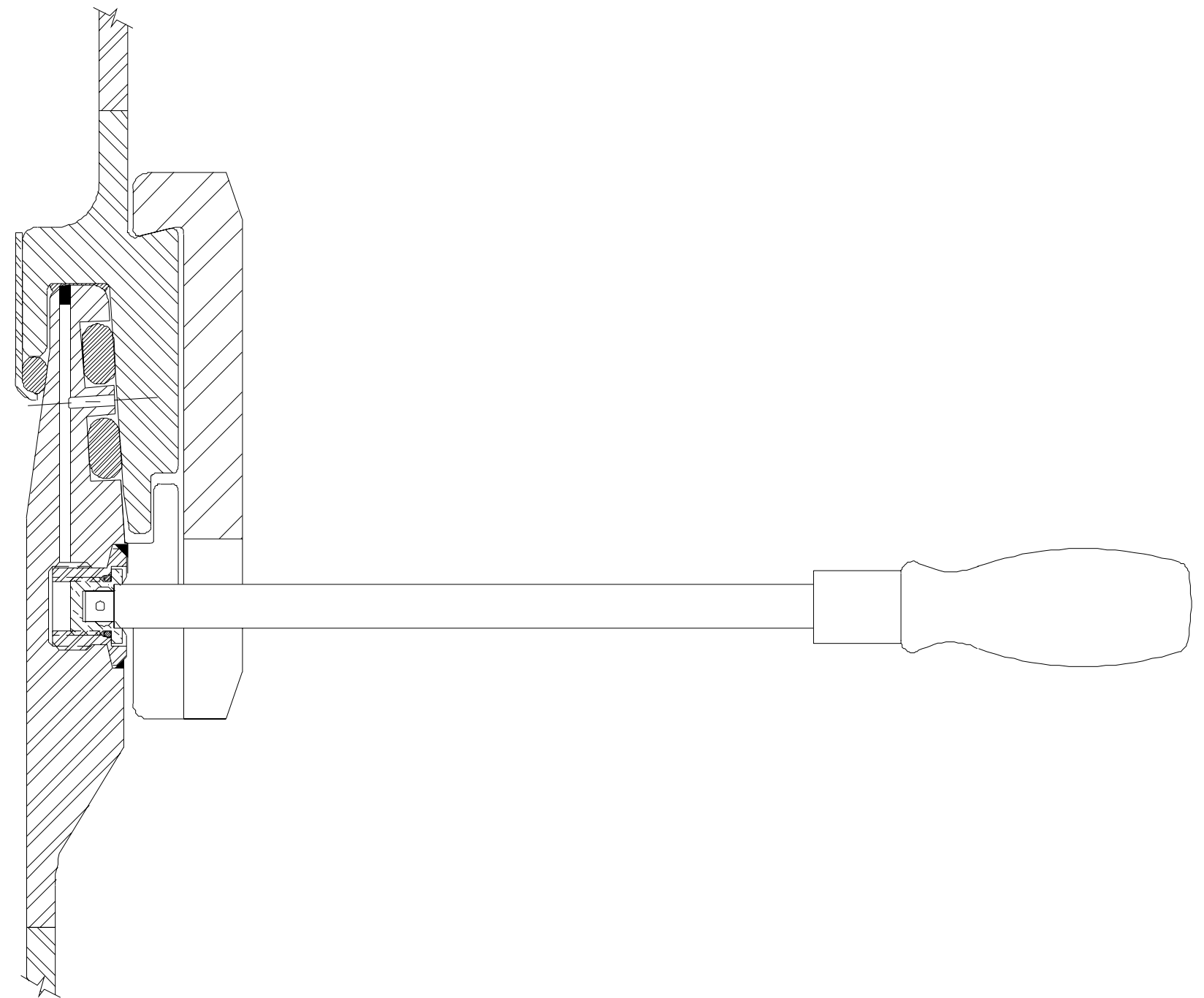

Not to scale

Note: "Proto" brand tools should be used to ensure proper fit. 


\section{Figure 1.12 ICV Seal-Leak Check Tool (2077-093-A1)}

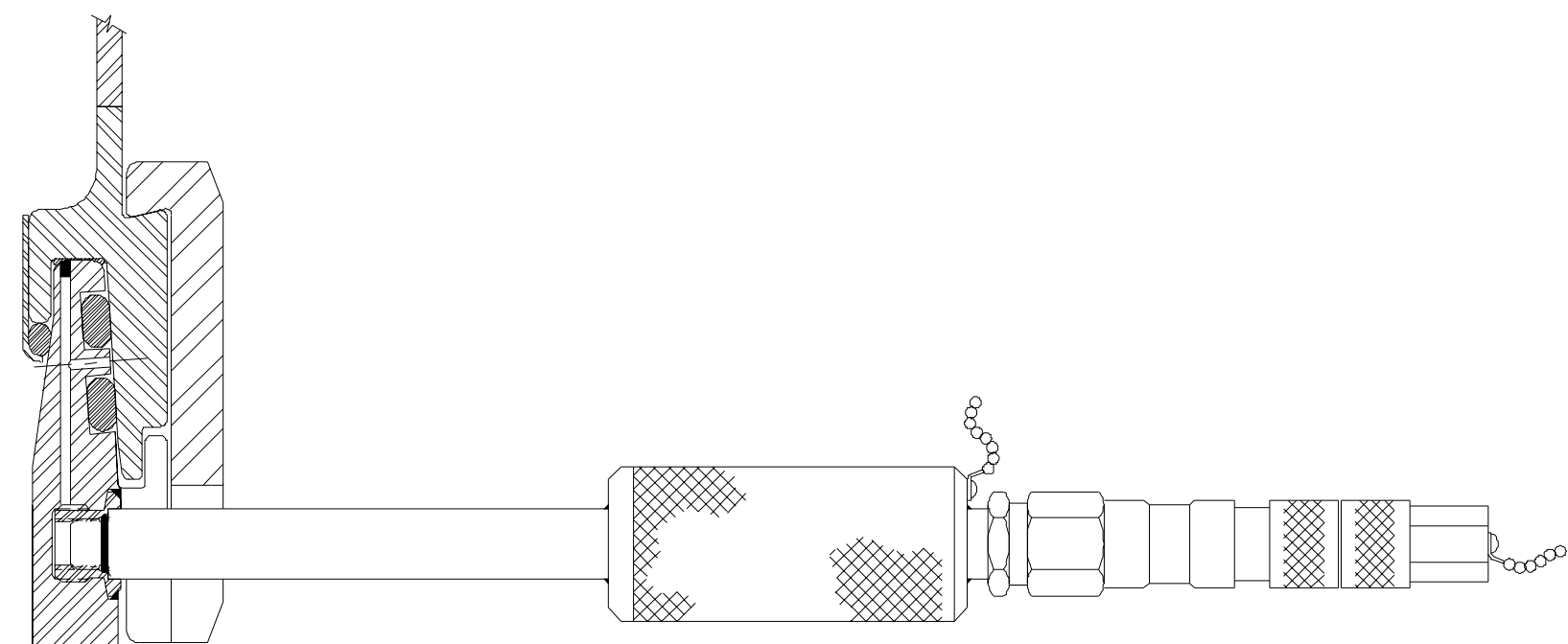

Not to scale

Note: Uses Parker O-ring, Buna-N, part \# 3-905 


\section{Figure 1.13}

\section{TRUPACT II PARTS INNER CONTAINMENT VESSEL}

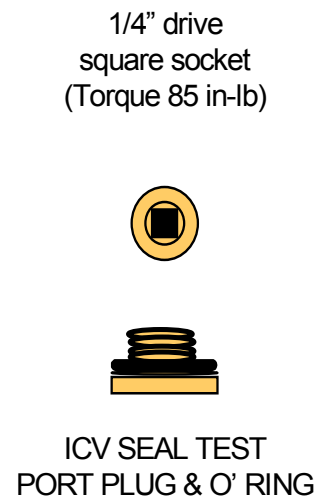

1/4" drive

square socket

PORT PLUG \& O' RING
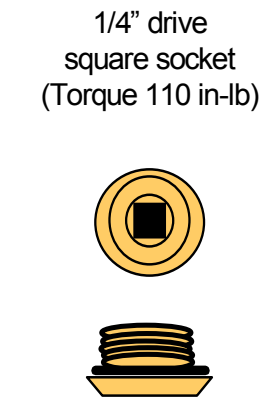

ICV INNER VENT PORT PLUG \& O' RING

\author{
3/8" drive \\ square socket \\ (Torque $135 \mathrm{in}-\mathrm{lb}$ )
}
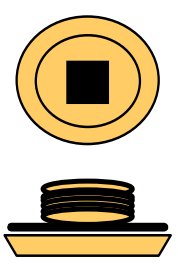

ICV OUTER VENT PORT PLUG \& O' RING

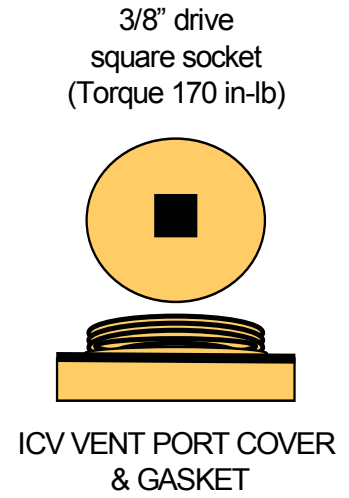

3/8" drive

square socket

orque 170 in-lb)

3/8" drive Allen

(Torque $30 \mathrm{ft}-\mathrm{lb}$ )
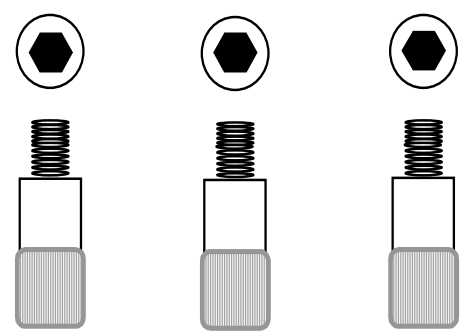

ICV LOCKING RING BOLTS (3)
(DRAWINGS NOT TO SCALE) 
Figure 1.14

\section{TRUPACT II PARTS OUTER CONTAINMENT VESSEL}

1" SOCKET

(Torque $40 \mathrm{ft}-\mathrm{lb}$ )

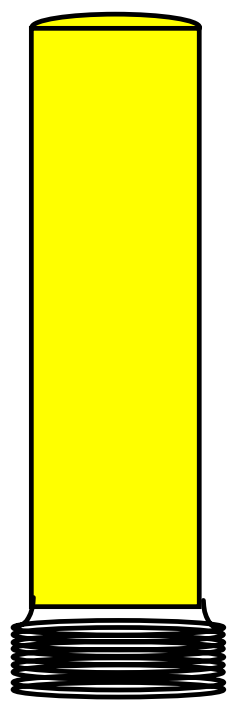

OCV VENT

PORT

ACCESS

PLUG

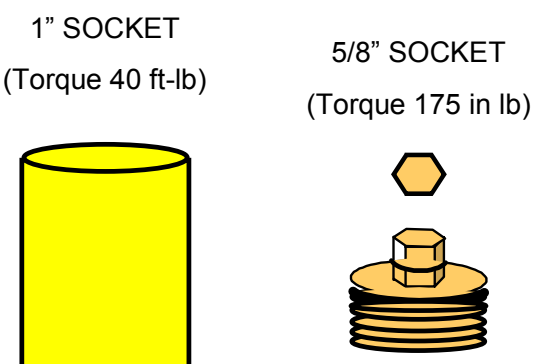

OCV VENT PORT COVER \& "O" RING'S
(DRAWINGS NOT TO SCALE)

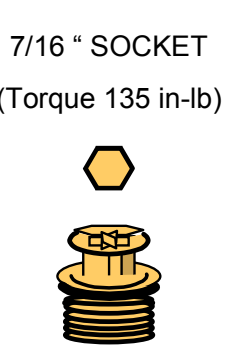

OCV VENT PORT PLUG \& "O" RING'S

OCV TEST PORT

PLUG \& "O" RING

1/4 " DRIVE

SOCKET

(Torque 85 in-lb)
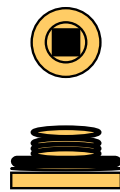
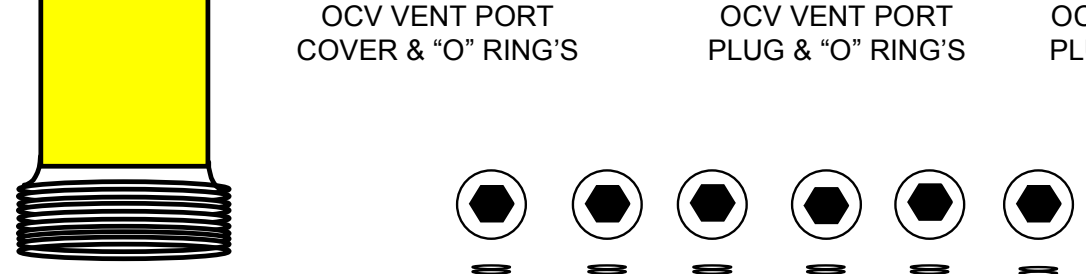

OCV TEST

PORT

ACCESS

PLUG
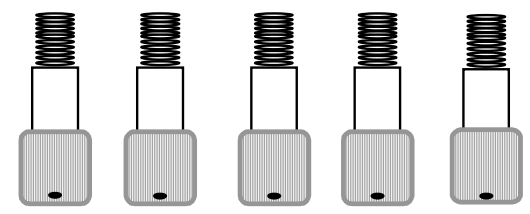

3/8" ALLEN

(Torque $30 \mathrm{ft}-\mathrm{lb}$ )

OCV ACTUATING RING BOLTS (6) 


\subsubsection{Bench stock for the TRUPACT-II}

Table 1.3 lists the required spare parts that support replacement of TRUPACT-II components during routine operations. Levels of supply are based on historical data relating to the frequency of usage of the TRUPACT-II and are expressed in terms of the quantity of parts that should be on hand with minimum/maximum levels to be stocked. A bench stock inventory should be conducted quarterly to determine shortages. Replacements will be provided through the WID TRUPACT-II Maintenance Engineer. All items should be checked against their listed shelf life. The "on-hand" and "needed" columns may be used to conduct inventories and should be faxed to the WID TRUPACT-II Maintenance Engineer quarterly (at the end of March, June, September, and December) for parts replacement.

Figures 1.13 and 1.14 show TRUPACT-II ICV and OCV parts removed as part of TRUPACT-II operations. As parts are removed from the TRUPACT-II, they should be placed in the WID provided "shadow board." A laminated copy of these figures placed behind the "shadow board" will assist in parts accountability and identification. 
Table 1.3 TRUPACT-II Spare Parts (Bench stock)

\begin{tabular}{||l|c|c|c|c||}
\hline \multicolumn{1}{||c|}{ Description } & $\begin{array}{c}\text { Part No.I } \\
\text { Substitute }\end{array}$ & Min/Max & $\begin{array}{c}\text { On } \\
\text { Hand }\end{array}$ & Needed \\
\hline \hline U-Bolt Nut Washer & $022-09$ & $1-6$ & & \\
\hline Course Thread U-Bolt & $022-10$ & $1-3$ & & \\
\hline U-Bolt Locknut & $022-11$ & $1-6$ & & \\
\hline Go/No Go Gauges & $022-13$ & $1-3$ & & \\
\hline ICV/OCV Seal-Test-Port-Plug & $156-07$ & $1-3$ & & \\
\hline ICV Outer Vent-Port-Plug & $156-09$ & $1-1$ & & \\
\hline ICV Inner Vent-Port-Plug & $156-10$ & $1-3$ & & \\
\hline ICV Vent-Port Cover & $156-11$ & $1-3$ & & \\
\hline OCA Seal-Test-Port Access Cover & $156-12$ & $1-3$ & & \\
\hline OCV Vent-Port/Test-Port Access & $156-13$ & $1-3$ & & \\
\hline Cover Plug & $156-14$ & $1-3$ & & \\
\hline OCA Test-Port Thermal Plug & $156-15$ & $1-3$ & & \\
\hline OCA Vent-Port Thermal Plug & $156-17$ & $1-1$ & & \\
\hline OCV Vent-Port-Plug & $156-18$ & $1-3$ & & \\
\hline OCV Vent-Port Cover & $156-A 1$ & $1-3$ & & \\
\hline ICV Lock-ring Bolt & $156-A 2$ & $1-3$ & & \\
\hline OCV Lock-ring Bolt & $160-13$ & $2-10$ & & \\
\hline OCV Locking Z-Flange Screw & $160-14 / 163-08$ & $2-10$ & & \\
\hline OCA Lid Guide Plate Screw & $160-15$ & $3-15$ & & \\
\hline OCV Upper Main O-ring & $160-16$ & $5-10$ & & \\
\hline OCV Vent-Port Cover, O-ring & $160-17 / 180-22$ & $5-10$ & & \\
\hline OCV Vent-Port-Plug O-ring & $160-18$ & $5-10$ & & \\
\hline OCV Vent-Port-Plug Handling O-ring & $160-19$ & $5-10$ & & \\
\hline OCV Vent-Port Cover Handling & $160-24$ & $3-15$ & & \\
\hline O-ring & $160-26 / 180-24$ & $5-10$ & & \\
\hline OCV Lower Main O-ring & $160-28$ & $1-3$ & & \\
\hline ICV/OCV Seal-Test-Port O-ring & $160-30$ & $2-10$ & & \\
\hline ICV/OCV Lock-ring Bolt Threaded & & $2-10$ & & \\
Insert & & $1-2$ & & \\
\hline OCA Forklift Pocket Screw & & & \\
\hline OCA Forklift Pocket Washer & 1602 & & \\
\hline OCA Lid Lift Pocket Tube & & & \\
\hline
\end{tabular}


Table 1.3 TRUPACT-II Spare Parts (Bench stock)

\begin{tabular}{||l|c|c|c|c||}
\hline \multicolumn{1}{|c|}{ Description } & $\begin{array}{c}\text { Part No.I } \\
\text { Substitute }\end{array}$ & Min/Max & $\begin{array}{c}\text { On } \\
\text { Hand }\end{array}$ & Needed \\
\hline \hline $\begin{array}{l}\text { OCA Lid Lift Pocket Tube Attachment } \\
\text { Screw }\end{array}$ & $163-03$ & $1-6$ & & \\
\hline Lift Pocket Washer & $163-04$ & $1-6$ & & \\
\hline OCA Lift Pocket Cover Fastener & $163-05$ & $1-6$ & & \\
\hline OCA Lift Pocket Cover Plate & $163-06$ & $1-6$ & & \\
\hline OCA Lift Pocket Cover Lanyard & $163-07$ & $1-5$ & & \\
\hline OCA Lift Pocket Cover Plate Screw & $163-08 / 160-14$ & $2-10$ & & \\
\hline OCA Lift Pocket Cover Nut & $163-09$ & $2-10$ & & \\
\hline OCA Lift Pocket Cover Clip & $163-10$ & $1-6$ & & \\
\hline Burn Out Plug & $170-06 / 163-13$ & $1-3$ & & \\
\hline Forklift Pocket Cover, Right Side & $171-11$ & $1-1$ & & \\
\hline Forklift Pocket Cover, Left Side & $171-12$ & $1-1$ & & \\
\hline ICV Upper and Lower Spacer Washer & $180-06$ & $1-6$ & & \\
\hline ICV Upper Main O-ring & $180-09$ & $3-15$ & & \\
\hline ICV Lower Spacer Screw & $180-10$ & $2-10$ & & \\
\hline $\begin{array}{l}\text { ICV Wiper O-ring Holder Driver } \\
\text { Screw }\end{array}$ & $180-11$ & $5-10$ & & \\
\hline ICV Vent-Port Cover Gasket & $180-16$ & $3-15$ & & \\
\hline ICV Lower Main O-ring & $180-19$ & $3-15$ & & \\
\hline ICV Upper Spacer Screw & $180-20$ & $3-15$ & & \\
\hline ICV Outer Vent-Port-Plug Seal & $180-21$ & $3-15$ & & \\
\hline ICV Inner Vent-Port-Plug Seal & $180-22 / 160-17$ & $3-15$ & & \\
\hline ICV Lid Debris Seal & $180-25$ & $1-2$ & & \\
\hline ICV Lid Debris seal tape & $180-26$ & $1-1$ & & \\
\hline $\begin{array}{l}\text { OCA forklift pocket cover threaded } \\
\text { insert (for sites that remove } \\
\text { TRUPACT-Ils from trailer }\end{array}$ & $160-29$ & $1-2$ & & \\
\hline ICV Wiper Seal O-ring & $180-27$ & $1-2$ & & \\
\hline $\begin{array}{l}\text { ICV Fastener, ICV Upper and Lower } \\
\text { Spacer }\end{array}$ & $180-23$ & $1-6$ & & \\
\hline
\end{tabular}




\subsubsection{TRUPACT-II Transport Trailer}

The TRUPACT-II transport trailer is designed for transportation of up to three loaded TRUPACT-II shipping packages. Air-ride suspension and spring-ride suspension trailers are designed with a goose neck that is equipped with a standard king pin arrangement. Trailers are illustrated on drawing 2077-300 listed in Attachment E.

Each trailer is equipped with 12 special tie-down devices used for securing up to three TRUPACT-II shipping packages to the trailer (four tie-downs for each package). The tie-downs are cam operated, adjustable length U-bolts that interface with, and clamp down on corresponding lugs on the TRUPACT-II packaging. Tie-downs are illustrated on drawing 2077-022 listed in Attachment E.

\subsubsection{TRUPACT-II Spare Parts}

A list of the TRUPACT-II packaging spare parts is also provided on drawing 2077-1120 listed in Attachment G. User bench stock is made up of selected components from Attachment $\mathrm{G}$ based upon previous usage factors.

\subsection{Revision}

Revision 3, supercedes Revision 2.

\subsection{GENERAL REQUIREMENTS}

\subsection{Record Maintenance}

TRUPACT-II users must comply with 10 CFR 71.91 regarding records. Specifically, records regarding inspections, tests, and maintenance must be retained for a period of three years after the life of the package to which they apply. Records relating to each shipment must be maintained for a period of three years after the shipment.

All records of maintenance activities performed on the TRUPACT-II packaging will be maintained by the WID for distribution and retention. Records are designated as QA records and will be maintained as permanent records. WID National TRU Programs will maintain records in accordance with DOE Order 1324.2.

\subsection{Document Distribution}

Upon completion, original TRUPACT-II Maintenance Records (Form 1709) and copies of supporting documentation shall be transmitted to the WID National TRU Programs, P. O. Box 2078, Carlsbad, NM 88221, and become a part of the permanent TRUPACT-II system record.

The users preparing the TRUPACT-II maintenance record should retain a copy for their file. WID National TRU Programs will retain the original and distribute copies, as appropriate.

The work instructions should be used as a check list by a user. Data attachments to the work instructions must be transmitted to WIPP, unless stated otherwise in the work instruction, with the original TRUPACT-II maintenance record. 


\subsection{Approved Work/Periodic Maintenance Instructions}

Approved work and periodic maintenance instructions and revisions will be retained by WID National TRU Programs and copies will be distributed to all users of TRUPACT-II (see Attachment D). The original will be filed with and become part of the TRUPACT-II system permanent record. For approved work instructions intended for one time use, either WID or vendor generated, the original will become part of the TRUPACT-II system permanent record.

\subsection{Material Control}

All initial and replacement components are procured by WIPP and shall be verified as complying with applicable material requirements as specified in SARP drawings. Inspection reports, applicable Certified Material Test Reports and Material Certificates of Conformance shall be maintained by the WID National TRU Programs and WID Purchasing.

All components will be furnished by the WID National TRU Programs to user sites. The parts package will be labeled with part number, description, WIPP purchase order number, and shelf-life expiration, if applicable. Users will segregate and store parts by TRUPACT-II part number. Site Bench stock will be maintained at levels consistent with that shown in Table 1.3 Shelf-life should be examined prior to issue of 0-Rings, with priority of issue given to O-Rings with the shortest remaining shelf-life. Shelf life should also be a consideration when conducting inventories and requesting additional stock.

All replaced (used) components should be disposed of in accordance with site procedures. If return of used components is deemed necessary for analysis, usage trends, or investigation, a formal request for return will be issued to user sites by the WID.

\subsection{Quality Assurance Requirements}

A QA system, meeting controlling functions of the applicable 18 criteria of 10 CFR 71, Subpart $\mathrm{H}$, shall be in place at the loading and unloading facilities as defined by DOE Order 460.2. Annex 2 of the NRC Regulatory Guide 7.10 shall be used as a guideline. These requirements also apply to maintenance, repair, replacement, and/or modifications as approved by the owner.

Existing QA programs may be used to satisfy the above requirements provided a review has been made as to its applicability to the scope of activities performed by each participant. It is the responsibility of the involved participant to obtain approval of their QA program from the appropriate DOE Field Office.

\subsection{Training Requirements}

Users shall have the responsibility for a training program specific to this work scope to ensure that qualified personnel experienced in their assigned tasks, satisfactorily perform maintenance, non-destructive testing, leak testing, component replacement, and related operations. To ensure uniformity of training, Attachment $\mathrm{H}$, Training Requirements, is included and provides the minimal requirements that must be included in site qualification cards required to use the TRUPACT-II. Users may supplement these requirements as appropriate.. 


\subsection{Maximum Packaging and Trailer Weights}

The maximum gross shipping weight of a TRUPACT-II shipping package is 19,250 pounds.

The maximum allowable gross weight for three loaded TRUPACT-II shipping packages, including the trailer is 62,000 pounds. This restriction does not allow the transport of three fully loaded TRUPACT-Ils (with maximum payloads) on one trailer. Tables 3.1 and 3.2 provide weights for components referencing packaging serial numbers and trailer stencil numbers.

\subsection{Forklift Specifications}

Forks shall have a minimum bearing area of 960 square inches (two forks: 8-inches wide by 60 -inches long). The forks shall be at the minimum spread to ensure the package is centered with respect to the direction of the forklift. Forklift capacity must equal or exceed 10 tons at 48 -inches.

Bumper pads should be provided on the face of the forklift if tip-back is used. A suitable bumper pad would be a 62 -inch-long-stainless steel plate, 24-inches high with a 48-inch radius. A thin pad of neoprene, rubber, or similar material would further preclude damage. The bumper should be located at the upper surface of the fork tine at the appropriate angle to the face of the forklift.

\subsection{Shipping Requirements}

When shipping an empty TRUPACT-II to the WIPP, a copy of the radiation and contamination survey and survey map (internal [if opened] and external) performed when the TRUPACT-II was last closed, will be faxed to WID Radiological Control at (505) 234-8298, 6040 (OHP), or 8963 (Shipping Coordination), prior to departure.

\subsection{TRUPACT-II Shipment Scheduling}

Shipments using the TRUPACT-II are coordinated by WID TRU Programs. Once agreed upon by the shipping site traffic manager and the National TRU Programs representative, National TRU Programs will enter the advance shipment schedule into the DOE TRANSCOM satellite based shipment tracking system. Based on this schedule, the shipper is responsible for entering the bill of lading into TRANSCOM at the time of shipment. Prior to departure of the shipment, the shipper is required to change the "Designated User" in the TRANSCOM bill of lading to that of the WIPP Central Monitoring Room. (See the Transportation and Tracking System for Windows Users Manual for details).

\subsection{Non-Conformance Reports (NCRs)}

Conditions encountered during inspection of the TRUPACT-II that are not correctable by using the Work Instructions contained in Attachment $D$ should be brought to the attention of the WID TRUPACT-II Maintenance Engineer for Resolution and possible initiation of an NCR for appropriate action. 


\subsection{TRUPACT-II LOAD PREPARATION}

This section provides the user with the instructions for the assembly of a TRUPACT-II payload. Slip sheets and reinforcing plates will be "drop shipped" by WID to shipping sites. Guide tubes, pallets, and SWB ratchet straps will be returned to shippers with empty TRUPACT-Ils. The following weights of materials used to build drum and SWB payloads may be used to establish total payload weight.

\begin{tabular}{|l|l|}
\hline MATERIAL NAME & MATERIAL WEIGHT \\
\hline Guide Tubes & $6 \mathrm{lbs}$ each/3 tubes in a load = 18 lbs. \\
\hline Payload Pallet & $134 \mathrm{lbs}$ each/1 in a load \\
\hline Slip Sheets & $26 \mathrm{lbs}$ each/2 in a load = 52 lbs \\
\hline Reinforcing Plate & $24.5 \mathrm{lbs} / 2$ in a load =49 lbs \\
\hline Plastic Wrap & $3 \mathrm{lbs}$ total \\
\hline Nylon Straps & $5 \mathrm{lbs}$ each/3 in a load of SWBs = 15 lbs \\
\hline Total weight for the materials used to build a payload of drums = 256 lbs \\
\hline
\end{tabular}

NOTE: If the TRUPACT-II payload pallet is to be placed on a square pallet for subsequent movement by forklift, care must be taken to ensure that all three pockets used for lifting with the Adjustable Center of Gravity Lift Fixture (ACGLF) rest on a flat surface. Failure to ensure this will result in pallet damage due to the weight of the ACGLF driving the pallet lift point through the pallet.

\subsection{Preparing a Drum Payload Assembly}

3.1.1 Place a clean TRUPACT-II pallet, right side up, (i.e., large diameter plate on top), used as the bottom support of the drum payload assembly on the floor or stretch wrap machine.

3.1.2 Place a TRUPACT-II slip sheet on top of the pallet. Verify the guide-tube holes on the slip sheet and pallet are aligned.

NOTE: The diameter of all drums to be loaded into the TRUPACT-II containers, including the locking ring, must be less than or equal to 24 inches. This dimension should not include the locking bolt. Tapping the locking ring with a hammer while torquing the lock ring nut may assist in ensuring the drum is tightly closed. The diameter of each layer of drums should not exceed 72 inches.

NOTE: If shipping less than fourteen loaded drums, empty dunnage drums must be used to form the payload while adhering to weight management practices (see Figure 3.1). To allow for pressure changes, the drum must be filtered or the filter opening must be left open.

3.1.3 Verify all waste drums are properly labeled (bar code and shipping category) at three locations 120 degrees apart, so that at least one label is clearly visible when drums are assembled into a seven pack. Place seven of the drums on 
the slip sheet. Verify the locking bolt (on each drum) is positioned between the drum gaps (which does not contain the guide tubes) so that it does not interfere with the loading operations.

3.1.4 Verify the heaviest seven-pack is on the bottom of the fourteen-pack (see Figure 3.1). Document step completion per site requirements.

3.1.5 Stretch wrap the upper portion of the drums with nine (9) wraps ensuring that the wraps extend down the sides of the drums nominally eighteen (18) inches with no overlap on top of the drums. Place a reinforcing plate on top and verify the guide tube holes are aligned with the bottom slip sheet/pallet holes by inserting and removing the guide tubes and adjusting the assembly as required. Apply nine (9) additional wraps of stretch wrap ensuring there is at least six (6) inches of overlap on the top of the drums. (See Figure 3.2. Fourteen-Pack Assembly, Typical) .

3.1.6 Place a TRUPACT-II slip sheet on top of the seven-pack (on top of the TRUPACT-II reinforcing plate) aligning the white stripe with the one on the lower assembly. Verify the guide tube holes are aligned with the bottom slip sheet/ pallet holes. (If desired, two guide tubes may be inserted to help maintain pallet alignment.)

3.1.7 Place seven of the drums on the slip sheet. Verify the locking bolt (on each drum) is positioned between the drum gaps (which will not contain the guide tubes) so that it does not interfere with the loading operations.

3.1.8 Stretch wrap the upper portion of the drums with nine (9) wraps ensuring that the wraps extend down the sides of the drums nominally eighteen (18) inches with no overlap on top of the drums. Place a reinforcing plate on top and verify the guide tube holes are aligned with the bottom slip sheet/pallet holes by inserting and removing the guide tubes and adjusting the assembly as required. Apply nine (9) additional wraps of stretch wrap ensuring there is at least six (6) inches of overlap on the top of the drums.

3.1.9 Verify all drums are properly labeled (bar code and shipping category) at three locations 120 degrees apart, so that at least one label is clearly visible when drums are assembled into a seven pack.

3.1.10 Insert the guide tube(s) into the drum payload assembly (two stacked TRUPACT-II seven-packs) adjusting the upper assembly (as required).

3.1.11 HPT/Operations - If beta-gamma and alpha surveys are required, perform in accordance with site specific procedures.

\subsection{Preparing a SWB Payload Assembly}

3.2.1 Visually verify at least two filters are installed in each Standard Waste Box (SWB). 
NOTE: $\quad$ If shipping only one loaded standard waste box, a second empty dunnage standard waste box must be used in the top position to form the payload. To allow for pressure changes, the dunnage SWB should be filtered or the filter opening left open.

3.2.2 Place the heaviest SWB on the floor.

3.2.3 Verify the heaviest SWB is located on the bottom of the load configuration. Document step completion per site requirements.

3.2.4 Before releasing the ACGLF from the SWB, verify the counterweights are positioned at $180^{\circ}$ and $000^{\circ}$.

3.2.5 Place the second SWB on top of the first, aligning the edges.

3.2.6 Attach the SWB turn buckles or ratchet straps (in three places) to the top and bottom SWBs, two on the outer lift clips on one side, the third on the middle clip on the opposite side, (see Figure 3.3).

3.2.7 Verify all Standard Waste Boxes are properly labeled (bar code and shipping category).

3.2.8 If beta-gamma and alpha surveys are required, perform in accordance with site specific procedures.

\subsection{Preparing a TDOP Payload Assembly}

To be published at a later date 
Figure 3.1 TRUPACT-II Drum Placement

The following drum placement is recommended for two seven-pack assemblies:

\begin{tabular}{|c|c|}
\hline \multicolumn{2}{|c|}{ Assembly of First Layer of Seven Drums } \\
\hline Position & Weight \\
\hline 1 & Heaviest drum \\
\hline 2 & Next heaviest drum \\
\hline 3 & Third heaviest drum \\
\hline 4 & Fourth heaviest drum \\
\hline 5 & Fifth heaviest drum \\
\hline 6 & Sixth heaviest drum \\
\hline 7 & Last drum \\
\hline
\end{tabular}

Assembly of Second Layer of Seven Drums Position Weight

8 Heaviest drum

9 Next heaviest drum

10 Third heaviest drum

11 Fourth heaviest drum

12 Fifth heaviest drum

13 Sixth heaviest drum

14 Last drum
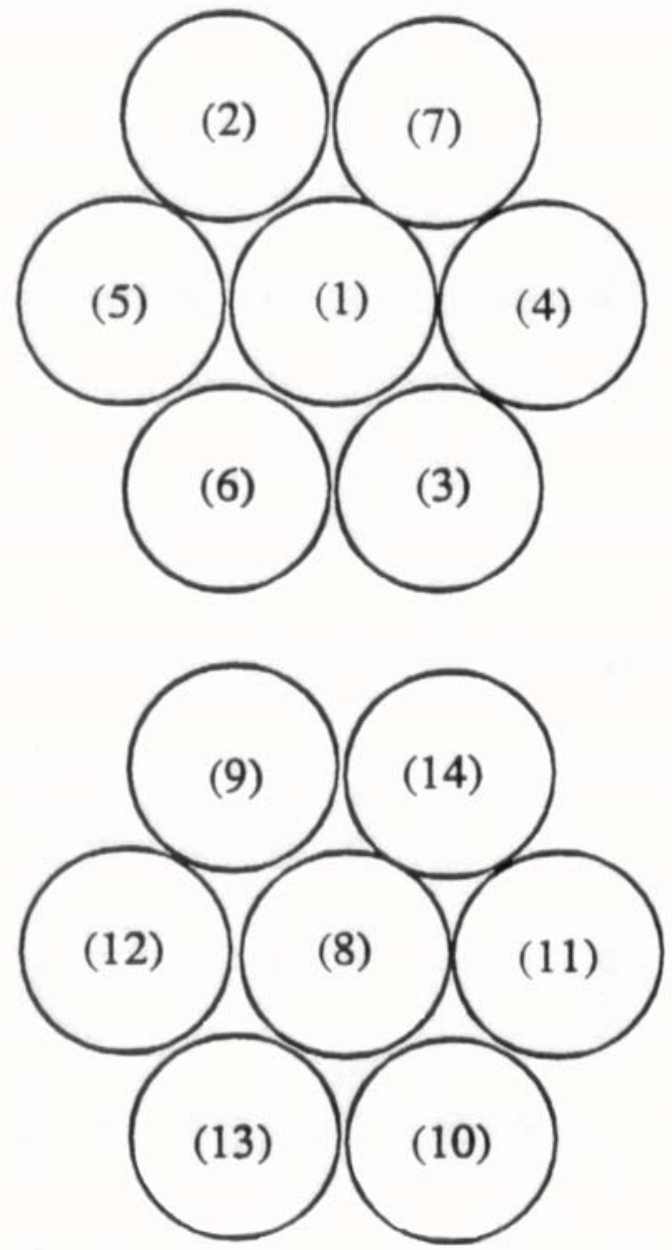

Not to scale

Note: If dunnage is used, it may be placed as needed.

Note: Verify the heaviest seven pack will comprise the lower layer of seven drums. 
Figure 3.2 Fourteen-Pack Assembly, Typical

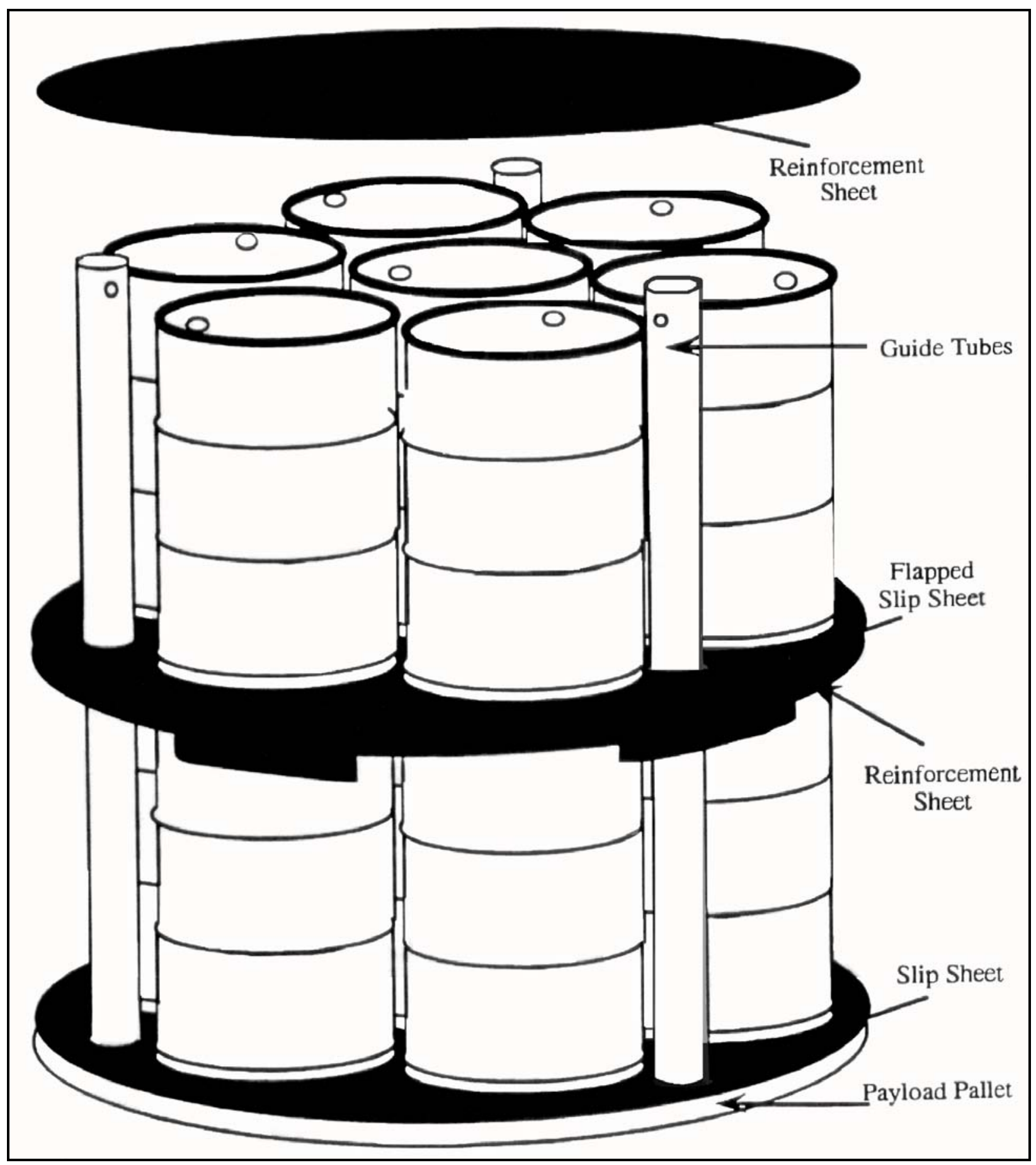

Not to scale 


\section{Figure 3.3 SWB and Adjustable Lifting Slings}

The SWB Lift Fixture attaches to these clips.

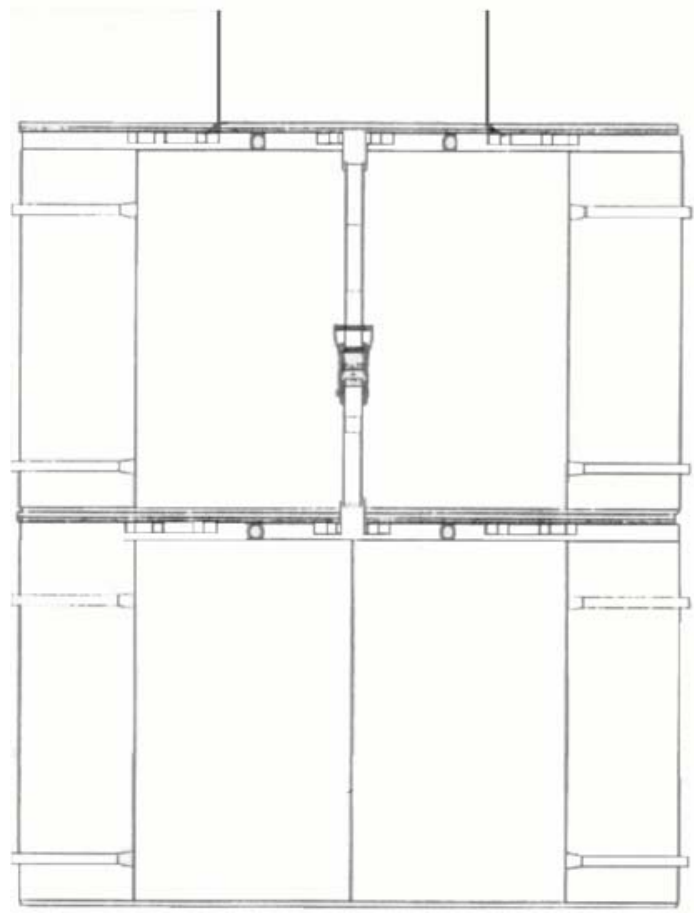

Two SWBs connected with SWB adjustable slingsone sling either side

Inspection- Prior to each use, each SWB adjustable sling assembly shall be visually inspected to verify that the webbing red wear indicator threads are not exposed due to abrasion.

Prior to lifting, the ratchet buckle shall be visually inspected to verify that the ratchet teeth are securely engaged and that there is nominally three wraps (or $1-1 / 2$ turns) or webbing around the mandrel.
The SWB Lift Fixture attaches to this clip.

Connect 2 SWB's with 3 slings and tighten per Mfgr. Instructions.

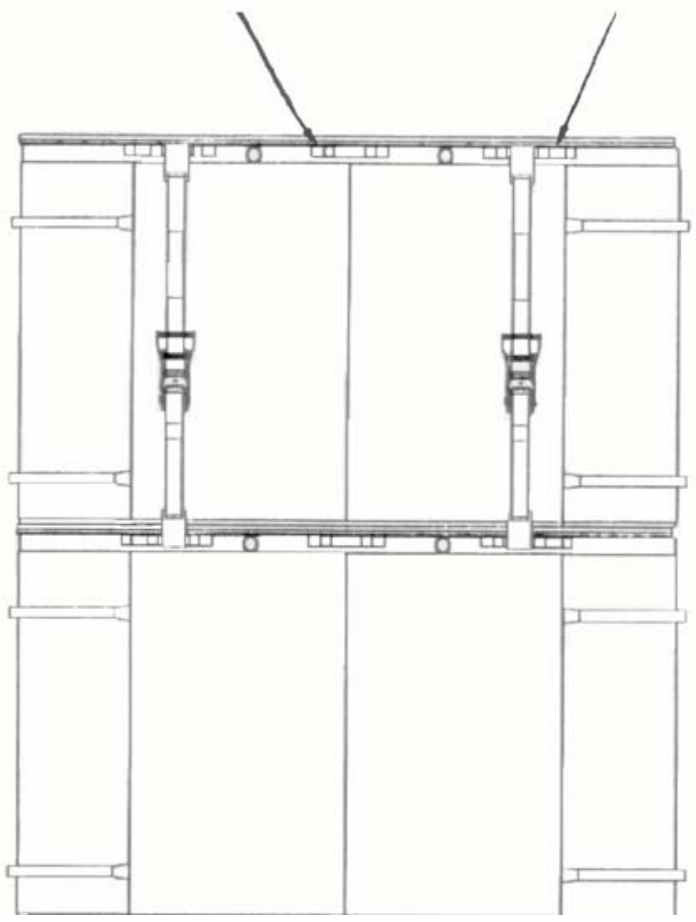

Two SWBs connected with SWB adjustable slingstwo slings opposite side

The assembly shall also be checked to verify that the webbing is in tension before each loading operation and before each unloading operation.

Annual Inspection - Each SWB sling assembly including webbing, ratchet buckle, and hooks shall be inspected for signs of excessive wear, cracking, or physical damage. If the webbing, ratchet buckle, or hooks are excessively worn, cracked, or damaged, the assembly shall NOT used. Annual inspection shall be recorded. 
Table 3.1 TRUPACT-II Packaging Component Weights (Pounds)

\begin{tabular}{||c|c:c:c|c:c|c|c||}
\hline \multirow{2}{*}{$\begin{array}{c}\text { Serial } \\
\text { Number }\end{array}$} & \multicolumn{3}{|c|}{ ICV } & & & OCA & $\begin{array}{c}\text { TOTAL } \\
\text { POUNDS }\end{array}$ \\
\cline { 2 - 8 } & Lid & Body & Total & Lid & Body & Total & 12,556 \\
\hline 125 & 922 & 1,894 & 2,816 & 3,604 & 6,136 & 9,740 & 12,476 \\
\hline 126 & 924 & 1,890 & 2,814 & 3,532 & 6,130 & 9,662 & 12,512 \\
\hline 127 & 912 & 1,872 & 2,784 & 3,630 & 6,098 & 9,728 & 12,739 \\
\hline 128 & 930 & 1,938 & 2,868 & 3,642 & 6,229 & 9,871 & 12,809 \\
\hline 129 & 922 & 1,912 & 2,834 & 3,610 & 6,365 & 9,975 & 12,842 \\
\hline 130 & 900 & 1,932 & 2,842 & 3,700 & 6,300 & 10,000 & 12,630 \\
\hline 131 & 906 & 1,900 & 2,806 & 3,594 & 6,230 & 9,824 & 12,656 \\
\hline 132 & 914 & 1,932 & 2,846 & 3,596 & 6,214 & 9,810 & 12,670 \\
\hline 133 & 900 & 1,900 & 2,800 & 3,624 & 6,246 & 9,870 & 12,634 \\
\hline 134 & 902 & 1,882 & 2,784 & 3,600 & 6,250 & 9,850 & 12,556 \\
\hline 135 & 906 & 1,900 & 2,806 & 3,600 & 6,150 & 9,750 & 13,140 \\
\hline 136 & 906 & 1,884 & 2,790 & 3,750 & 6,600 & 10,356 & 13,100 \\
\hline 137 & 900 & 1,850 & 2,750 & 3,650 & 6,700 & 10,350 & 12,700 \\
\hline 138 & 900 & 1,800 & 2,700 & 3,600 & 6,400 & 10,000 & 12,550 \\
\hline 139 & 900 & 1,850 & 2,750 & 3,600 & 6,200 & 9,800 & \\
\hline \hline
\end{tabular}


Table 3.2 TRUPACT-II Trailer Identification Data and Weights

\begin{tabular}{|c|c|c|c|c|}
\hline $\begin{array}{l}\text { Stencil } \\
\text { Number }\end{array}$ & Trailer Serial Number & $\begin{array}{c}\text { U.S. } \\
\text { Government } \\
\text { License Number }\end{array}$ & $\begin{array}{l}\text { WIPP Property } \\
\text { Tag Number }\end{array}$ & $\begin{array}{c}\text { Total } \\
\text { Weight } \\
\text { (Pounds) }\end{array}$ \\
\hline 1 & 1ALST9282LS900543 & E-22825 & Co13415 & 9,870 \\
\hline 2 & 1ALST9284LS900544 & E-22826 & Co13410 & 9,860 \\
\hline 3 & 1ALST9286LS900545 & E-22827 & CO13405 & 9,880 \\
\hline 4 & 1ALST9288LS900546 & E-22828 & Co13400 & 9,870 \\
\hline 5 & 1ALST928XLS900547 & E-22829 & C013395 & 9,900 \\
\hline 6 & 1ALST9281LS900548 & $\mathrm{E}-22830$ & C013390 & 9,890 \\
\hline 7 & 1ALST9283LS900549 & E-22831 & C013385 & 9,860 \\
\hline 8 & 1ALST928XLS900550 & $\mathrm{E}-22832$ & CO13420 & 9,860 \\
\hline 9 & 1ALST9281LS900551 & E-22833 & CO13425 & 9,860 \\
\hline 10 & 1ALST9283LS900552 & E-22834 & Co13386 & 9,870 \\
\hline 11 & 1ALST928XLS900791 & $\mathrm{E}-22835$ & C013391 & 9,870 \\
\hline 12 & 1ALST9281LS900792 & E-22836 & C013396 & 9,870 \\
\hline 13 & 1ALST9283LS900793 & E-22837 & C013401 & 9,860 \\
\hline 14 & 1ALST9285LS900794 & $E-22838$ & CO12014 & 9,840 \\
\hline 15 & 1ALST9287LS900795 & E-22839 & C012015 & 9,890 \\
\hline 16 & 1ALST9289LS900796 & $E-22840$ & Co12016 & 9,850 \\
\hline 17 & 1ALST9280LS900797 & E-22841 & C012017 & 9,840 \\
\hline
\end{tabular}




\subsection{TRUPACT-II PACKAGE OPERATING INSTRUCTIONS}

This section addresses the operation of the TRUPACT-II. Included are "TRUPACT-II Operating Tips and Techniques." This section provides users the benefit of lessons learned when using the TRUPACT-II. The user should note that many of the techniques are intentionally not included in the operating sections unless they affect safety, but are available for reference.

Should users decide to prepare their own site specific procedures, they need only address the functions performed at their site. If fixed loading facilities are used, the user need not include removal of the TRUPACT-II from the trailer. If only empty TRUPACT-IIs are received, there is no need for a procedure on receipt of loaded TRUPACT-IIs. DOE/WIPP 93-1001 may always be used as an authorized operating procedure.

Section 4.2 includes all applicable notes and cautions associated with TRUPACT-II operations with which a user should be familiar. Those affecting safety are included in the Operating Instructions (Section 4.3).

\subsection{TRUPACT-II Operating Tips and Techniques}

The following information is provided as guidance for training in TRUPACT-II operations. It provides supportive information to the operating section (Section 4.3) of this manual.

\subsubsection{Unloading a TRUPACT-II from a trailer}

The spring pins, padlocks, etc., used to secure the tie-down cam handles in place must be removed initially. The adjusting nuts must be loosened until the tension has been released from the Bellville springs when releasing the tie-down assemblies. This will enable the operator to rotate the cam handles to the "UP" position. The U-bolts can then be lifted and rotated outward away from the TRUPACT-II tie-down lugs. The U-bolts must be lowered as far as possible onto the trailer bracket below the tie-down lugs to prevent damage to the TRUPACT-II exterior as well as the U-bolts.

Experience has shown that rotating the forklift pocket covers, and tightening the screws is more than adequate to hold the covers out of the way while transporting the TRUPACT-II from the trailer to the loading/unloading area.

When using a forklift in conjunction with the TRUPACT-II, the fork tines must fully engage the pockets. This, however, does not imply contact between the fork uprights and the TRUPACT-II exterior. In addition, it is necessary to keep the package level to prevent damage to the exterior of the TRUPACT-II (i.e., Do not tilt the forks backwards for transport).

\subsubsection{Outer Containment Assembly (OCA)/Inner Containment Vessel (ICV) Lid Removal}

Before unlocking the OCA lid, the alignment of the seal test port, in relation to the lid, must be checked to verify that the seal test tool can be installed with no binding. In the event the alignment is not correct, the lid should be temporarily marked to show the proper orientation of the lock-ring when aligned correctly. This marking can then be used to realign the lock-ring after the lid has been removed, and is on the lid stand. 
The ACGLF legs must be verified to be locked into the load/lift fixture prior to placing any load weight on the ACGLF. The legs are locked when the green "LOCKED" lights are ON and the amber "UNLOCKED" lights are OFF at the ACGLF console. Verify the legs physically rotate when the Leg Lock/Unlock switch is engaged in either position.

The ACGLF counterweights should be used to assist in the removal of OCA and ICV Lids. Rotating the weights clockwise, and/or counter-clockwise, while placing tension on the crane will allow the operator to remove a lid.

When the ACGLF is used properly, the lid will shift toward the high point compensating for an uneven lift. This is done when the weights are rotated toward the area of the lid that is at the highest point. After the weight shift has occurred, the lid can be lifted normally by repositioning the weights to the $180^{\circ}$ and $000^{\circ}$ positions and continuing with the upward motion of the crane.

In the event the ICV has rotated within the OCV during shipment, the following corrective actions can be implemented. The operator can lift an empty ICV with the ACGLF and crane, and reorient it to the required position, or insert the T-Handles into the slots and rotate the ICV as necessary. When the ICV is loaded, the T-Handles must be inserted into the slots and the ICV rotated as necessary.

When OCA and ICV lid component parts are removed from their installed positions, they should be placed in a tray that includes a full scale picture or drawing of all parts. There should be space to set each part in front of its associated picture to allow for easy identification of what parts have and have not been removed during the lid removal process. This tray should also provide for the segregation of OCA parts from ICV parts.

The Operator should verify that the proper T-Handles are being used for the respective lids. The ICV T-Handles have a longer shaft on the pins than the OCA T-Handles due to the difference in thickness between the lock-rings. If the ICV T-Handles are used in the OCA lock-ring, there will be excessive play, which creates the potential for damaging the lock-ring.

In addition to the T-Handles, there are lock-ring tools which are (T-handle) extensions to aid the operator in the rotation of the lock-rings. They provide additional leverage and control to prevent slamming the lock-ring up against the stop tabs. These tools should be used for all lock-ring manipulations to minimize the possibility of damage to the lock-ring stop tabs.

After evacuating the OCV or ICV, the associated Vent-Port tool must be removed. This needs to occur prior to lifting the lid to prevent damage to the tool, the lock-ring, the lid and/or the body of the TRUPACT-II during lid removal. It also facilitates thread inspections, and allows the cavity to return to atmospheric pressure in less time because the vent port has a larger opening than the vent port tool adaptor.

It may be necessary to hold the Vent-Port tool to prevent the rotation of the ICV body when rotating the ICV lock ring. If this is done, the operator must hold the tool at the base (i.e., closest to the TRUPACT-II body). If the tool is held at the end with the rotating handle, the lateral stresses being applied could break the tool.

When lifting the OCA lid, verify that the load exerted on the lift pockets does not exceed 7,500 pounds through the use of a load cell. (Load cell indication of 
10,000 pounds minus weight of the ACGLF @ 2,500 pounds=7,500 pound load). An indication of 10,000 pounds or greater may mean the lid is binding.

When lifting the ICV lid, verify that the load exerted on the lift pockets does not exceed 5,000 pounds through the use of a load cell. (Load cell indication of 7,500 pounds minus weight of the ACGLF @ 2,500 pounds $=5,000$ pound load). An indication of 7,500 pounds or greater may mean the lid is binding.

\subsubsection{Inspections and Cleaning}

The alignment of the seal test port with regard to the OCA lid must be verified prior to reinstalling the lid. If necessary, the lock-ring can be realigned, with the lid on the stand, using the marks made on the lid prior to unlocking and removal. Using the OCA T-Handles, three (3) operators located around the circumference of the lid can lift slightly and evenly on the lock-ring and rotate it in the required direction to realign the seal test port.

When applying the Dow Corning ${ }^{\mathrm{TM}}$ high vacuum grease to the threads of the plugs and covers, and their associated O-rings, the term "very light coat" should be understood to mean no more than what is necessary to give the O-rings a glossy appearance or the threads a dull appearance.

The Main O-rings should be lubricated with approximately one (1) tablespoon of Dow Corning ${ }^{\mathrm{TM}}$ high vacuum grease. When two operators (recommended) are greasing a Main O-ring, they should use approximately one-half $(1 / 2)$ tablespoon each, or one operator should use approximately one (1) tablespoon while the other assists in holding the Main O-ring during greasing.

When applying the Nickel Never-Seize ${ }^{\mathrm{TM}}$ (or equivalent), to the threads of the access covers, bolts, and/or access ports, only use enough to give the threads a dull appearance.

Due to the leak test sensitivity, it is imperative that all sealing surfaces are cleaned thoroughly. If not, a failed leak test may result, and it will be necessary to repeat the cleaning process.

If water is found in the ICV cavity, it is necessary to remove the water by means of a wet/dry vacuum, or by entering the cavity and using absorbent materials to soak up the water. After this is accomplished, it is then necessary to remove the ICV to inspect the OCV for water, and remove the water if found. When removing the ICV, care should be taken to prevent damage to the bottom, and to verify that the ICV is placed in a safe, secure place.

\subsubsection{Loading a Payload}

When initially raising a payload to balance it with the ACGLF, the operator needs to note the counterweight positions. These positions are then to be written on tape affixed to the top of the payload in the vicinity of the \#1 leg of the ACGLF. The \#1 leg has been defined as the leg opposite the two electrical junction boxes on the ACGLF.

The payload needs to be balanced to minimize the possibility of damage to the interior of the ICV. The clearance around the payload pallet, when centered over the ICV body, is at most 0.3125 inch. Care should be exercised to avoid hitting, scraping, or 
binding the payload assembly against the ICV body flange, because damage could result.

The payload must be aligned such that the center-of-gravity is in alignment with the centerline of the trailer. This is necessary to minimize the effects of an unbalanced load on the safe handling of the truck-trailer ensemble when traveling over-the-road.

\subsubsection{Unloading a Payload}

Prior to removing the payload, the operator must note the counterweight positions marked on the top of the payload. This will indicate the proper orientation of the ACGLF legs (i.e., Leg \#1 to be inserted near the location of the counterweight markings), and let the operator know where to position the weights for a balanced lift.

The payload must be balanced prior to being removed from the ICV to prevent damage to the interior of the ICV body.

\subsubsection{ICV / OCA Lid Installation}

The ICV is designed for safe operation with a full internal vacuum. However, due to the possible presence of VOCs in the payload, general operations of the ICV should be accomplished using less than $15-$ inch- $\mathrm{Hg}$ vacuum.

An appropriate T- Handle should be installed in the slots of the lock-ring near the vent port to assist in aligning the lid during installation.

The operators should check for proper alignment of the unlock arrows with the seal test port arrows, and check for proper orientation of the vent port with the cutout in the lock-ring during alignment of the lids. The operators must also verify the lid is balanced when lowered. They can listen for air rushing out of the vent port to indicate that the lid has fully seated.

Care should be taken to avoid scraping the guide plates against the ICV lock-ring, by ensuring that the OCA lid is centered directly over the OCA body when installing the OCA lid.

If installing lids on an empty TRUPACT-II, it is quicker to vent the internal pressure by removing the vent port tool than to leave the tool in place and insert an adaptor. The vent port has a larger opening than the vent port tool adaptor.

\subsubsection{Loading a TRUPACT-II onto a Trailer}

When loading a TRUPACT-II on to a trailer, the forklift operator is required to have and use a spotter at all times.

It is necessary to align the tie-down lugs with the tie-down U-bolts prior to setting the TRUPACT-II into place. The operator should lower the TRUPACT-II slowly onto the trailer in the designated location.

The TRUPACT-II designated for the \#1 trailer position should be loaded first; the TRUPACT-II designated for position \#2 (if applicable) next, and the TRUPACT-II designated for position \#3 (if applicable) last. This ensures the maximum amount of operating room for the forklift operator. 
When all TRUPACT-Ils designated for the trailer have been loaded, the four (4) tiedown cam handles must be rotated to the "UP" position for each TRUPACT-II. Each of the U-bolts must be lifted up and positioned toward and over the TRUPACT-II tie down lugs. The operator should then engage the U-bolts into the TRUPACT-II tie-down lug recesses. The tie down cam handles should then be rotated to the "DOWN" position. The spring safety pins, padlocks, or other mechanisms should be installed to prevent rotation of the cam handles to the "UP" position during shipping.

When tightening the two adjustment nuts for each of the tie-down U-bolts, the operator is required to obtain a gap condition of 0.070 to 0.100 inches (A Go/No Go gauge shall be used). If this gap condition cannot be obtained on a tie-down assembly, it will be necessary to remove the tie-down assembly, disassemble it, and clean it. When reassembling the tie-down assembly the operator must check that the Bellville springs are installed properly (two up, two down, two up). Once this has been completed, the tie-down assembly then needs to be reassembled, tightened and the gap verified to be within the tolerance as stated above.

The forklift pocket covers may be installed at any time after the TRUPACT-II is loaded onto the trailer.

\subsubsection{Lifting A Stuck Lid}

The crane should be operated at the slowest possible operating speed when attempting to lift a stuck lid.

When using heat guns, it is necessary to ensure that the lock-ring is heated evenly. This may require the use of more than one heat gun. The time limits are provided as a guideline to ensure the even and complete heating of the lock-ring. Additional heating time may be required in colder climates. This should be determined by the TRUPACT-II Maintenance Engineer.

If it is necessary to pressurize a TRUPACT-II to remove a stuck lid, the ABNORMAL OPERATIONS SECTION must be followed as written to prevent personnel injury/contamination and/or equipment damage.

Under no circumstances are the safe working limits of the crane, ACGLF, and/or any associated rigging materials to be exceeded to remove a stuck lid. To do so could result in undue stresses and damage to equipment, personnel injury, and various other costly and unnecessary delays to the overall TRU Waste Operations Program.

\subsubsection{Releasing Tiedowns and Removal of a Package from the Trailer}

4.1.9.1 If the package is not to be removed from the trailer, the user must only loosen the tie-down adjusting nuts until the tension has been released from the Bellville springs.

4.1.9.2 If the package is to be removed from the trailer, the user must also remove the four spring pins, padlocks, or other devices securing the tie-down cam handles located on the frame of the trailer for each package.

4.1.9.3 Loosen the adjusting nuts, as necessary, and rotate the four tie-down cam handles to the "UP" position. 
4.1.9.4 Lift upward and rotate outward the four U-bolts from over the package tiedown lugs.

4.1.9.5 Lower the U-bolts as low as possible onto the trailer bracket below the package tie-down lug.

4.1.9.6 Rotate the four forklift pocket covers to up position or REMOVE the four covers and store in a designated area.

CAUTION: Forks can cause damage to the exterior surfaces of the package.

4.1.9.7 Operate a forklift to fully engage the package forklift pockets.

CAUTION: Tip-back may damage the package exterior surface.

4.1.9.8 Lift the forks vertically until the package is clear of the trailer frame.

4.1.9.9 If required, clean the TRUPACT-II before transport to a designated area. The TRUPACT-II may be cleaned with dampened cloths or a brush with water.

4.1.9.10 Transfer the package to the designated unloading/loading area.

4.1.9.11 Remove the forklift from the package forklift pockets.

\subsection{Notes and Cautions Regarding TRUPACT-II Operating Instructions:}

\subsubsection{Notes:}

The package unloading operation shall only be performed in a dry environment. In the event of precipitation during outdoor unloading or loading operations, precautions, such as covering the Outer Containment Assembly (OCA) and Inner Containment Vessel (ICV) cavities, shall be implemented to prevent precipitation from entering the package interior cavities. If precipitation does enter the interior cavities, all free-standing water shall be removed prior to loading the package for shipment and handled according to the site's waste management procedures.

- $\quad$ ACGLF may be left in place while leak tests are performed so as to be available if the leak tests fail and a lid must be removed for additional cleaning.

- $\quad T h e ~ I C V$ is designed for safe operation with a full internal vacuum. However, due to the possible presence of VOCs in the payload, general operations of the loaded ICV should be accomplished using less than 15-inch-Hg vacuum.

- $\quad$ Verify the TRUPACT-II lugs are aligned with the tiedown U-Bolts prior to setting the package into place on the trailer.

- If required, clean and/or dry the TRUPACT-Il before transport to a designated area. The TRUPACT-II may be cleaned with dampened cloths or a soft brush and water. Used cleaning materials should be managed according to site waste management procedures. 
- When replacing main O-ring(s), leak testing is not required if making an empty shipment (see Work Instruction 4.2). However, a "Leak Check Required" tag with the name of the containment O-ring(s)/seal(s) replaced written on it must be attached to the vent port indicating testing is required prior to loaded shipment and the appropriate Maintenance Record (Form 1709) entries are required.

- For shipments to WIPP, the shipper should verify that each payload container number has been entered into the WIPP Waste Information System (WWIS) and verify that the shipment has been approved by the WIPP WWIS Data Administrator. The verification is needed to preclude losing a portion of the allowable 60 day shipping period.

- If the payload will be installed in the TRUPACT-II while the TRUPACT-II is on the trailer, weight distribution must be considered. If only one TRUPACT-II is in the shipment, it should be in the \#1 position on the trailer. If two TRUPACT-Ils are in the shipment, the heavier TRUPACT-II should be in the \#1 position and the lighter in the \#2 position. If three TRUPACT-Ils are in the shipment, the heaviest TRUPACT-II should be in the \#1 position, next heaviest in the \#3 position, and the lightest in the \#2 position. Weight is not a factor until the weight differences are greater than 2000 pounds.

- Rotation of the ACGLF weights should be used to assist in the removal of the OCA and ICV lids; however, care must be taken to verify the weights are positioned in the $180^{\circ}$ and $000^{\circ}$ positions prior to lifting either lid.

- Security seals are only required on loaded shipments. A "Leak Test Required" tag attached to the vent port seal boss indicates that containment rings/seals were replaced prior to an empty shipment per WI 4.2, and a leak test is required prior to shipping a loaded TRUPACT-II. Remove the tag and forward a copy of the leak test results to the TRUPACT-II Maintenance Engineer to be filed with the original work instruction and maintenance record.

- Refer to a site-specific lift fixture Operation and Maintenance Manual for detailed ACGLF operating instructions.

- The radiation/contamination surveys listed in the body of the operations procedures are recommendations. Site-specific procedures and policies shall be referenced to determine the necessity and sequencing of actual surveys and hold-points.

\subsubsection{Cautions:}

- A physical check should be made to verify the air bags on the trailer have fully inflated before the trailer is moved by a user site trailer jockey. Failure to do so may cause the tires to rub on the bottom of the rear TRUPACT-II.

- $\quad$ Tip-back may damage the exterior surface when utilizing a forklift to relocate a TRUPACT-II.

- $\quad$ Three operators should be able to rotate the locking ring with reasonable effort. Do not attempt to rotate the OCA or ICV lock ring assembly with mechanical force other than the TRUPACT-II lock ring tool (an extension to provide 
additional leverage and control). Care should be used to prevent the lock rings from slamming into the stops.

- Verify that the two Adjustable Center-of-Gravity Lift Fixture (ACGLF) counterweights are located at the $180^{\circ}$ and $000^{\circ}$ positions respectively, prior to lifting an ACGLF, lid, or payload.

- Exceeding a crane load cell indication of 10,000 lbs can damage TRUPACT-II OCA Lid lift points.

- Exceeding a crane load cell indication of 7,500 lbs can damage TRUPACT-II ICV Lid lift points.

- $\quad$ Operator shall obtain protective clothing and equipment prior to entering the OCV cavity. Operator shall also enter the OCV cavity using precautions to preclude damage to the OCV body sealing flange.

- Operators shall avoid hitting or scraping the payload assembly against the ICV body flange and causing damage.

\subsection{TRUPACT-II Package Operating Instructions}

\subsubsection{Receiving a Package - Empty}

NOTE: $\quad$ The package unloading operation shall only be performed in a dry environment. In the event of precipitation during outdoor unloading or loading operations, precautions, such as covering the Outer Containment Vessel (OCV) and Inner Containment Vessel (ICV) cavities, shall be implemented to prevent precipitation from entering the package interior cavities. If precipitation does enter the interior cavities, all free-standing water shall be removed prior to loading the package for shipment and handled according to the site's waste management procedures.

4.3.1.1 Record TRUPACT-II serial number on Attachment A, Empty TRUPACT-II Receipt and Inspection Data Sheet, page A-2.

\section{SIGN OFF}

4.3.1.2 Verify that the appropriate site representative has validated shipping documents, inspected TRUPACT-IIs for damage, checked the nameplate to verify that packages are proper for the contents to be shipped, and released TRUPACT-Ils for loading.

\section{SIGN OFF}

4.3.1.3 Check the maintenance labels located adjacent to the name plate to verify the TRUPACT-II maintenance is current.

\section{SIGN OFF}

CAUTION: A physical check should be made to verify the air bags on the trailer have fully inflated before the trailer is moved by a trailer jockey. Failure to do so may cause the tires to rub on the bottom of the rear TRUPACT-II. 
4.3.1.4 Position the transport trailer in a designated parking area.

4.3.1.5 Lower the trailer jacks (landing gear) ensuring the trailer is level.

4.3.1.6 Install wheel chocks.

4.3.1.7 Install trailer stands on free standing trailers.

\subsubsection{Releasing Tie-downs and Removal of a Package from the Trailer}

4.3.2.1 Loosen the tie-down adjusting nuts until the tension has been released from the Bellville springs.

4.3.2.2 IF the TRUPACT-II is not to be removed from the trailer for loading operations,

THEN GO TO Section 4.3.3.

4.3.2.3 IF TRUPACT-II is to be removed from trailer,

THEN lift tie-down assemblies from TRUPACT-II lugs, AND rotate away from lugs, lowering completely to the trailer brackets.

4.3.2.4 Rotate the forklift pocket covers (4) to the "UP" position or remove the covers and store in a designated area.

4.3.2.5 If required, dry the TRUPACT-II before transport to a designated area.

CAUTION: Forklift tip-back beyond level may damage the package exterior surface.

4.3.2.6 Transfer the TRUPACT-II to the designated loading area.

\subsubsection{OCA Lid Removal}

4.3.3.1 Prepare the OCA lid for removal by removing the following components:

- OCA Lid Lift Pocket Covers

- OCV Lock Ring Bolts (6)

- OCA Test-Port Access Plug

- OCA Vent-Port Access Plug

4.3.3.2 Remove OCV Seal-Test Port Plug

4.3.3.3 Remove Outer Containment Vessel (OCV) Vent-Port Cover.

4.3.3.4 Remove OCV Vent-Port Plug

4.3.3.5 With the crane and ACGLF, lower the ACGLF short legs into the lift pockets on the OCA lid.

4.3.3.6 Verify the ACGLF legs are locked

4.3.3.7 Attempt to rotate Lock Ring to "UNLOCK" position by rotating the OCA Lock Ring assembly counterclockwise.

4.3.3.8 IF Lock Ring does NOT rotate, 
THEN perform the following:

4.3.3.8.1 Install Vent-Port Tool.

4.3.3.8.2 Connect vacuum line to Vent-Port Tool.

4.3.3.8.3 Start vacuum pump.

4.3.3.8.4 Pull a vacuum until Lock Ring can be rotated.

4.3.3.8.5 Stop vacuum pump.

4.3.3.8.6 Disconnect vacuum line from Vent-Port Tool.

4.3.3.8.7 Remove Vent-Port Tool.

CAUTION: Operator shall verify that the two Adjustable Center-of-Gravity Lift Fixture (ACGLF) counterweights are located at the $180^{\circ}$ and $000^{\circ}$ respectively, prior to lifting an ACGLF or lid.

CAUTION: When lifting the OCA lid by the lift pockets, the load cell indicator shall not exceed 10,000 lbs.

4.3.3.9 Remove OCA lid.

4.3.3.10 IF the lid does not lift off,

THEN contact supervisor and attempt to remove the lid by using heat guns or pressurizing with nitrogen or compressed air in accordance with Abnormal Operations Sections 4.4.2 and 4.4.3 respectively.

4.3.3.11 Place the OCA lid on its designated storage stand.

\subsubsection{ICV Lid Removal}

CAUTION: Operator shall verify that the two Adjustable Center-of-Gravity Lift Fixture (ACGLF) counterweights are located at the $180^{\circ}$ and $000^{\circ}$ respectively, prior to lifting an ACGLF or lid.

4.3.4.1 With the crane and ACGLF, lower the ACGLF short legs into the lifting pockets on the ICV lid.

4.3.4.2 Verify the ACGLF legs are locked.

4.3.4.3 Prepare the ICV lid for removal by performing the following:

- Remove ICV Lock Ring Bolts (3)

- Remove ICV Vent-Port Cover

4.3.4.4 Remove ICV Outer Vent-Port Plug.

4.3.4.5 Remove ICV Inner Vent-Port Plug.

4.3.4.6 UNLOCK the ICV Lock Ring by performing the following: 
4.3.4.6.1 Install ICV Vent-Port Tool.

4.3.4.6.2 Connect vacuum line to Vent-Port Tool.

4.3.4.6.3 Start vacuum pump.

4.3.4.6.4 Manually rotate the ICV lock ring to the "UNLOCKED" position.

4.3.4.6.5 Stop vacuum pump.

4.3.4.6.6 Disconnect vacuum line from Vent-Port Tool.

4.3.4.6.7 Remove Vent-Port Tool allowing ICV to vent to atmosphere.

CAUTION: When lifting the ICV lid by the lift pockets, the load cell indicator shall not exceed $7,500 \mathrm{lbs}$.

4.3.4.7 Remove ICV lid using ACGLF and crane.

4.3.4.8 IF lid does not lift off ICV,

THEN contact Supervisor and attempt to remove lid by using heat guns or pressurizing with nitrogen/compressed air per Abnormal Operations

Sections 4.4 .2 and 4.4 .3 respectively.

4.3.4.9 Place ICV Lid on Storage Stand.

4.3.4.10 Remove any Payload Pallets, Guide Tubes, Slip Sheets and/or Reinforcement Sheets.

\subsubsection{Preloading/Shipping Operational Checks and Examinations}

4.3.5.1 Radiological Control Technician (RCT), IF surveys for items in steps 4.3.6.1, 4.3.7.1, or 4.3.8.1 have been previously completed, AND results are below contamination limits, THEN enter applicable information for each step on Attachment A, Empty TRUPACT-II Receipt and Inspection Data Sheet.

4.3.5.2 RCT, IF survey has not been previously completed,

THEN GO TO section 4.3.6, 4.3.7, or 4.3.8 as applicable.

\subsubsection{Outer Containment Assembly (OCA) Lid Inspection and Preparation}

4.3.6.1 RCT, IF survey has not been previously completed,

THEN perform survey of interior and exterior of the OCA lid, AND record applicable information on Attachment A, Empty TRUPACT-II Receipt and Inspection Data Sheet.

\section{SIGN OFF}

4.3.6.2 Inspect OCA Lid for the following:

- Visible deformation

- Dents or abnormal flat spots $>1 / 2$ inch 
- Abnormal scratches or gouges

- Obvious punctures, tears, or cracks in exposed welds

- Plastic burn-out plugs (3) in place and intact

- Fiberglass tubes in place

- Distortions or cracks on or around lifting attachments

- Lid lift pocket covers attached and serviceable

- OCV Locking Z-Flange Screws in place and tight

- Guide Plates and screws in place and tight

4.3.6.3 Remove any foreign material from the following:

- Lock Ring

- Sealing Surfaces

- Test-Access Port Threads

4.3.6.4 Initial Attachment A, Empty TRUPACT-II Receipt and Inspection Data

Sheet, to document OCA Lid components and hardware are satisfactory.

\section{SIGN OFF}

\subsubsection{Inner Containment Vessel (ICV) Lid Inspection and Preparation}

4.3.7.1 RCT, IF survey has not been previously completed,

THEN perform survey of interior and exterior of the ICV lid, AND record applicable information on Attachment A, Empty TRUPACT-II Receipt and Inspection Data Sheet.

\section{SIGN OFF}

4.3.7.2 Inspect ICV Lid for the following:

- Visible deformation

- Punctures

- Abnormal scratches or gouges

- Distortions on or around lifting attachments

- Upper Spacer and screws are installed and tight

- Foam Debris Seal installed and intact

- Lock Ring undamaged

4.3.7.3 Remove any foreign material from the following:

- Lock Ring Flange

- Debris Seal

- Sealing surfaces

4.3.7.4 Inspect ICV Wiper O-Ring for the following:

- O-Ring cleanliness (no visible dirt or debris)

- Damage (voids, cracks, and gouges)

4.3.7.5 IF O-Ring is found to be damaged,

THEN GO TO Work Instruction 4.2, replace O-ring per instructions, AND RETURN TO Step 4.3.7.7. 
4.3.7.6 IF O-Ring is removed for cleaning,

THEN apply Dow Corning ${ }^{\text {TM }}$ high vacuum grease, as required before installing.

4.3.7.7 Initial Attachment A, Empty TRUPACT-II Receipt and Inspection Data Sheet, to document ICV Lid components and hardware are satisfactory.

\section{SIGN OFF}

\subsubsection{OCA Body Inspection and Preparation}

4.3.8.1 RCT, IF survey has not been previously completed,

THEN perform survey of OCA Body exterior and ICV Body interior AND record applicable information on Attachment A, Empty TRUPACT-II

Receipt and Inspection Data Sheet.

\section{SIGN OFF}

4.3.8.2 Remove the Upper and Lower Main O-rings and set aside for cleaning and inspection.

4.3.8.3 Inspect OCA body for the following:

- Obvious punctures or tears

- Obvious cracks in exposed welds

- Dents or abnormal flat spots $>1 / 2$ inch

- Abnormal scratches or gouges

- Six burn-out plugs are in place and intact

- Eight forklift pocket inserts are intact and threads are undamaged

- Six lock ring threaded inserts are intact and threads are undamaged.

- Tears or excessive wear on the ceramic fiber gasket.

4.3.8.4 Remove any foreign material from the following:

- Test Port

- Vent Port

- Lock Ring Flange

- O-Ring grooves

- Sealing Surfaces

4.3.8.5 Initial Attachment A, Empty TRUPACT-II Receipt and Inspection Data Sheet, to document OCA Body inspection is satisfactory.

\section{SIGN OFF}

\subsubsection{OCA components preparation and inspection}

4.3.9.1 Clean the following and inspect for deformation, scratches or burrs:

- OCA Vent-Port Access Plug (foam plug intact and glued to steel plug)

- OCV Vent-Port Plug and O-Rings

- OCV Vent-Port Cover and O-Rings

- OCA Test-Port Access Plug (foam plug intact and glued to steel plug)

- OCV Test-Port Plug and O-Ring 
- Lock Ring Bolts (6)

4.3.9.2 IF any O-Rings are found to be damaged, THEN GO TO TRUPACT-II Work Instruction 4.1, replace O-ring(s) per instructions, AND RETURN TO Step 4.3.9.4.

4.3.9.3 Apply a very light coat of Dow Corning $\square$ high vacuum grease to the following:

- OCV Vent-Port Plug threads and sealing O-Ring

- OCV Vent-Port Cover threads and sealing O-Ring

- OCV Test-Port Plug threads and O-Ring

4.3.9.4 Verify Annulus Debris Shield is installed and intact.

4.3.9.5 Lightly coat the following with Nickel Never-Seize or equivalent:

- OCA Lock Ring Bolts (6)

- OCA Test-Port Access Plug

- OCA Vent-Port Access Plug

4.3.9.6 Clean the Upper and Lower Main O-Rings and inspect for tears, nicks, flat spots or cracks.

4.3.9.7 IF any O-Rings are found to be damaged,

THEN GO TO TRUPACT-II Work Instruction 4.2, replace O-ring(s) per instructions , AND RETURN TO Step 4.3.9.10.

4.3.9.8 Lubricate the Upper and Lower Main O-Rings with a very light coat of Dow Corning $\square$ high vacuum grease.

4.3.9.9 Install Upper and Lower Main O-Rings.

4.3.9.10 Initial Attachment A, Empty TRUPACT-II Receipt and Inspection Data Sheet, to document OCA component and hardware inspections are satisfactory.

\section{SIGN OFF}

\subsubsection{ICV Body inspection and preparation:}

4.3.10.1 Remove the Upper and Lower Main O-rings and set aside for cleaning and inspection.

4.3.10.2 Remove any foreign material from the following:

- Test Port

- Vent Port

- Lock Ring Flange

- O-Ring Grooves

- Polyethylene Filter ports

- Sealing Surfaces

4.3.10.3 Inspect the following for deformation, scratches or burrs: 
- Upper and Lower O-ring grooves

- Vent-Port threads

- Seal-Test-Port threads

- Lock Ring Flange

- Three Polyethylene Filters installed

- Lower Spacer installed with no tears in skin

- Lower Spacer fasteners are installed

4.3.10.4 Initial Attachment A, Empty TRUPACT-II Receipt and Inspection Data Sheet, to document ICV Body inspection is satisfactory.

\section{SIGN OFF}

\subsubsection{ICV Components Preparation and Inspection}

4.3.11.1 Clean the following and inspect for deformation, scratches, or burrs:

- ICV Vent-Port Cover and gasket

- ICV Vent-Port Outer-Plug and O-Ring

- ICV Vent-Port Inner-Plug and O-Ring

- ICV Seal-Test-Port Plug and O-Ring

- ICV Lock Ring Bolts (3)

4.3.11.2 IF any O-Rings are found to be damaged, THEN GO TO TRUPACT-II Work Instruction 4.1, replace O-ring(s) per instructions, AND RETURN TO Step 4.3.11.4.

4.3.11.3 Apply a very light coat of Dow Corning $\square$ high vacuum grease to the following:

- ICV Vent-Port Cover threads

- ICV Vent-Port Outer Plug threads and O-Ring

- ICV Vent-Port Inner Plug threads and O-Ring

- ICV Seal-Test-Port Plug threads and O-Ring

4.3.11.4 Lightly coat the ICV Lock Ring Bolts (3) with Nickel Never-Seize.

4.3.11.5 Clean the Upper and Lower Main O-Rings and inspect for tears, nicks, flat spots or cracks.

4.3.11.6 IF any O-Rings are found to damaged,

THEN GO TO TRUPACT-II Work Instruction 4.2, replace O-ring(s) per instructions, AND RETURN TO Step 4.3.11.9.

4.3.11.7 Lubricate the Upper and Lower Main O-Rings with a very light coat of Dow Corning $\square$ high vacuum grease.

4.3.11.8 Install Upper and Lower Main O-Rings.

4.3.11.9 Initial Attachment A, Empty TRUPACT-II Receipt and Inspection Data Sheet, to document ICV components and hardware inspections are satisfactory. 


\section{SIGN OFF}

\subsubsection{ICV Cavity Inspection}

4.3.12.1 Inspect ICV cavity for water by performing one of the following:

- Insert a rod through the hole in lower spacer assembly

- Visual inspection

NOTE: Disposal of absorbent material and water will be at the direction of the RCT.

4.3.12.2 IF water is found inside ICV, THEN perform one of the following:

- Remove water through center hole of lower spacer assembly using a wet/dry vacuum.

- Attach absorbent material to rod and insert in hole in center of lower spacer assembly.

4.3.12.3 GO TO Section 4.4.1, perform Abnormal Operations, AND RETURN TO Step 4.3.12.4.

4.3.12.4 Initial Attachment A, Empty TRUPACT-II Receipt and Inspection Data to document ICV is free of water.

\section{SIGN OFF}

\subsubsection{Pre-loading Operations}

Verify all pre-loading preparations and inspections are complete.

\section{SIGN OFF}

\subsubsection{TRUPACT-II Receipt and Inspection Data Sheet Validation}

Supervisor, review/validate and sign Attachment A, Empty TRUPACT-II Receipt and Inspection Data Sheet.

\section{SIGN OFF}

\subsubsection{Loading a Payload Assembly}

NOTE: For shipments to WIPP, the shipper should verify that each payload container number has been entered into the WIPP Waste Information System (WWIS) and verify that the shipment has been approved by the WIPP WWIS Data Administrator. The verification is needed to preclude losing a portion of the allowable 60 day shipping period.

4.3.15.1 Record the TRUPACT-II Serial Number on Attachment A, TRUPACT-II Loading Data Sheet, page A-3.

\section{SIGN OFF}


4.3.15.2 Prepare the TRUPACT-II payload assembly per Section 3.0 and record all required information on the shipping documentation.

4.3.15.3 Verify the payload is assembled in accordance with the requirements delineated in Appendix 1.3.7 (TRAMPAC) of the TRUPACT-II SARP, and initial Attachment A, TRUPACT-II Loading Data Sheet.

\section{SIGN OFF}

CAUTION: Operator shall verify that the two Adjustable Center-of-Gravity Lift Fixture (ACGLF) counterweights are located at the $180^{\circ}$ and $000^{\circ}$ respectively, prior to lifting an ACGLF or payload.

4.3.15.4 Attach the appropriate legs/adapter to the ACGLF.

4.3.15.5 With the crane and ACGLF, lower the ACGLF long legs into the 14-pack guide tubes until the red stripes are no longer visible or lower SWB or TDOP adaptor until no load is indicated on the crane load cell.

4.3.15.6 As applicable, lock the ACGLF legs or attach the SWB lift fixture to the upper SWB or TDOP adaptor to TDOP.

4.3.15.7 Raise the payload 2 to 6 inches.

4.3.15.8 If necessary, balance the payload using the counter weight controls at the ACGLF console until a reading of $\pm 0.5^{\circ}$ is obtained.

4.3.15.9 Record the payload assembly weight (i.e., drum [or SWBs] + pallet + guide tubes + slip sheets) on Attachment A, TRUPACT-II Loading Data Sheet.

SIGN OFF

4.3.15.10 Using the weights provided in Table 3.1, locate the appropriate package unit number.

4.3.15.11 Record the empty package weight on Attachment A, TRUPACT-II Loading Data Sheet.

\section{SIGN OFF}

4.3.15.12 Add the two previously recorded weight values to calculate the total package weight and record on data sheet verifying total loaded package weight does not exceed 19,250 lbs.

\section{SIGN OFF}

4.3.15.13 Using the crane and ACGLF, raise and position the payload assembly over the ICV cavity.

4.3.15.14 Verify the payload is centered over the ICV prior to lowering the load. 
CAUTION: Care should be exercised to avoid hitting, scraping, or binding the payload assembly against the ICV body flange.

4.3.15.15 Lower the payload assembly into the package.

4.3.15.16 Record the weight positions of the ACGLF on the top of the payload near the number one leg.

\subsubsection{ICV Lid Installation}

4.3.16.1 Match the ICV lid and body serial numbers and record the ICV body serial number on data sheet.

\section{SIGN OFF}

CAUTION: Operator shall verify that the two Adjustable Center-of-Gravity Lift Fixture (ACGLF) counterweights are located at the $180^{\circ}$ and $000^{\circ}$ respectively, prior to lifting an ACGLF or lid.

4.3.16.2 With the crane and ACGLF, lower the ACGLF short legs into the lifting pockets on the ICV lid.

4.3.16.3 Verify the ACGLF legs are locked.

4.3.16.4 Using the crane and ACGLF, align the "UNLOCK" arrows and install the ICV lid onto the ICV body.

4.3.16.5 Install the ICV Vent-Port Tool with the Inner Vent-Port Plug retracted.

4.3.16.6 Connect the vacuum pump system to the ICV Vent-Port Tool and evacuate the ICV cavity enough to allow the ICV lock ring to rotate freely.

CAUTION: Vacuum should not exceed 15 inches Hg when evacuating the ICV cavity.

4.3.16.7 Manually rotate the ICV lock ring to the locked position.

4.3.16.8 Turn off the vacuum system pump, and disconnect the vacuum line.

4.3.16.9 Allow pressure to equalize between the ICV and the atmosphere.

4.3.16.10 Rotate the stem handle of the ICV Vent-Port Tool clockwise to install and seat the ICV Inner Vent-Port Plug, hand tight.

4.3.16.11 Remove the Vent-Port Tool.

4.3.16.12 Torque the Inner Vent-Port Plug to 96 to 120 in-lbs.

\section{SIGN OFF}


4.3.16.13 Install the ICV lock ring bolts (3) and torque to 28 to $32 \mathrm{ft}-\mathrm{lbs}$ each. SIGN OFF 
4.3.16.14 Perform the Assembly Verification Leak Test for the ICV Containment Seals per Section 6.1.

\section{SIGN OFF}

\subsubsection{OCA Lid Installation}

4.3.17.1 Match the OCA lid and body serial numbers. Record the OCA body serial number on data sheet.

\section{SIGN OFF}

CAUTION: Operator shall verify that the two Adjustable Center-of-Gravity Lift Fixture (ACGLF) counterweights are located at the $180^{\circ}$ and $000^{\circ}$ respectively, prior to lifting an ACGLF or lid.

4.3.17.2 Using the crane and the ACGLF, lower the ACGLF short legs into the lifting pockets on the OCA lid.

4.3.17.3 Verify the ACGLF legs are locked.

4.3.17.4 Install the OCA lid onto the OCA body.

4.3.17.5 Attempt to manually rotate the lock ring.

4.3.17.6 IF lock ring will not rotate,

THEN perform the following:

4.3.17.6.1 Install the OCV Vent-Port Tool.

4.3.17.6.2 Connect the vacuum pump system to the OCV Vent-Port Tool and evacuate the OCV cavity to allow the OCV lock ring to rotate freely.

4.3.17.6.3 Manually rotate the OCV lock ring clockwise to the locked position.

4.3.17.6.4 Turn off the vacuum system and disconnect the vacuum line.

4.3.17.6.5 Remove the OCV Vent-Port Tool.

4.3.17.7 Install the OCA lock ring bolts (6) and torque to 28 to $32 \mathrm{ft}$-lbs each.

\section{SIGN OFF}

4.3.17.8 Perform the Assembly Verification Leak Test for the OCV containment seals as described in Section 6.2.

\section{SIGN OFF}

4.3.17.9 Install OCA lid lift pocket covers.

4.3.17.10 Install a tamper-indicating security seal in the lock-ring bolt on the OCA lock ring assembly and in the OCA Vent-Port Access Plug. 
4.3.17.11 Record tamper-indicating security seals serial numbers on Attachment $A$, TRUPACT-II Loading Data Sheet.

\section{SIGN OFF}

4.3.17.12 Supervisor, review/validate and sign Attachment A, TRUPACT-II Loading Data Sheet.

\subsubsection{Installation of the Package onto the Transport Trailer}

NOTE: If only one package is in the shipment, locate the package in the \#1 position on the trailer. If two packages are in the shipment, locate the heaviest package in the \#1 position and lighter in the \#2 position. If three packages are in the shipment, the heaviest is to be loaded in the \#1 position, next heaviest in the \#3 position, and lightest in the \#2 position. Weight is not a factor for positioning until the weight differences of the packages are 2,000 lbs or more.

4.3.18.1 Record the following on Attachment A, Loaded TRUPACT-II Trailer Data Sheet, page A-4:

- Shipment Number

- Trailer Number

- TRUPACT-II Number(s)

\section{SIGN OFF}

4.3.18.2 Verify trailer has current annual inspection label affixed on trailer gooseneck.

4.3.18.3 Record trailer inspection date on Attachment A, TRUPACT-II Trailer Data Sheet.

\section{SIGN OFF}

4.3.18.4 Visually inspect the tie downs for the following:

- Damage

- Defects

- Cleanliness

4.3.18.5 IF the TRUPACT-II was not removed from the trailer for the loading operations,

THEN tighten the two adjustment nuts on each tie-down device, AND GO TO Step 4.3.18.7.

4.3.18.6 IF the TRUPACT-II was removed for the loading operations, THEN perform the following:

4.3.18.6.1 Position the transport trailer in a designated parking area.

4.3.18.6.2 Lower the trailer jacks (landing gear) ensuring the trailer is level.

4.3.18.6.3 Install wheel chocks. 
4.3.18.6.4 Install jack stands on free-standing trailers.

CAUTION: Tip-back may damage the package exterior surface.

4.3.18.6.5 Transport the TRUPACT-II to the transport trailer.

4.3.18.6.6 Load the TRUPACT-II designated for position \#1 onto the trailer with Vent-Port on driver side of trailer.

4.3.18.6.7 If applicable, load the TRUPACT-II designated for position \#2 onto the trailer with Vent-Port on driver side of trailer.

4.3.18.6.8 If applicable, load the TRUPACT-II designated for position \#3 onto the trailer with Vent-Port on driver side of trailer.

4.3.18.6.9 Install the four tie-down assemblies, for each TRUPACT-II loaded on the trailer.

4.3.18.6.10 Install the TRUPACT-II forklift pocket access covers.

4.3.18.7 Record TRUPACT-II positions and weights on Attachment A, TRUPACT-II Trailer Data Sheet, as applicable.

\section{SIGN OFF}

4.3.18.8 Record total weight of all loaded TRUPACT-Ils as Net Payload Weight on Attachment A, TRUPACT-II Trailer Data Sheet,

\section{SIGN OFF}

4.3.18.9 Verify that TRUPACT-II is in compliance with 49 CFR 172, Subpart D Marking, Subpart E Labeling, and Subpart F Placarding.

\section{SIGN OFF}

4.3.18.10 Complete information transfer to "shipping papers" as required for the specific shipment.

4.3.18.11 Verify that shipping papers are in accordance with 49 CFR 172 , Subpart C.

\section{SIGN OFF}

4.3.18.12 Initial for trailer loading complete on Attachment A, TRUPACT-II Trailer Loading Data Sheet.

\section{SIGN OFF}


4.3.18.13 Supervisor, review/validate and sign data sheet.

\section{SIGN OFF}




\subsubsection{Receiving a Package - Loaded}

NOTE: $\quad$ The package unloading operation shall only be performed in a dry environment. In the event of precipitation during outdoor unloading or loading operations, precautions, such as covering Outer Containment Vessel (OCV) and Inner Containment Vessel (ICV) cavities, shall be implemented to prevent precipitation from entering package interior cavities. If precipitation does enter the interior cavities, all free-standing water shall be removed prior to loading the package for shipment and handled according to the site's waste management procedures.

4.3.19.1 Record TRUPACT-II Serial Number on Attachment A, Loaded TRUPACTII Receipt and Processing Data Sheet, page A-5.

\section{SIGN OFF}

4.3.19.2 Verify that the appropriate site representative has validated the shipping documents, inspected TRUPACT-Ils for damage, and released TRUPACT-Ils for unloading.

\section{SIGN OFF}

4.3.19.3 Perform an external radiation and contamination survey of TRUPACT-II in accordance with site-specific procedures.

\section{SIGN OFF}

CAUTION: A physical check shall be made to verify the air bags on the trailer have fully inflated before the trailer is moved by a user-site trailer jockey. Failure to do so may cause the tires to rub on the bottom of the rear TRUPACT-II.

4.3.19.4 Position the transport trailer in a designated parking area.

4.3.19.5 Lower the trailer jacks (landing gear) ensuring the trailer is level.

4.3.19.6 Install wheel chocks.

4.3.19.7 Install trailer stands on free standing trailers.

\subsubsection{Releasing Tie-downs and Removal of a Package from the Trailer}

4.3.20.1 Loosen the tie-down adjusting nuts until the tension has been released from the Bellville springs.

4.3.20.2 IF the TRUPACT-II is not to be removed from the trailer, THEN GO TO Section 4.3.21.

4.3.20.3 IF TRUPACT-II is to be removed from trailer THEN lift tie-down assemblies from TRUPACT-II lugs, AND rotate away from lugs, lowering completely to the trailer brackets.

4.3.20.4 Rotate the four forklift pocket covers to the "UP" position or remove the four covers and store in a designated area. 
4.3.20.5 If required, dry the TRUPACT-II before transport to a designated area.

CAUTION: Tip-back may damage the TRUPACT-II exterior surface.

4.3.20.6 Transfer the TRUPACT-II to the designated unloading area.

\subsubsection{OCA Lid Removal}

4.3.21.1 Remove and dispose of the security seals.

4.3.21.2 If seal is broken or missing, follow applicable site policy.

4.3.21.3 Prepare the OCA lid for removal by removing the following components:

- OCA Lid Lift Pocket Covers

- OCA Lock Ring Bolts (6)

- OCA Test-Port Access Plug

- OCA Vent-Port Access Plug

4.3.21.4 Remove the OCV Seal-Test Port Plug.

4.3.21.5 Remove the OCV Vent-Port Cover.

4.3.21.6 Remove OCV Vent-Port Plug.

4.3.21.7 Attempt to rotate Lock Ring to "UNLOCKED" position by rotating the OCV lock ring assembly counterclockwise.

4.3.21.8 IF Lock Ring will not rotate, THEN perform the following:

4.3.21.8.1 Install Vent-Port Tool.

4.3.21.8.2 Connect vacuum line to Vent-Port Tool.

4.3.21.8.3 Start vacuum pump.

4.3.21.8.4 Pull a vacuum until Locking Ring can be rotated.

4.3.21.8.5 Stop vacuum pump.

4.3.21.8.6 Disconnect vacuum line from Vent-Port Tool.

4.3.21.8.7 Remove Vent-Port Tool.

CAUTION: Operator shall verify that the two Adjustable Center-of-Gravity Lift Fixture (ACGLF) counterweights are located at the $180^{\circ}$ and $000^{\circ}$ respectively, prior to lifting an ACGLF or lid.

4.3.21.9 Using the crane and ACGLF, lower the ACGLF short legs into the lift pockets on the OCA lid.

4.3.21.10 Verify the ACGLF legs are locked. 
CAUTION: When lifting the OCA lid by the lift pockets, the load cell indicator shall not exceed 10,000 pounds.

4.3.21.11 Slowly raise the OCA lid approximately 6 inches above the top of the ICV lid or as directed by the Rad Con Tech (RCT).

4.3.21.12 IF the lid does not lift off, THEN contact Supervisor and attempt to remove the lid by using heat guns or pressurizing with nitrogen or compressed air in accordance with Abnormal Operations Sections 4.4.2 and 4.4.3 respectively.

\section{HOLD POINT}

4.3.21.13 RCT personnel, perform radiation/contamination surveys of the OCA lid interior surface and the ICV lid exterior surface following site specific procedures.

\section{SIGN OFF}

4.3.21.14 Place the OCA lid on its designated storage stand.

\subsubsection{ICV Lid Removal}

CAUTION: Operator shall verify that the two Adjustable Center-of-Gravity Lift Fixture (ACGLF) counterweights are located at the $180^{\circ}$ and $000^{\circ}$ respectively, prior to lifting an ACGLF or lid.

4.3.22.1 Using the crane and ACGLF, lower the ACGLF short legs into the lifting pockets on the ICV lid.

4.3.22.2 Verify the ACGLF legs are locked.

4.3.22.3 Prepare the ICV lid for removal by performing the following:

- Remove ICV Lock Ring Bolts (3)

- Remove ICV Vent-Port Cover

4.3.22.4 Remove the ICV Outer Vent-Port Plug.

4.3.22.5 Install the ICV Vent-Port Tool.

4.3.22.6 Install a Radiation Assessment Filter (RAF) assembly onto the ICV VentPort Tool.

4.3.22.7 Install vacuum hose to the RAF.

4.3.22.8 Retrieve the ICV Inner Vent-Port Plug into the ICV Vent-Port Tool.

CAUTION: Vacuum should not exceed $15 \mathrm{in.} \mathrm{Hg}$ when attempting to open ICV.

4.3.22.9 Evacuate the ICV cavity until the ICV lock ring can be rotated.

4.3.22.10 Manually rotate the ICV lock ring to the unlocked position. 
4.3.22.11 Secure the vacuum system.

4.3.22.12 Remove the RAF assembly from ICV Vent-Port Tool.

\section{HOLD POINT}

4.3.22.13 RCT, verify the assessment filter activity is at or below acceptable limits in accordance with site-specific procedures.

\section{SIGN OFF}

4.3.22.14 Remove the ICV Vent-Port Tool and ICV Inner Vent-Port Plug.

CAUTION: When lifting the ICV lid by the lift pockets, the load cell indicator shall not exceed 7,500 lbs.

4.3.22.15 Slowly raise the ICV lid to clear the ICV body and hold it approximately $2 \mathrm{ft}$ above the top of the ICV body flange or as directed by the RCT.

4.3.22.16 IF the lid does not lift off the ICV, THEN contact Supervisor and attempt to remove the lid by using heat guns or pressurizing with nitrogen or compressed air in accordance with Abnormal Operations Sections 4.4 .2 and 4.4 .3 respectively.

\section{HOLD POINT}

4.3.22.17 RCT personnel, perform radiation/contamination surveys of the ICV lid interior surface and top of payload in accordance with site specific procedures.

\section{SIGN OFF}

4.3.22.18 Place the ICV lid on its designated storage stand.

\subsubsection{Unloading a Payload Assembly}

4.3.23.1 Attach the appropriate legs/adaptor to the ACGLF.

CAUTION: Operator shall verify that the two Adjustable Center-of-Gravity Lift Fixture (ACGLF) counterweights are located at the $180^{\circ}$ and $000^{\circ}$ respectively, prior to lifting an ACGLF or lid.

4.3.23.2 Using the crane and ACGLF, engage the payload.

4.3.23.3 As applicable, lock the ACGLF legs into the payload pallet or connect lifting clips to the SWB or TDOP.

4.3.23.4 Position the ACGLF counterweights to the predetermined positions as marked on the top of the payload.

4.3.23.5 Raise the payload less than $1 \mathrm{ft}$. If necessary, further balance the payload using the counter weight controls at the ACGLF console until a balance of $\pm 0.5^{\circ}$ is obtained on both axis. 
NOTE: $\quad$ Perform steps 4.3.23.6, 4.3.23.7, and 4.3.23.8 concurrently to remove the payload.

4.3.23.6 Monitor ACGLF indicated balance and adjust counter weights as needed.

4.3.23.7 Slowly raise the payload assembly.

4.3.23.8 Visually inspect payload.

\section{SIGN OFF}

4.3.23.9 RCT, perform radiation/contamination surveys of the payload assembly as it is raised in accordance with site-specific procedures.

\section{HOLD POINT}

\section{SIGN OFF}

4.3.23.10 If the payload is damaged, follow site-specific procedures.

4.3.23.11 Place the payload assembly in a designated area.

4.3.23.12 Supervisor review/validate and sign Attachment A, Loaded TRUPACT-II Receipt and Processing Data Sheet.

\subsubsection{TRUPACT-II Shipment Operational Checks and Examinations}

NOTE: Deficient/defective items may be corrected in accordance with the TRUPACT-II Work Instructions contained in Attachment D.

4.3.24.1 Record TRUPACT-II serial number on Attachment A, Empty TRUPACT-II Shipment Data Sheet, page A-6.

\section{SIGN-OFF}

4.3.24.2 Check the maintenance labels located adjacent to the name plate to verify TRUPACT-II maintenance is current.

\section{SIGN-OFF}

4.3.24.3 Radiological Control Technician (RCT), IF surveys for items in steps 4.3.25.1, 4.3.26.1, or 4.3.27.1 have been previously completed, AND results are below contamination limits,

THEN enter applicable information for each step on Attachment A, Empty TRUPACT-II Shipment Data Sheet.

4.3.24.4 RCT, IF surveys have not been previously completed, THEN GO TO section 4.3.25, 4.3.26, or 4.3.27 as applicable.

\subsubsection{Outer Containment Assembly (OCA) Lid Inspection and Preparation}


4.3.25.1 RCT, IF survey has not been previously completed,

THEN perform survey of interior and exterior of the OCV lid, AND record applicable information on Attachment A, Empty TRUPACT-II Shipment Data Sheet.

\section{SIGN OFF}

4.3.25.2 Inspect OCA Lid for the following:

- Visible deformation

- Dents or abnormal flat spots $>1 / 2$ inch

- Abnormal scratches or gouges

- Obvious punctures, tears, or cracks in exposed welds

- Plastic burn-out plugs (3) in place and intact

- Fiberglass tubes in place

- Distortions or cracks on or around lifting attachments

- Lid lift pocket covers attached and serviceable

- Z-Ring screws in place and tight

- Guide Plates and screws in place and tight

4.3.25.3 Remove any foreign material from the following:

- Lock Ring Flange

- Sealing Surfaces

- Test-Port Access Threads

4.3.25.4 Verify that the arrow above Seal-Test Port aligns with the "UNLOCKED" arrow on the Lock Ring.

4.3.25.5 Initial Attachment A, Empty TRUPACT-II Shipment Data Sheet, to document OCA Lid components and hardware are satisfactory.

\section{SIGN OFF}

\subsubsection{Inner Containment Vessel (ICV) Lid Inspection and Preparation}

4.3.26.1 RCT, IF survey has not been previously completed, THEN perform survey of interior and exterior of the ICV lid, AND record applicable information on Attachment A, Empty TRUPACT-II Shipment Data Sheet.

\section{SIGN OFF}

4.3.26.2 Inspect ICV Lid for the following:

- Visible deformation

- No punctures

- Abnormal scratches or gouges

- Distortions on or around lifting attachments

- Upper Spacer and screws are installed and tight

- Foam Debris Seal intact and undamaged

- Lock Ring undamaged

4.3.26.3 Remove any foreign material from the following: 
- Lock Ring Flange

- Debris Seal

- Sealing surfaces

4.3.26.4 Inspect ICV Wiper O-Ring for the following:

- O-Ring cleanliness (no visible dirt or debris)

- Damage (voids, cracks, and gouges)

4.3.26.5 IF O-Ring is found to be damaged,

THEN replace O-ring per TRUPACT-II Work Instruction 4.2, AND RETURN TO Step 4.3.26.7.

4.3.26.6 IF O-Ring is removed for cleaning,

THEN apply a light coat of Dow Corning $\square$ high vacuum grease, as required before installing.

4.3.26.7 Initial Attachment A, Empty TRUPACT-II Shipment Data Sheet, to document ICV Lid components and hardware are satisfactory.

\section{SIGN OFF}

\subsubsection{OCA Body Inspection and Preparation}

4.3.27.1 RCT, IF survey has not been previously completed,

THEN perform survey of OCA Body exterior and ICV Body interior AND record applicable information on Attachment A.

\section{SIGN OFF}

4.3.27.2 Remove the Upper and Lower Main O-Rings and set aside for cleaning and inspection.

4.3.27.3 Inspect OCA body for the following:

- Obvious punctures or tears

- Obvious cracks in exposed welds

- Dents or abnormal flat spots $>1 / 2$ inch

- Abnormal scratches or gouges

- Six burn-out plugs are in place and intact

- Eight forklift pocket threaded inserts are intact

- Six lock ring threaded inserts are intact

- Tears or excessive wear on the ceramic fiber gasket

- Lock Ring stop undamaged

4.3.27.4 Remove any foreign material from the following:

- Test Port

- Vent Port

- Lock Ring Flange

- Sealing Surfaces 
4.3.27.5 Initial Attachment A, Empty TRUPACT-II Shipment Data Sheet, to document OCA Body inspection is satisfactory.

SIGN OFF

4.3.28 OCA Components Preparation and Inspection

4.3.28.1 Clean the following and inspect for deformation, scratches or burrs:

- OCA Vent-Port Access Plug (foam plug intact and glued to steel plug)

- OCV Vent-Port Plug and O-Rings

- OCA Test-Port Access Plug (foam plug intact and glued to steel plug)

- OCV Test-Port Plug and O-Ring

- Lock Ring Bolts (6)

4.3.28.2 IF any O-Rings are found to be damaged, THEN replace O-ring(s) per TRUPACT-II Work Instruction 4.1, AND RETURN TO Step 4.3.28.4.

4.3.28.3 Apply a very light coat of Dow Corning $\square$ high vacuum grease to the following:

- OCV Vent-Port Plug threads and sealing O-Ring

- OCV Vent-Port Cover threads and sealing O-Ring

- OCV Test-Port Plug threads and O-Ring

4.3.28.4 Verify Annulus Debris Shield is intact and installed.

4.3.28.5 Lightly coat the following with Nickel Never-Seize or equivalent:

- OCA Lock Ring Bolt threads (6)

- OCV Test-Port Access Plug threads

- OCA Vent-Port Access Plug threads

4.3.28.6 Clean the Upper and Lower Main O-Rings and inspect for tears, nicks, flat spots or cracks.

4.3.28.7 IF any O-Rings are found to be damaged, THEN replace O-ring(s) per TRUPACT-II Work Instruction 4.2, AND RETURN TO Step 4.3.28.10.

4.3.28.8 Lubricate the Upper and Lower Main O-Rings with a very light coat of Dow Corning $\square$ high vacuum grease.

4.3.28.9 Install Upper and Lower Main O-Rings.

4.3.28.10 Initial Attachment A, Empty TRUPACT-II Shipment Data Sheet, to document OCA component and hardware inspections are satisfactory.

\section{SIGN OFF}

\subsubsection{ICV Body Inspection and Preparation}


4.3.29.1 Remove the Upper and Lower Main O-Rings and set aside for cleaning and inspection.

4.3.29.2 Remove any foreign material from the following:

- Test Port

- Vent Port

- O-Ring Grooves

- Polyethylene Filter ports

- Sealing Surfaces

4.3.29.3 Inspect the following for deformation, scratches or burrs:

- Upper and Lower O-Ring grooves

- Vent-Port threads

- Seal-Test-Port threads

- Lock Ring Flange

- Three Polyethylene Filters installed

- Lower Spacer installed with no tears in skin

- Lower Spacer fasteners are installed

4.3.29.4 Initial Attachment A, Empty TRUPACT-II Shipment Data Sheet, to document ICV Body inspection is satisfactory.

\section{SIGN OFF}

\subsubsection{ICV Components Preparation and Inspection}

4.3.30.1 Clean the following and inspect for deformation, scratches, or burrs:

- ICV Vent-Port Cover and gasket

- ICV Vent-Port Outer Plug and O-Ring

- ICV Vent-Port Inner Plug and O-Ring

- ICV Seal-Test-Port Plug and O-Ring

- ICV Lock Ring Bolts (3)

4.3.30.2 IF any O-Rings are found to be damaged, THEN replace O-ring(s) per TRUPACT-II Work Instruction 4.1, AND RETURN TO Step 4.3.30.4.

4.3.30.3 Apply a very light coat of Dow Corning $\square$ high vacuum grease to the following:

- ICV Vent-Port Cover threads

- ICV Vent-Port Outer Plug threads and O-Ring

- ICV Vent-Port Inner Plug threads and O-Ring

- ICV Seal-Test-Port Plug threads and O-Ring

4.3.30.4 Lightly coat the ICV Lock Ring Bolts (3) with Nickel Never-Seize or equivalent.

4.3.30.5 Clean the Upper and Lower Main O-Rings and inspect for tears, nicks, flat spots or cracks. 
4.3.30.6 IF any O-Rings are found to damaged,

THEN replace O-ring(s) per TRUPACT-II Work Instruction 4.2, AND RETURN TO Step 4.3.30.9.

4.3.30.7 Lubricate the Upper and Lower Main O-Rings with a very light coat of Dow Corning $\square$ high vacuum grease.

4.3.30.8 Install Upper and Lower Main O-Rings.

4.3.30.9 Initial Attachment A, Empty TRUPACT-II Shipment Data Sheet, to document ICV components and hardware inspections are satisfactory.

\section{SIGN OFF}

\subsubsection{ICV Cavity Inspection}

4.3.31.1 Inspect ICV cavity for water by performing one of the following:

- Insert a rod through the hole in lower spacer assembly

- Visual inspection

NOTE: Disposal of absorbent material and water will be at the direction of the RCT.

4.3.31.2 IF water is found inside ICV, THEN remove water as follows:

- Remove water through center hole of lower spacer assembly using a wet/dry vacuum.

- Attach absorbent material to rod and insert in hole in center of lower spacer assembly.

4.3.31.3 Perform Abnormal Operations Section 4.4.1, AND RETURN TO step 4.3.31.4.

4.3.31.4 Initial Attachment A, Empty TRUPACT-II Shipment Data Sheet, to document ICV is free of water.

\section{SIGN OFF}

4.3.31.5 Verify all pre-shipment inspections are complete.

\section{SIGN OFF}

\subsubsection{ICV Lid Installation}

4.3.32.1 Match the ICV lid and body serial numbers.

4.3.32.2 Record the ICV body serial number on Attachment A, Empty TRUPACT-II Shipment Data Sheet.

\section{SIGN OFF}


CAUTION: Operator shall verify that the two Adjustable Center-of-Gravity Lift Fixture (ACGLF) counterweights are located at the $180^{\circ}$ and $000^{\circ}$ respectively, prior to lifting an ACGLF or lid.

4.3.32.3 Using the crane and the ACGLF, lower the ACGLF short legs into the lifting pockets on the ICV lid.

4.3.32.4 Verify the ACGLF legs are locked.

4.3.32.5 Using the crane and ACGLF, align the "UNLOCK" arrows and install the ICV lid onto the ICV body.

4.3.32.6 Install the Vent-Port Tool.

4.3.32.7 Connect the vacuum pump system to the ICV Vent-Port Tool and evacuate the ICV cavity enough to allow the ICV lock ring to rotate freely (being careful not to exceed 15 inches $\mathrm{Hg}$ vacuum).

4.3.32.8 Manually rotate the ICV lock ring to the locked position.

4.3.32.9 Turn off the vacuum system pump and disconnect the vacuum line.

4.3.32.10 Remove Vent-Port Tool allowing pressure to equalize between the ICV and the atmosphere.

4.3.32.11 Install the Inner Vent-Port Plug and torque to 96 to 120 inch-lbs.

4.3.32.12 Install the Outer Vent-Port Plug and torque to 120 to 156 in-lbs.

4.3.32.13 Install the Seal-Test-Port Plug and torque to 72 to 96 in-lbs.

4.3.32.14 Install the Vent-Port Cover and torque to 156 to 192 in-lbs.

4.3.32.15 Install the ICV locking ring bolts (3) and torque to 28 to $32 \mathrm{ft}-\mathrm{lbs}$ each.

\subsubsection{OCA Lid Installation}

4.3.33.1 Match the OCA lid and body serial numbers.

4.3.33.2 Record the OCA body serial number on data sheet.

\section{SIGN OFF}

CAUTION: Operator shall verify that the two Adjustable Center-of-Gravity Lift Fixture (ACGLF) counterweights are located at the $180^{\circ}$ and $000^{\circ}$ respectively, prior to lifting an ACGLF or lid.

4.3.33.3 Using the crane and the ACGLF, lower the ACGLF short legs into the lifting pockets on the OCA lid.

4.3.33.4 Verify the ACGLF legs are locked.

4.3.33.5 Install the OCA lid onto the OCA body. 
4.3.33.6 Attempt to manually rotate the lock ring.

4.3.33.7 If lock ring will not rotate, then perform the following:

4.3.33.7.1 Install the OCV Vent-Port Tool.

4.3.33.7.2 Install a vacuum pump system to the OCV Vent-Port Tool and evacuate the OCV cavity to allow the OCV lock ring to rotate freely.

4.3.33.7.3 Manually rotate the OCV lock ring until the OCV is locked.

4.3.33.7.4 Secure the vacuum system and disconnect the vacuum line.

4.3.33.7.5 Remove OCV Vent-Port Tool allowing the OCV to vent to atmosphere.

4.3.33.8 Install the Vent-Port Plug and torque to 120 to 156 in-lbs

4.3.33.9 Install the Vent-Port Cover and torque to 156 to 192 in-lbs.

4.3.33.10 Install the Seal-Test-Port Plug and torque to 72 to 96 in-lbs.

4.3.33.11 Install the Seal-Test-Port Access Cover and torque to 35 to $45 \mathrm{ft}-\mathrm{lbs}$

4.3.33.12 Install the Vent-Port Access Cover and torque to 35 to $45 \mathrm{ft}-\mathrm{lbs}$.

4.3.33.13 Install the OCA lock ring bolts (6) and torque to 28 to $32 \mathrm{ft}-\mathrm{lbs}$ each.

4.3.33.14 Install OCA lid lift pocket covers.

4.3.33.15 Verify pre-shipment preparations complete, unit ready for transport.

SIGN OFF

4.3.33.16 Supervisor, review/validate and sign Attachment A, Empty TRUPACT-II Shipment Data Sheet.

\section{SIGN OFF}

\subsubsection{Installation of the Package onto the Transport Trailer}

NOTE: If only one package is in the shipment, locate the package in the \#1 position on the trailer. If two packages are in the shipment, locate the heaviest package in the \#1 position and lighter in the \#2 position. If three packages are in the shipment, the heaviest is to be loaded in the \#1 position, next heaviest in the \#3 position, and lightest in the \#2 position. Weight is not a factor until the weight differences of the packages are $2000 \mathrm{lbs}$ or more.

4.3.34.1 Record the following on Attachment A, TRUPACT-II Empty Trailer Data Sheet, page A-7:

- Shipment Number

- Trailer Number 
- TRUPACT-II Number(s)

\section{SIGN OFF}

4.3.34.2 Verify trailer has current annual inspection label affixed on trailer gooseneck.

4.3.34.3 Record trailer inspection date on Attachment A, TRUPACT-II Trailer Data Sheet.

\section{SIGN OFF}

4.3.34.4 Visually inspect the tie downs for the following:

- Damage

- Defects

- Cleanliness

4.3.34.5 IF the TRUPACT-II was not removed from the trailer for the loading operations,

THEN tighten the two adjustment nuts on each tie-down device, AND RETURN TO Step 4.3.34.7.

4.3.34.6 IF the TRUPACT-II was removed for the loading operations, THEN perform the following:

4.3.34.6.1 Position the transport trailer in a designated parking area.

4.3.34.6.2 Lower the trailer jacks (landing gear) ensuring the trailer is level.

4.3.34.6.3 Install wheel chocks.

4.3.34.6.4 Install jack stands on free-standing trailers.

CAUTION: Tip-back may damage the package exterior surface.

4.3.34.6.5 Transport the TRUPACT-II to the transport trailer.

4.3.34.6.6 Load the TRUPACT-II designated for position \#1 onto the trailer with VentPort on driver side of trailer.

4.3.34.6.7 If applicable, load the TRUPACT-II designated for position \#2 onto the trailer with Vent-Port on driver side of trailer.

4.3.34.6.8 If applicable, load the TRUPACT-II designated for position \#3 onto the trailer with Vent-Port on driver side of trailer.

4.3.34.6.9 Install the four tie-down assemblies, for each TRUPACT-II loaded on the trailer.

4.3.34.6.10 Install the TRUPACT-II forklift pocket access covers.

4.3.34.7 Record TRUPACT-II positions and weights on Attachment A, TRUPACT-II Trailer Data Sheet, as applicable. 


\section{SIGN OFF}

4.3.34.8 Record total weight of all loaded TRUPACT-Ils as Net Payload Weight on Attachment A, TRUPACT-II Trailer Data Sheet,

\section{SIGN OFF}

4.3.34.9 Verify that TRUPACT-II shipment is in compliance with 49 CFR 172, Subpart D, Marking; Subpart E, Labeling; and Subpart F, Placarding.

\section{SIGN OFF}

4.3.34.10 Complete information transfer to shipping documents as required for the specific shipment.

4.3.34.11 Verify that shipping papers are in accordance with 49 CFR 172, Subpart C.

\section{SIGN OFF}

4.3.34.12 Initial for trailer loading complete on Attachment A, TRUPACT-II Trailer Loading Data Sheet.

\section{SIGN OFF}

4.3.34.13 Supervisor, review/validate and sign data sheet.

\section{SIGN OFF}

\subsection{Abnormal Operations of the TRUPACT-II}

\subsubsection{Empty ICV Assembly Removal - (If Water Found in ICV or Annual Maintenance Only)}

4.4.1.1 Verify the ICV lid has been installed and locked.

CAUTION: Operator shall verify that the two Adjustable Center-of-Gravity Lift Fixture (ACGLF) counterweights are located at the $180^{\circ}$ and $000^{\circ}$ respectively.

4.4.1.2 With the crane and ACGLF, lower the ACGLF short legs into the lifting pockets of the ICV lid.

4.4.1.3 Verify the ACGLF legs are locked.

4.4.1.4 Using the crane and ACGLF, remove the empty ICV assembly from the OCV body and place in a safe location.

NOTE: If required by site-specific policy to ensure personnel safety, RCT shall perform a radiation/contamination survey of the OCV interior prior to initiating the OCV inspection process.

4.4.1.5 Visually inspect or swab for the presence of water in the bottom of the OCV. 
4.4.1.6 If free-standing water is NOT observed in the bottom of the OCV body, GO TO Step 4.1.9.1.

CAUTION: Operator shall obtain protective clothing and equipment prior to entering the OCV cavity. Operator also shall enter the OCV cavity using precautions to preclude damage to the OCV body sealing flange.

4.4.1.7 Use a wet/dry vacuum and/or absorbent materials to remove free-standing water.

NOTE: $\quad$ Cleaning and waste materials should be managed according to site waste management procedures.

4.4.1.8 Remove equipment and exit the OCV cavity using precautions not to damage the OCV Body Sealing Flange.

4.4.1.9 Verify the OCV is free of standing water.

CAUTION: Operator shall verify that the two Adjustable Center-of-Gravity Lift Fixture (ACGLF) counterweights are located at the $180^{\circ}$ and $000^{\circ}$ respectively.

4.4.1.10 Using the crane and ACGLF, re-install the ICV assembly into the OCV body.

\subsubsection{Using Heat Guns}

4.4.2.1 Using heat guns, heat the ICV/OCV lid O-rings (as necessary) for up to 1 hour.

CAUTION: Operator shall verify that the two Adjustable Center-of-Gravity Lift Fixture (ACGLF) counterweights are located at the $180^{\circ}$ and $000^{\circ}$ respectively.

CAUTION: When lifting the ICV lid, the operator shall verify that the load exerted on the ICV lift pockets does not exceed 5,000 pounds (Load cell indication of 7,500 pounds minus ACGLF @ 2,500 pounds). An indication of 7,500 pounds or greater may indicate ICV lid binding.

CAUTION: When lifting the OCA lid, the operator shall verify that the load exerted on the OCA lift pockets does not exceed 7,500 pounds (Load cell indication of 10,000 pounds minus ACGLF @ 2500 pounds). An indication of 10,000 pounds or greater may indicate OCA lid binding.

4.4.2.2 At the slowest possible rate, attempt to raise the lid. If the lid lifts, raise the lid as directed by the RCT and RETURN TO steps 4.3.3.11, 4.3.4.9, 4.3.21.13, or 4.3.22.17 (as applicable). If not, continue with Section 4.4.3.

\subsubsection{Pressurizing with Nitrogen or Compressed Air}

4.4.3.1 Obtain the following:

- Nitrogen bottle with $\geq 500-\mathrm{lb}$ pressure or other air source capable of being regulated to $2 \mathrm{psi}$

- TRUPACT-II Leak-Test Vacuum/Pressure Assembly 
- ICV/OCV Vent-Port Tools, as applicable, if not already installed

4.4.3.2 Perform the following for compressed air or nitrogen:

4.4.3.2.1 Attach the TRUPACT-II Leak-Test Vacuum/Pressure Assembly in accordance with Figure 4.1, Flow Diagram for Nitrogen Bottle/Compressed Air ICV/OCA Lid Pressurization.

4.4.3.2.2 If not already installed, install the Vent-Port Tool hand tight.

4.4.3.2.3 Connect the Leak-Test Assembly to the quick disconnect on the Vent-Port Tool.

4.4.3.2.4 Close valve V-1.

4.4.3.2.5 Close valve $\mathrm{V}-2$.

4.4.3.2.6 Close valve V-3.

4.4.3.2.7 Verify the supply valve is closed.

4.4.3.2.8 Connect the supply line and regulator to the nitrogen-bottle or compressed air source.

4.4.3.2.9 Adjust pressure slowly to 1 psi.

4.4.3.3 Verify the counter weights are positioned at $180^{\circ}$ and $000^{\circ}$.

WARNING:The TRUPACT-II shipping cask (ICV or OCV) should not be pressurized above 2 psi to avoid personnel injury. Do NOT pressurize a loaded ICV unless precautions are taken to prevent possible contamination when the lid is raised.

CAUTION: When lifting the ICV lid, the operator shall verify that the load exerted to the ICV lifting pockets does not exceed 5,000 pounds (Load cell indication of 7,500 pounds minus ACGLF @ 2,500 pounds). An indication of 7,500 pounds or greater may indicate ICV lid binding.

CAUTION: When lifting the OCA lid by the lift pockets, the operator shall verify that the load exerted on the lift pockets does not exceed 7,500 pounds (Load cell indication of 10,000 pounds minus ACGLF @ 2500 pounds). An indication of 10,000 pounds or greater may indicate OCA lid binding.

4.4.3.4 Using the crane, attempt to lift the lid at the slowest rate possible while monitoring the load cell.

4.4.3.5 While attempting to lift the lid with the crane, perform the following:

4.4.3.5.1 Open the supply valve and adjust the regulator to $2 \mathrm{psi}$.

4.4.3.5.2 Open Valve V-2.

4.4.3.5.3 Throttle valve $\mathrm{V}-3$, keeping the pressure below 2 psi. 
4.4.3.5.4 When the lid becomes loose, close V-3.

4.4.3.5.5 Close the supply valve.

4.4.3.5.6 Open V-1 and V-3 to depressurize the assembly.

4.4.3.5.7 Disconnect Leak-Test Assembly from the Vent-Port Tool.

4.4.3.5.8 Disconnect the Vent-Port Tool and survey the tool if applicable.

4.4.3.5.9 Disconnect the supply line and regulator from the nitrogen bottle or compressed air source.

4.4.3.6 If after pressurizing to 2 psi maximum, the lid lifts, raise the lid as directed by the RCT and continue with step 4.3.3.11, 4.3.4.9, 4.3.21.13, or 4.3.22.17 (as applicable).

4.4.3.7 IF the lid still does not lift,

THEN contact the Waste Isolation Division (WID) TRUPACT-II Maintenance Engineer. 
Figure 4.1 Flow Diagram for Nitrogen Bottle/Compressed Air ICV/OCA Lid Pressurization

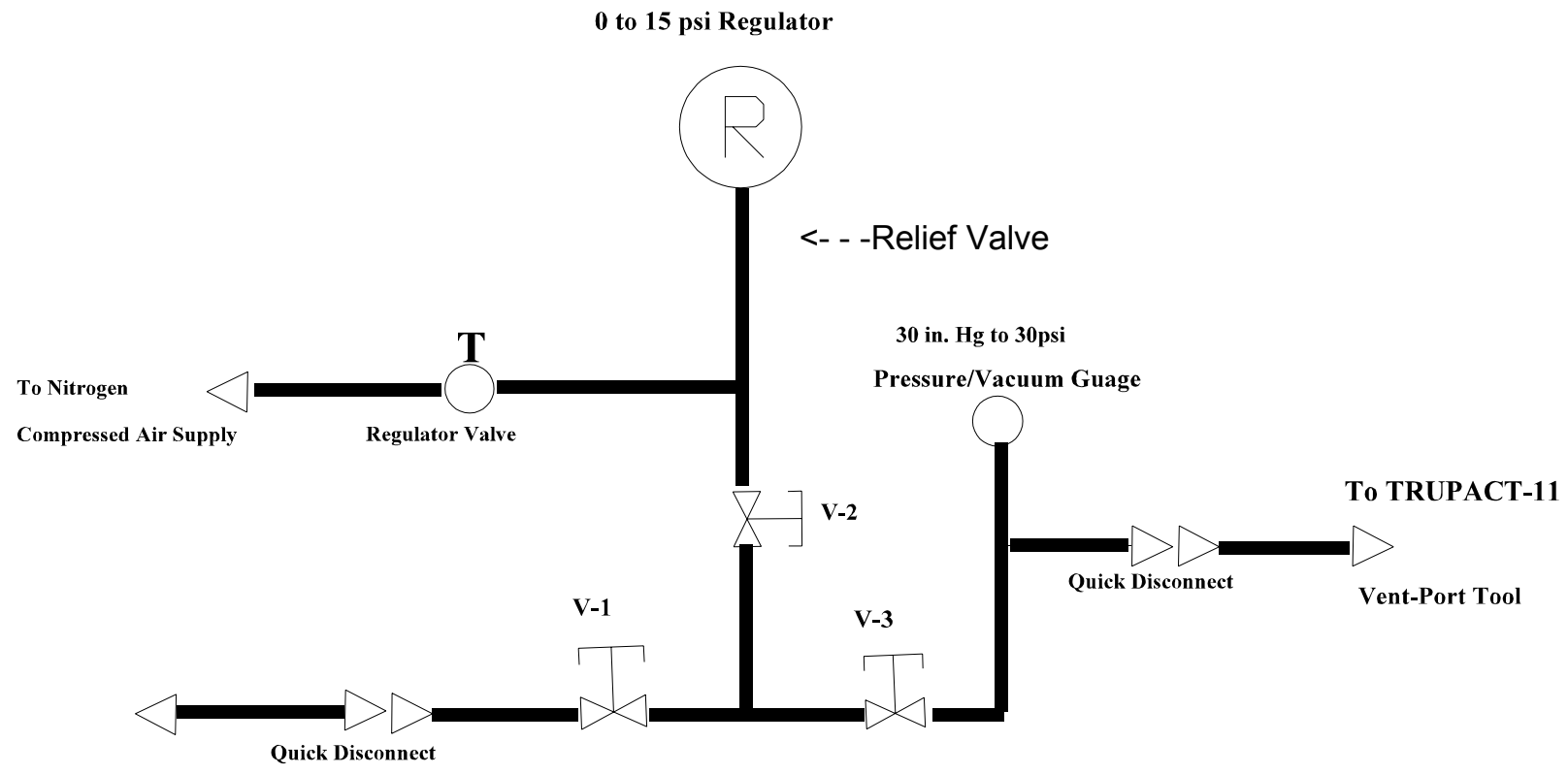

Not to scale 


\subsection{TRUPACT-II PACKAGE MAINTENANCE INSTRUCTIONS}

This section describes the maintenance program used to ensure continued performance of the TRUPACT-II Packaging (see definition section for annual and five year maintenance). The annual maintenance tests and inspections described in this section shall be performed within 12 months prior to each shipment. Annual maintenance tests and inspections need not be performed for out-of-service packages. The five-year cycle for structural and pressure tests and fastener replacement shall begin when the packaging is first placed into service and shall include cumulative inservice time only.

All maintenance, repairs performed, or components replaced will be documented using WP Form 1709, "Transuranic Package Transporter Model II (TRUPACT-II) Maintenance Record". Information regarding preparation of the TRUPACT-II Maintenance Record is outlined in Section 5.8 of this document. Forms (WP Form 1709) will be furnished to each user by the Waste Isolation Division (WID) TRUPACT-II Maintenance Engineer. Proper records shall be maintained by the TRUPACT-II Packaging owner to document completion of the maintenance schedule.

If a deficiency is found that is not covered by this document, or that is beyond repair capability of the discovering site, that site will follow its approved procedure for reporting deficiencies and contact the WID within 24 hours for disposition. All questions regarding the continued integrity of TRUPACT-II containers shall be addressed, in writing, to the WID National TRU Programs, P.O. Box 2078, Carlsbad, New Mexico 88221.

Approved work instructions are listed in Attachment D. Work instructions not listed must have approval by the WID. Recommendations for new work instructions or modifications to existing work instructions should be forwarded to the WID National TRU Programs.

Scheduled and unscheduled maintenance will be coordinated by the WID National TRU Programs. Maintenance will be scheduled so as to maximize the availability of packaging.

NOTE: $\quad$ Sections 5.1 through 5.4 are normally done at the WIPP or by a WID subcontracted vendor. Work Instruction 4.15, Annual and 5-Year Maintenance Inspections should be used as a check list when performing these inspections.

\subsection{Annual Visual Inspections}

Tables 5.1 and 5.2 define the annual visual inspections to be performed on the Inner Containment Vessel (ICV) and Outer Containment Assembly (OCA), respectively. General cleanliness should be observed for all components. Use cloths or towels and ethyl alcohol to enable proper visual inspection of the components. Visual inspections shall determine that surfaces are free of excessive deformation, sliding surfaces do not have excessive wear, and all threaded components are as specified and in good operating condition.

\subsection{Annual Dimensional Inspections}

Table 5.3 denotes the annual dimensional inspections to be performed on the ICV and OCA. General cleanliness should be observed for all components. Use cloths or 
towels and ethyl alcohol to enable proper dimensional inspection of the components. Should components fail to meet the defined acceptance criteria following any corrective action(s), prepare a Non-Conformance Request (NCR) for disposition. All NCRs shall be dispositioned by the WID National TRU Programs.

\subsection{Annual ICV Interior Surfaces Inspection}

An annual inspection shall be performed on the interior welds and accessible base metal surfaces of the ICV. The inspections shall be performed by visual inspection and liquid penetrant examination. The visual inspection shall be for surface corrosion. If surface corrosion indications are found, record the locations, make a photographic record, and submit on an Authorization Request/Variation Request (AR/VR) for disposition by the WID National TRU Programs.

A liquid penetrant examination shall be performed of the ICV interior surfaces including accessible shell, head, flange and weld surfaces for stress corrosion cracking or other relevant indications. The examination shall be performed in accordance with ASME Boiler and Pressure Vessel Code, Section V, Article 6. Acceptance criteria shall be per Section III, Division 1, subsection NB, Article 2546 and NB-5000. Relevant indications shall be repaired in accordance with Work Instruction 4.12.

When an annual inspection is performed in conjunction with a 5-year Structural Pressure Test, required dye penetrant examinations should be conducted AFTER the structural pressure test to avoid duplication of effort.

\subsection{Five Year Structural Pressure Tests}

After being placed in service, the Outer Containment Vessel (OCV) and ICV shall be pressure-tested per Section 6.0 of this document to $150 \%$ of the maximum normal operating pressure to verify structural integrity once every five years, or after repairs to the containment structure. The maximum normal operating pressure of the OCV and ICV is 50 psig, therefore the OCV and ICV shall be pressure-tested to 75 psig.

Accessible adjacent base material and welds directly related to the pressure-testing of the OCV and ICV shall be visually inspected for plastic deformation or cracking, and liquid penetrant inspected to Section V, Article 6, and Section III, Division 1, Subsection NB, Article NB-5000 of ASME Boiler and Pressure Vessel Code. Indications of cracking or distortion shall be recorded on an NCR for disposition by the WID National TRU Programs.

Upon successful completion of the Structural Pressure-Tests specified in Section 6.0, Leak-Testing the ICV and OCV Containment Seals and Structure shall be performed in accordance with Sections 6.3 and 6.4 of this document.

\subsection{Packaging Component Replacement Schedule}

Packaging components shall be replaced as defined in the schedule provided in Table 5.4 or when damage is noted. Should replacement of a given component fail to meet the acceptance criteria, prepare an NCR for disposition by the WID National TRU Programs. 


\subsection{Periodic Transport Trailer Inspections and Component Replacement Schedule}

Periodic transport trailer inspections, development of a component replacement schedule, and maintenance activities are the responsibility of the contract carrier based on manufacturer's recommendations or experience factors.

\subsection{Periodic Lift Fixture Inspections and Component Replacement Schedule}

Periodic lift fixture inspections, development of a component replacement schedule, and maintenance activities are the responsibility of the individual user sites.

\subsection{TRUPACT-II Maintenance Records (Form 1709)}

All maintenance performed on the TRUPACT-II shall be documented on a TRUPACT-II Maintenance Record form 1709. Figure 5.1 is a sample of Form 1709. TRUPACT-II users may obtain preprinted forms from the TRUPACT-II Maintenance Engineer.

\subsubsection{Instructions for completing Form 1709}

- $\quad$ TRUPACT-II S/N

Record the three digit serial number of the TRUPACT-II.

- $\quad$ Date Initiated

Enter the date that the maintenance was initiated. (If no corrective actions are immediately performed, enter the date the discrepancy was discovered).

- Location/Site

Enter the acronym for the site or location initiating the maintenance. (Example: INEEL, WIPP, or EPD, etc.)

- Job No.

Enter the next sequential job number from your site's TRUPACT-II maintenance log. (See Section 5.9)

- $\quad$ Reason for Maintenance

Check the appropriate block. Check "other" for unscheduled inspections, modification or repairs that are not listed in Appendix D.

- Discrepancy Description

Provide a short narrative description of "repair" or "other" discrepancies. No entry is required specifically for annual or 5 year maintenance, but list discrepancies discovered as part of these scheduled inspections. List NCR numbers, Tag numbers, or correspondence letter numbers, if applicable, to the discrepancy.

- Work Performed

Provide a concise description of the actions taken to correct discrepancies listed in the "Discrepancy Description" block. (Example: Replaced ICV upper Main O-Ring) 
- Work Instructions Used

List the work instruction numbers (e.g., 4.10, 4.11, etc.) used to perform the maintenance covered by the maintenance record.

- $\quad$ Spare Parts Used

List any spare parts that were used by description, part number, and WIPP Purchase Order (PO) number. (Required information is printed on packages).

- Work Inspected by:

Should be signed and dated by the supervisor of the personnel who performed the work. The signature verifies that the actions taken were within the scope of the work instructions or traveler (if applicable) and the TRUPACT-II can be returned to service. This signature also indicates that the maintenance record is accurate and complete (i.e., all applicable supporting documentation is attached).

\subsubsection{Maintenance Record Disposition}

Upon completion, the ORIGINAL TRUPACT-II Maintenance Record (Form 1709), including attachments to the Work Instructions, shall be transmitted to: TRUPACT-II Maintenance Engineer, P.O. Box 2078, Carlsbad, NM, 88221.

\subsection{Maintenance Log}

Each user site shall maintain a TRUPACT-II maintenance log. The log shall contain copies of completed TRUPACT-II maintenance records and a sequential listing, by job number, of maintenance performed on TRUPACT-II's. The user copies of TRUPACT-II maintenance records should be kept for 3 years, after which they may be discarded.

\subsection{Maintenance Due Labels}

Upon completion of annual maintenance, the TRUPACT-II maintenance facility shall affix a blue Maintenance Due Label indicating the month after maintenance was performed. The TRUPACT-II is considered "Out-of-Service" on the first day of the month indicated on this label, i.e., if annual maintenance is performed on September 15, 1999, it may be used until the end of September 2000, the blue Maintenance Due Label, adjacent to the name plate, should indicate October 2000.

Upon completion of five (5) year maintenance, the TRUPACT-II maintenance facility shall affix a green maintenance due label indicating the month after maintenance was performed. The TRUPACT-II is considered "Out-of-Service" on the first of the month indicated on this label, i.e., if the five (5) year maintenance was performed on September 15, 1999, it may be used until the end of September 2000, only. The green Maintenance Due Label adjacent to the name plate, should indicate October 2000. 
Figure 5.1 TRUPACT-II Maintenance Record

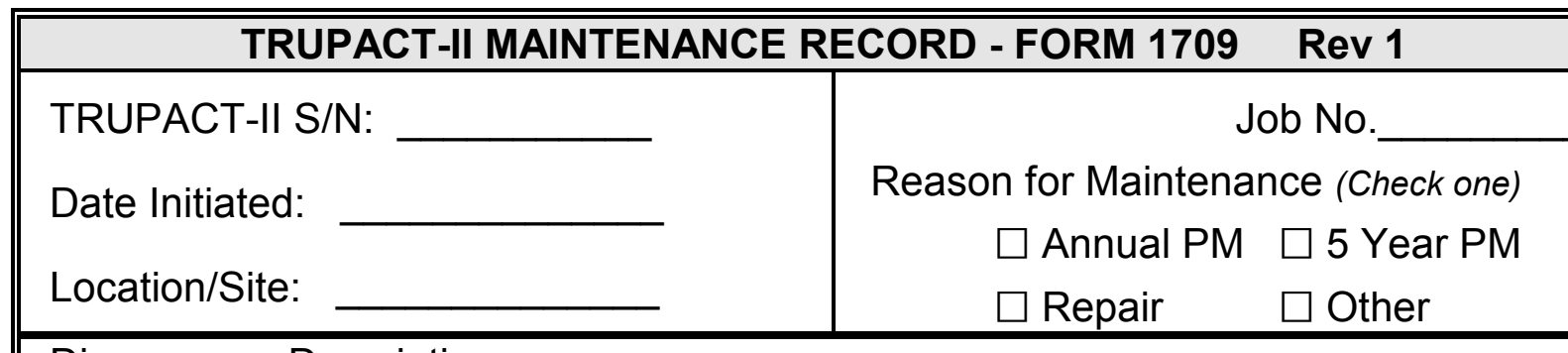

Discrepancy Description:

Work Performed:

Work Instructions Used:

Spare Parts Used

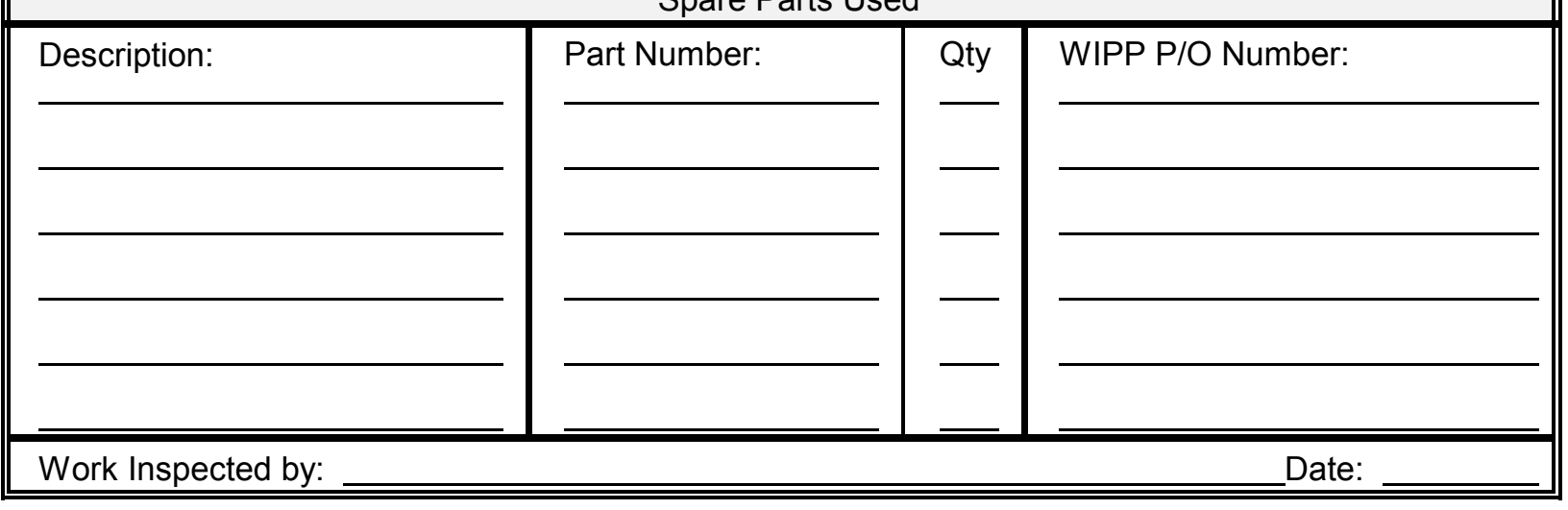

WP Form 1709; 7/16/92

591B:0424

Page 1 of 2 
Figure 5.1 TRUPACT-II Maintenance Record (continued)

TRUPACT-II MAINTENANCE RECORD - FORM 1709 - (CONTINUATION SHEET)

WP Form 1709: 7/16/92

Page 2 of 2 


\begin{tabular}{|c|c|c|c|}
\hline Component/Part No. & Acceptance Criteria & Corrective Action & $\checkmark$ \\
\hline ICV Vent-Port Cover (2077-156-11) & $\begin{array}{l}\text { No damaged threads or damaged recessed } \\
\text { head }\end{array}$ & Replace per WI 4.1 & \\
\hline ICV Vent-Port Cover Gasket (2077-180-16) & No damage affecting operation & Replace per WI 4.1 & \\
\hline ICV Vent-Port Insert (2077-156-6) & $\begin{array}{l}\text { No damaged threads or damaged sealing } \\
\text { area }\end{array}$ & NCR for disposition & \\
\hline ICV Outer Vent-Port-Plug (2077-156-9) & $\begin{array}{l}\text { No damaged threads or damaged recessed } \\
\text { head }\end{array}$ & Replace per WI 4.1 & \\
\hline $\begin{array}{l}\text { ICV Outer Vent-Port-Plug O-ring Seal } \\
(2077-180-21)\end{array}$ & No damage affecting operation & Replace per WI 4.1 & \\
\hline ICV Inner Vent-Port-Plug (2077-156-10) & $\begin{array}{l}\text { No damaged threads or damaged recessed } \\
\text { head }\end{array}$ & Replace per WI 4.1 & \\
\hline $\begin{array}{l}\text { ICV Inner Vent-Port-Plug O-ring Seal } \\
(2077-180-22)\end{array}$ & No damage affecting operation & Replace per WI 4.1 & \\
\hline ICV Upper Main O-ring Seal (2077-180-9) & No damage affecting operation & Replace per WI 4.2 & \\
\hline ICV Lower Main O-ring Seal (2077-180-19) & No damage affecting operation & Replace per WI 4.2 & \\
\hline ICV Seal-Test-Port Insert (2077-156-5) & $\begin{array}{l}\text { No damaged threads or damaged sealing } \\
\text { area }\end{array}$ & NCR for disposition & \\
\hline ICV Seal-Test-Port-Plug (2077-156-7) & $\begin{array}{l}\text { No damaged threads or damaged recessed } \\
\text { head }\end{array}$ & Replace per WI 4.1 & \\
\hline ICV Seal-Test-Port O-ring Seal (2077-180-24) & No damage affecting operation & Replace per WI 4.1 & \\
\hline ICV Wiper O-ring Seal (2077-180-27) & No damage affecting operation & Replace per WI 4.2 & \\
\hline ICV Wiper O-ring Holder & No distortion affecting operation & NCR for disposition & \\
\hline ICV Lid Debris Seal & No damage affecting operation & Replace per WI 4.2 & \\
\hline
\end{tabular}




\begin{tabular}{|c|c|c|c|}
\hline Component/Part No. & Acceptance Criteria & Corrective Action & $\checkmark$ \\
\hline $\begin{array}{l}\text { ICV Upper and Lower Flange Sealing } \\
\text { Surfaces (Grooves and Flats) }\end{array}$ & $\begin{array}{l}\text { No scratch(es) causing leakage or finish } \\
>125 \text { RMS micro-finish }\end{array}$ & Repair per WI 4.12 & \\
\hline ICV Upper and Lower Visible Shell Surfaces & $\begin{array}{l}\text { No dents over } 0.5 \text {-inch deep, gouges } \\
\text { causing wall thickness under } 0.240 \text {-inch, } \\
\text { weld cracks or punctures }\end{array}$ & NCR for disposition & \\
\hline ICV Locking Ring Fasteners (2077-156-A1) & $\begin{array}{l}\text { No damaged threads or damaged } \\
\text { recessed head, welds intact }\end{array}$ & Replace per WI 4.6 & \\
\hline ICV Locking Ring Inserts (2077-160-28) & $\begin{array}{l}\text { No damaged threads or missing insert } \\
\text { lock keys }\end{array}$ & Replace per WI 4.6 & \\
\hline ICV Locking Ring (2077-182-1) & No defects that impair general operation & NCR for disposition & \\
\hline \multirow[t]{2}{*}{ ICV Upper Spacer (2077-053-A1) } & No damaged or missing fasteners & Replace per WI 4.13 & \\
\hline & No punctures in plate & Replace per WI 4.13 & \\
\hline \multirow[t]{2}{*}{ ICV Lower Spacer (2077-053-A2) } & No damaged or missing fasteners & Replace per WI 4.13 & \\
\hline & No punctures in plate & Replace per WI 4.13 & \\
\hline ICV Polyethylene Filters (2077-183-4) & Not damaged or missing & Replace per WI 4.5 & \\
\hline
\end{tabular}




\begin{tabular}{|c|c|c|c|}
\hline Component & Acceptance Criteria & Corrective Action & $\checkmark$ \\
\hline OCV Vent-Port Access Cover (2077-156-A4) & $\begin{array}{l}\text { No damaged threads or damaged recessed } \\
\text { head; foam plug not damaged and still } \\
\text { attached }\end{array}$ & Replace per WI 4.1 & \\
\hline \multirow[t]{2}{*}{ OCV Vent-Port Flange (2077-173-13) } & No damaged threads & Repair per WI 4.4 & \\
\hline & No cracked welds & NCR for disposition & \\
\hline OCV Vent-Port Insert (2077-156-19) & $\begin{array}{l}\text { No damaged threads or damaged sealing } \\
\text { area }\end{array}$ & NCR for disposition & \\
\hline OCV Vent-Port Cover (2077-156-18) & No damaged threads or damaged hex head & Replace per WI 4.1 & \\
\hline $\begin{array}{l}\text { OCV Vent-Port Cover O-ring Seal } \\
(2077-160-16)\end{array}$ & No damage affecting operation & Replace per WI 4.1 & \\
\hline $\begin{array}{l}\text { OCV Vent-Port Cover Handling O-ring } \\
(2077-160-19)\end{array}$ & No damage affecting operation & Replace per WI 4.1 & \\
\hline OCV Vent-Port-Plug (2077-156-17) & $\begin{array}{l}\text { No damaged threads or damaged recessed } \\
\text { head }\end{array}$ & Replace per WI 4.1 & \\
\hline $\begin{array}{l}\text { OCV Vent-Port-Plug O-ring Seal } \\
(2077-160-17)\end{array}$ & No damage affecting operation & Replace per WI 4.1 & \\
\hline OCV Upper Main O-ring Seal (2077-160-15) & No damage affecting operation & Replace per WI 4.2 & \\
\hline OCV Lower Main O-ring Seal (2077-160-24) & No damage affecting operation & Replace per WI 4.2 & \\
\hline $\begin{array}{l}\text { OCV Seal-Test-Port Access Cover } \\
(2077-156-A 3)\end{array}$ & $\begin{array}{l}\text { No damaged threads or damaged recessed } \\
\text { head; foam plug not damaged and still } \\
\text { attached }\end{array}$ & Replace per WI 4.1 & \\
\hline \multirow[t]{2}{*}{ OCV Seal-Test-Port Flange (2077-167-6) } & No damaged threads & Repair per WI 4.4 & \\
\hline & No cracked welds & NCR for disposition & \\
\hline
\end{tabular}




\begin{tabular}{|c|c|c|c|}
\hline Component & Acceptance Criteria & Corrective Action & $\checkmark$ \\
\hline OCV Seal-Test-Port Insert (2077-156-5) & $\begin{array}{l}\text { No damaged threads or damaged sealing } \\
\text { area }\end{array}$ & NCR for disposition & \\
\hline OCV Seal-Test-Port-Plug (2077-156-7) & $\begin{array}{l}\text { No damaged threads or damaged } \\
\text { recessed head }\end{array}$ & Replace per WI 4.1 & \\
\hline $\begin{array}{l}\text { OCV Seal-Test-Port O-ring Seal } \\
(2077-160-26)\end{array}$ & No damage affecting operation & Replace per WI 4.1 & \\
\hline $\begin{array}{l}\text { OCV Upper and Lower Flange Sealing } \\
\text { Surfaces (Grooves and Flats) }\end{array}$ & $\begin{array}{l}\text { No scratch(es) causing leakage or surface } \\
\text { finish damage }>125 \text { RMS micro-finish }\end{array}$ & Repair per WI 4.12 & \\
\hline $\begin{array}{l}\text { OCV Upper and Lower Visible Shell } \\
\text { Surfaces }\end{array}$ & $\begin{array}{l}\text { No dents over } 0.5 \text {-inch deep, gouges } \\
\text { causing wall thickness under } 0.240 \text {-inch } \\
\text { for } 1 / 4 \text {-inch material or } 0.365 \text {-inch for } \\
3 / 8 \text {-inch material, weld cracks or } \\
\text { punctures }\end{array}$ & NCR for disposition & \\
\hline OCV Locking Ring Fasteners (2077-156-A2) & $\begin{array}{l}\text { No damaged threads or damaged } \\
\text { recessed head, welds intact }\end{array}$ & Replace per WI 4.6 & \\
\hline OCV Locking Ring Inserts (2077-160-28) & $\begin{array}{l}\text { No damaged threads or missing insert } \\
\text { lock keys }\end{array}$ & Replace per WI 4.6 & \\
\hline OCV Locking Ring (2077-162-3) & No defects that impair general operation & NCR for disposition & \\
\hline $\begin{array}{l}\text { OCV Locking Ring Actuator Assembly } \\
(2077-161-\mathrm{A} 1)\end{array}$ & No defects that impair general operation & $\begin{array}{l}\text { Clean or replace per } \\
\text { WI } 4.7\end{array}$ & \\
\hline OCA Ceramic Fiber Gaskets (2077-160-27) & No tears or excessive wear & Replace per WI 4.2 & \\
\hline OCA Upper Burn-Out Plugs (2077-163-13) & Properly tightened and not missing & $\begin{array}{l}\text { Tighten or replace per } \\
\text { WI } 4.3\end{array}$ & \\
\hline OCA Lower Burn-Out Plugs (2077-170-6) & Properly tightened and not missing & $\begin{array}{l}\text { Tighten or replace per } \\
\text { Wl } 4.3\end{array}$ & \\
\hline
\end{tabular}




\begin{tabular}{|c|c|c|c|}
\hline Component & Acceptance Criteria & Corrective Action & $\checkmark$ \\
\hline $\begin{array}{l}\text { OCA Upper Burn-Out Plug Flanges } \\
(2077-163-13)\end{array}$ & No damaged threads or cracked welds & NCR for disposition & \\
\hline $\begin{array}{l}\text { OCA Lower Burn-Out Plug Flanges } \\
(2077-170-15)\end{array}$ & No damaged threads or cracked welds & NCR for disposition & \\
\hline OCA Lid Guide Plates (2077-163-11) & Screws tight, not missing & Replace per WI 4.3 & \\
\hline $\begin{array}{l}\text { OCA Forklift Pocket Cover Plates } \\
\text { (2077-171-11 and 2077-171-12) }\end{array}$ & No distortion affecting operation & Replace per WI 4.3 & \\
\hline $\begin{array}{l}\text { OCA Forklift Pocket Cover Screws } \\
(2077-160-30)\end{array}$ & No damaged threads & Replace per WI 4.3 & \\
\hline $\begin{array}{l}\text { OCA Forklift Pocket Cover Inserts } \\
(2077-160-29)\end{array}$ & $\begin{array}{l}\text { No damaged threads or missing insert } \\
\text { lock keys }\end{array}$ & Replace per WI 4.6 & \\
\hline $\begin{array}{l}\text { OCA Lid Lift Pocket Cover Assembly } \\
(2077-163-A 2)\end{array}$ & No damaged or missing components & Replace per WI 4.3 & \\
\hline OCA Lid Lift Pocket Tube (2077-163-2) & Not damaged or missing & Replace per WI 4.3 & \\
\hline $\begin{array}{l}\text { OCA Lid Lift Pocket Tube Fasteners } \\
(2077-163-3)\end{array}$ & Not damaged or missing & Replace per WI 4.3 & \\
\hline $\begin{array}{l}\text { OCA Lid Lift Pocket Tube Washers } \\
(2077-163-4)\end{array}$ & Not damaged or missing & Replace per WI 4.3 & \\
\hline $\begin{array}{l}\text { Optional OCA Annulus Debris Seal } \\
(2077-156-21)\end{array}$ & No damage affecting operation & Replace per WI 4.3 & \\
\hline Optional OCA Weather Seal (2077-156-22) & No damage affecting operation & Replace per WI 4.3 & \\
\hline $\begin{array}{l}\text { OCA Cushion/Wear Pad, if visible } \\
(2077-156-23)\end{array}$ & Not torn or missing & Replace per WI 4.8 & \\
\hline
\end{tabular}


Table 5.3 Annual Component Inspection, Acceptance Criteria, and Corrective Action

\begin{tabular}{|c|c|c|c|}
\hline Component & Acceptance Criteria & Corrective Action & $\sqrt{ }$ \\
\hline ICV/OCV Lid to Body Axial Play & Inspect and accept to WI 4.8 & $\begin{array}{l}\text { If acceptance criteria cannot be met, } \\
\text { prepare NCR for disposition }\end{array}$ & \\
\hline $\begin{array}{l}\text { ICV/OCV Lid and Body Flange Tab } \\
\text { Widths }\end{array}$ & Inspect and accept to WI 4.9 & $\begin{array}{l}\text { If acceptance criteria cannot be met, } \\
\text { prepare NCR for disposition }\end{array}$ & \\
\hline $\begin{array}{l}\text { ICV/OCV Lid and Body Flange Groove } \\
\text { Widths }\end{array}$ & Inspect and accept to WI 4.10 & $\begin{array}{l}\text { If acceptance criteria cannot be met, } \\
\text { prepare NCR for disposition }\end{array}$ & \\
\hline $\begin{array}{l}\text { ICV/OCV Upper Main O-Ring Seal } \\
\text { Groove Depth }\end{array}$ & Inspect and accept to WI 4.11 & $\begin{array}{l}\text { If acceptance criteria cannot be met, } \\
\text { prepare NCR for disposition }\end{array}$ & \\
\hline ICV/OCV Seal Surface & Inspect and accept to WI 4.11 & $\begin{array}{l}\text { If acceptance criteria cannot be met, } \\
\text { prepare NCR for disposition }\end{array}$ & \\
\hline ICV Upper and Lower Spacers & Inspect and accept to WI 4.13 & $\begin{array}{l}\text { If acceptance criteria cannot be met, } \\
\text { prepare NCR for disposition }\end{array}$ & \\
\hline $\begin{array}{l}\text { ICV interior surfaces to include } \\
\text { accessible shell, head, flange, and } \\
\text { weld surfaces Liquid Penetrant } \\
\text { Inspection }\end{array}$ & $\begin{array}{l}\text { Inspect and accept to } \\
\text { NB-5000 }\end{array}$ & $\begin{array}{l}\text { If acceptance criteria cannot be met, } \\
\text { prepare NCR for disposition }\end{array}$ & \\
\hline
\end{tabular}

NOTE: After completion of maintenance, the maintenance provider will affix a label, provided by the TRUPACT-II Maintenance Engineer, indicating the date the next annual or five year maintenance is due, adjacent to the TRUPACT-II name plate. A TRUPACT-II is considered out of service after this date if required maintenance has not been performed. 
Table 5.4 Component Replacement Schedule and Work Instruction

\begin{tabular}{|c|c|c|c|}
\hline Component and Part Number & Frequency & $\begin{array}{c}\text { Work } \\
\text { Instruction }\end{array}$ & $\checkmark$ \\
\hline OCV Upper Main O-Ring (2077-160-15) & Annual & WI 4.2 & \\
\hline OCV Lower Main O-Ring (2077-160-24) & Annual & WI 4.2 & \\
\hline $\begin{array}{l}\text { OCV Seal-Test-Port-Plug O-Ring } \\
(2077-160-26 / 180-24)\end{array}$ & Annual & WI 4.1 & \\
\hline $\begin{array}{l}\text { OCV Vent-Port-Plug Seal O-Ring } \\
(2077-160-17 / 180-22)\end{array}$ & Annual & WI 4.1 & \\
\hline OCV Vent-Port-Plug Cover O-Ring (2077-160-16) & Annual & WI 4.1 & \\
\hline OCV Locking Ring Bolts (2077-156-A2) & 5 years & WI 4.6 & \\
\hline ICV Upper Main O-Ring (2077-180-9) & Annual & WI 4.2 & \\
\hline ICV Lower Main O-Ring (2077-180-19) & Annual & WI 4.2 & \\
\hline ICV Seal-Test-Port-Plug O-Ring (2077-180-24/160-26) & Annual & WI 4.1 & \\
\hline ICV Outer Vent-Port-Plug O-Ring (2077-180-21) & Annual & WI 4.1 & \\
\hline ICV Inner Vent-Port-Plug O-Ring (2077-180-22/160-17) & Annual & WI 4.1 & \\
\hline ICV Vent-Port Cover Gasket (2077-180-16) & Annual & WI 4.1 & \\
\hline ICV Wiper O-Ring (2077-180-27) & Annual & WI 4.1 & \\
\hline ICV Lid Debris Seal (2077-180-25) & Annual & WI 4.1 & \\
\hline ICV Locking Ring Bolts (2077-156-A1) & 5 years & WI 4.6 & \\
\hline OCV Vent-Port-Plug Handling O-Ring (2077-160-18) & Annual & WI 4.1 & \\
\hline OCV Vent-Port Cover Handling O-Ring (2077-160-19) & Annual & WI 4.1 & \\
\hline
\end{tabular}




\subsection{TRUPACT-II PACKAGE LEAKAGE-TESTING}

\subsection{Assembly Leak-Testing the ICV Containment Seals}

NOTE: The following leak test instructions are for reference only. Each user shall develop and qualify procedures to perform this test by qualified personnel by following the guidelines of ANSI N14-5-1997, "Radioactive Materials Leakage Tests on Packages for Shipment."

\subsubsection{Testing Prerequisites include the following:}

- To be acceptable, the containment vessel shall have a leakage rate of $1.0 \times 10^{-7}$ standard cubic centimeters per second (scc/s) (leaktight), air (i.e., 1.4 $\times 10^{-7} \mathrm{scc} / \mathrm{s}$, helium (assumes $80 \%$ concentration), at an ambient temperature of $40^{\circ} \mathrm{F}$, or above);

- $\quad$ Record the Inner Containment Vessel (ICV) lid and body serial numbers on the "ICV Containment Seals Leakage-Test Data Sheet" found in Attachment B-2;

- Obtain a helium mass spectrometer leak detector capable of detecting a leakage rate of $5.0 \times 10^{-8} \mathrm{scc} / \mathrm{s}$, air (i.e., $1.3 \times 10^{-8} \mathrm{scc} / \mathrm{s}$, helium @ $40^{\circ} \mathrm{F}$, or above). Record the leak detector's serial number;

- Obtain a calibrated standard leak and calibrate the leak detector according to the manufacturer's recommendations such that the leak detector's sensitivity is $5.0 \times 10^{-8} \mathrm{scc} / \mathrm{s}$, air (i.e., $1.3 \times 10^{-8} \mathrm{scc} / \mathrm{s}$ ). Record the calibrated standard leak serial number and calibration date;

- Obtain a calibrated ambient temperature measuring device and record the device serial number and ambient temperature.

6.1.2 Visually check the ICV lid has been installed in accordance with the guidelines of the steps in Section 4.3.16.

6.1.3 Verify the ICV seal-test-port-plug has been removed.

6.1.4 Install the ICV seal leak check tool (see Figure 1.12).

6.1.5 Attach the leak detector to the ICV seal leak check tool (see Figure 6.1).

6.1.6 Evacuate the ICV seal-test-port until the vacuum is sufficient to operate the leak detector to the manufacturer's recommendations.

6.1.7 Install the ICV vent-port-plug removal/pressure relief tool (see Figure 1.8) into the ICV vent-port, with the ICV outer vent-port-plug retracted into the tool.

6.1.8 Using appropriate fittings, attach in parallel a vacuum pump assembly and helium gas supply assembly to the ICV vent-port-plug removal/pressure relief tool; install an isolation valve into each line to allow independent closure of each line.

6.1.9 IF evacuation of the ICV vent-port cavity does not achieve a $90 \%$ vacuum (i.e., a vacuum $\leq 10 \%$ of ambient barometric pressure) and provide a seal sufficient to backfill with helium,

THEN perform the following: 
6.1.9.1 Disconnect the leak detector and vacuum pump/helium supply assemblies.

6.1.9.2 Vent to atmosphere.

6.1.9.3 Remove the ICV lid.

6.1.9.4 Inspect the ICV wiper O-ring seal, ICV inner vent-port-plug O-ring seal, and the ICV upper main (containment boundary) O-ring seal and sealing areas for damage.

6.1.9.5 If necessary, replace the damaged seal(s) and/or repair the sealing areas, and return to step 6.1.1.

6.1.10 Close the valve to the helium gas supply, open the valve to the vacuum pump, and evacuate the ICV vent-port cavity to a $90 \%$ vacuum, or better. Record the vacuum pressure level.

6.1.11 Record the leak detector's background leak rate reading.

NOTE: After helium pressure is stabilized within the ICV vent-port cavity, the operator shall monitor the leak detector for a period of three minutes before beginning the test.

6.1.12 Close the isolation valve to the vacuum pump and open the isolation valve to the helium source. Backfill the ICV vent-port cavity with helium gas to atmospheric pressure. Record the backfill pressure. Begin timing for helium leak-testing of the ICV main O-ring seal.

6.1.13 Rotate the ICV vent-port-plug removal/pressure relief tool handle clockwise to install the ICV outer vent-port-plug hand tight.

6.1.14 Remove the ICV vent-port-plug removal/pressure relief tool and tighten the ICV outer vent-port-plug to 10 to $13 \mathrm{ft}-\mathrm{lbs}$ (120 to 156 in-lbs) torque with an appropriate torque wrench.

6.1.15 At the end of three minutes, record the leakage rate.

6.1.16 Determine the actual leakage rate by subtracting the background reading (step 6.1.11) from the leakage rate (step 6.1.15). If the ICV main O-ring seal fails to pass the leak test, isolate the leak path, replace the O-ring seal(s) per WI 4.2 and/or repair the seal surface(s) per WI 4.12, and repeat the leak-test. If the seal replacement does not bring the equipment into compliance, prepare an NCR for disposition by the WID National TRU Programs.

6.1.17 Remove the ICV seal leak check tool and associated leak-test equipment from the ICV seal-test-port.

6.1.18 Install the ICV seal-test-port-plug (see Figure 1.11), and tighten to 6 to $8 \mathrm{ft}-\mathrm{lbs}$ (72 to 96 in-lbs) torque with an appropriate torque wrench.

6.1.19 Install a clean helium-free ICV vent-port-plug leak check tool (see Figure 1.10) into the ICV vent-port (see Figure 6.2). 
Rev. 3

6.1.20 Attach the leak detector to the ICV vent-port-plug leak check tool. 
6.1.21 Evacuate the ICV vent-port-plug leak check tool until the vacuum is sufficient to operate the leak detector to the manufacturer's recommendations.

NOTE: Initial spurious leakage rate readings on the leak detector do NOT necessarily indicate a leak. Some residual helium gas may still be entrapped around the vent-port-plug seal and threaded areas.

6.1.22 When the leak detector reading is within the test range (i.e., less than $2.6 \times 10^{-7} \mathrm{scc} / \mathrm{s}$, helium), begin timing the leak-test. At the end of three minutes, record the leakage rate.

NOTE: If the ICV outer vent-port-plug seal fails to pass the leak-test, the operator shall isolate the leak path, replace the O-ring seal per WI 4.1 and/or repair the seal surface(s) per WI 4.12, and repeat the leak-test. If, after repeated attempts, the system cannot be made to pass the leak-test, the operator shall prepare an NCR for disposition by the WID National TRU Programs.

6.1.23 Remove the ICV vent-port-plug leak check tool and associated leak-test equipment from the ICV vent-port.

6.1.24 Install the ICV vent-port cover and tighten to 13 to $16 \mathrm{ft}-\mathrm{lbs}$ (156 to $192 \mathrm{in}-\mathrm{lbs}$ ) torque with an appropriate torque wrench.

6.1.25 Return to step 4.3.17.9.

\subsection{Assembly Leak-Testing the OCV Containment Seals}

NOTE: The following leak-test instructions are for reference only. Each user shall develop and qualify procedures to perform this test by qualified personnel by following the guidelines of ANSI N14-5-1997, "Radioactive Materials Leakage-Tests on Packages for Shipment."

\subsubsection{Testing Prerequisites}

- To be acceptable, the containment vessel shall have a leakage rate of $1.0 \times 10^{-7} \mathrm{scc} / \mathrm{s}$ (leaktight), air (i.e., $2.6 \times 10^{-7} \mathrm{scc} / \mathrm{s}$, helium, at an ambient temperature of $40^{\circ} \mathrm{F}$, or above).

- $\quad$ Record the Outer Containment Assembly (OCA) lid and body serial numbers on the "Outer Containment Vessel (OCV) Containment Seals Leakage-Test Data Sheet" found in Attachment B-3.

- $\quad$ Obtain a helium mass spectrometer leak detector capable of detecting a leakage rate of $5.0 \times 10^{-8} \mathrm{scc} / \mathrm{s}$, air (i.e., $1.3 \times 10^{-7} \mathrm{scc} / \mathrm{s}$, helium). Record the leak detector's serial number.

- Obtain a calibrated standard leak and calibrate the leak detector according to the manufacturer's recommendations such that the leak detector's sensitivity is $5.0 \times 10^{-8} \mathrm{scc} / \mathrm{s}$, air (i.e., $1.3 \times 10^{-7} \mathrm{scc} / \mathrm{s}$, helium). Record the calibrated standard leak serial number and calibration date.

- $\quad$ Obtain a calibrated ambient temperature measuring device and record the device serial number and ambient temperature.

6.2.2 Visually check the OCA lid has been assembled in accordance with the guidelines of the steps in Section 4.3.17. 
6.2.3 Remove the OCV seal-test-port-plug. Install the OCV seal leak check tool (see Figure 1.7).

6.2.4 Attach the leak detector to the OCV seal leak check tool (see Figure 6.3).

6.2.5 Evacuate the OCV seal-test-port until the vacuum is sufficient to operate the leak detector per the manufacturer's recommendations.

6.2.6 Install the OCV vent-port-plug removal/pressure relief tool (see Figure 1.4) into the OCV vent-port, with the OCV vent-port-plug retracted into the tool.

6.2.7 Using appropriate fittings, attach in parallel a vacuum pump assembly and helium gas supply assembly to the OCV vent-port-plug removal/pressure relief tool; install an isolation valve into each line to allow independent closure of each line.

NOTE: If evacuation of the OCV annulus is not able to achieve a vacuum, the operator shall disconnect the leak detector and vacuum pump/helium supply assemblies and inspect for possible leaks.

6.2.8 Close the valve to the helium gas supply, open the valve to the vacuum pump, and evacuate the OCV annulus to a 25 inches of $\mathrm{Hg}$, or better. Record the vacuum pressure level.

6.2.9 Record the leak detector's background leak rate reading.

NOTE: After helium pressure is stabilized within the OCV annulus, the operator shall monitor the leak detector for a period of three minutes.

6.2.10 Close the isolation valve to the vacuum pump and open the isolation valve to the helium source. Backfill the OCV annulus with helium gas to atmospheric pressure. Record the backfill pressure. Begin timing for helium leak-testing of the OCV main O-ring seal.

6.2.11 Rotate the OCV vent-port-plug removal/pressure relief tool handle clockwise to install the OCV vent-port-plug hand tight.

6.2.12 Remove the OCV vent-port-plug removal/pressure relief tool and tighten the OCV vent-port-plug to 10 to $13 \mathrm{ft}-\mathrm{lbs}$ (120 to $156 \mathrm{in}-\mathrm{lbs})$ torque with an appropriate torque wrench.

6.2.13 At the end of three minutes, record the leakage rate.

6.2.14 Determine the actual leakage rate by subtracting the background reading (step 6.2.9) from the leakage rate (step 6.2.13). If the OCV main O-ring seal fails to pass the leak-test, isolate the leak path, replace the O-ring seal(s) per WI 4.2 and/or repair the seal surface(s) per WI 4.12, and repeat the leak-test. If, after repeated attempts, the system cannot be made to pass the leak-test, prepare an NCR for disposition by the WID National TRU Programs.

6.2.15 Remove the OCV seal leak check tool and associated leak-test equipment from the OCV seal-test-port. 
6.2.16 Install the OCV seal-test-port-plug using the ICV seal-test-port-plug removal tool (see Figure 1.6), and tighten to 6 to $8 \mathrm{ft}-\mathrm{lbs}$ (72 to 96 in-lbs) torque with an appropriate torque wrench.

6.2.17 Install a clean helium-free OCV vent-port-plug leak check (see Figure 1.5) into the OCV vent-port (see Figure 6.4).

6.2.18 Attach the leak detector to the OCV vent-port-plug leak check tool.

6.2.19 Evacuate the OCV vent-port-plug leak check tool until the vacuum is sufficient to operate the leak detector to the manufacturer's recommendations.

NOTE: Initial spurious leakage rate readings on the leak detector do NOT necessarily indicate a leak. Some residual helium gas may still be entrapped around the vent-port-plug seal and threaded areas.

6.2.20 When the leak detector reading is within the test range (i.e., less than $2.6 \times 10^{-7}$ $\mathrm{scc} / \mathrm{s}$, helium), begin timing the leak-test. At the end of three minutes, record the leakage rate. If the OCV vent-port-plug seal fails to pass the leak-test, isolate the leak path, replace the O-ring seal per WI 4.1 and/or repair the seal surface(s) per WI 4.12, and repeat the leak-test. If, after repeated attempts, the system cannot be made to pass the leak-test, prepare an NCR for disposition by the WID National TRU Programs.

6.2.21 Remove the OCV vent-port-plug leak check tool and associated leak-test equipment from the OCV vent-port.

6.2.22 Install the OCV vent-port cover using the OCV vent-port cover removal tool (see Figure 1.3), and tighten to 13 to $16 \mathrm{ft}-\mathrm{lbs}$ (156 to $192 \mathrm{in}-\mathrm{lbs}$ ) torque.

6.2.23 Install the OCV seal-test-port access cover/thermal plug assembly and tighten to 35 to $45 \mathrm{ft}-\mathrm{lbs}$ torque with an appropriate torque wrench (lubricated with a suitable stainless steel compatible, nickel bearing lubricant).

6.2.24 Install the OCV vent-port access cover/thermal plug assembly and tighten to 35 to $45 \mathrm{ft}-$ lbs torque with an appropriate torque wrench (lubricated with a suitable stainless steel compatible, nickel bearing lubricant).

\subsection{Leak-Testing the ICV Containment Seals and Structure}

\subsubsection{Testing Prerequisites}

- To be acceptable, the containment vessel shall have a leakage rate of $1.0 \times 10^{-7} \mathrm{scc} / \mathrm{s}$ per second (leaktight), air (i.e., $2.6 \times 10^{-7} \mathrm{scc} / \mathrm{s}$, helium, at an ambient temperature of $40^{\circ} \mathrm{F}$, or above).

- $\quad$ Record the ICV lid and body serial numbers on the "ICV Containment Structure Leakage-Test Data Sheet" found in Attachment B-4.

- Obtain a helium mass spectrometer leak detector capable of detecting a leakage rate of $5.0 \times 10^{-8} \mathrm{scc} / \mathrm{s}$ air (i.e., $1.3 \times 10^{-7} \mathrm{scc} / \mathrm{s}$, helium. Record the leak detector's serial number. 
- Obtain a calibrated standard leak and calibrate the leak detector according to the manufacturer's recommendations such that the leak detector's sensitivity is $5.0 \times 10^{-8} \mathrm{scc} / \mathrm{s}$ helium, air (i.e., $1.3 \times 10^{-7} \mathrm{scc} / \mathrm{s}$ ). Record the calibrated standard leak serial number and calibration date.

- Obtain a calibrated ambient temperature measuring device and record the device serial number and ambient temperature.

6.3.2 Remove the ICV honeycomb spacers in accordance with the guidelines of WI 4.13.

6.3.3 Install the ICV lid in accordance with the guidelines of the steps in Section 4.3.16.

6.3.4 Verify the inner-vent-port-plug has been removed. Remove the ICV inner ventport-plug.

6.3.5 Verify the ICV seal-test-port-plug has been removed.

6.3.6 Install the ICV seal leak check tool (see Figure 1.12).

6.3.7 Attach the leak detector to the ICV seal-test-port tool (see Figure 6.1).

6.3.8 Evacuate the ICV seal-test-port until the vacuum is sufficient to operate the leak detector per the manufacturer's recommendations.

6.3.9 Install the ICV vent-port-plug removal/pressure relief tool (see Figure 6.1) into the ICV vent-port, with the ICV outer vent-port-plug retracted into the tool.

6.3.10 Using appropriate fittings, attach in parallel a vacuum pump assembly and helium gas supply assembly to the ICV vent-port-plug removal/pressure relief tool; install an isolation valve into each line to allow independent closure of each line.

NOTE: If evacuation of the ICV cavity cannot achieve a vacuum, disconnect the leak detector and vacuum pump/helium supply assemblies and inspect for possible leaks.

6.3.11 Close the valve to the helium gas supply, open the valve to the vacuum pump, and evacuate the ICV cavity to a $90 \%$ vacuum, or better. Record the vacuum pressure level.

6.3.12 Record the leak detector's background leak rate reading.

NOTE: $\quad$ After helium pressure is stabilized within the ICV cavity, monitor the leak detector for a period of three minutes.

6.3.13 Close the isolation valve to the vacuum pump and open the isolation valve to the helium source. Backfill the ICV cavity with helium gas to atmospheric pressure. Record the backfill pressure. Begin timing for helium leak-testing of the ICV main O-ring seal. 
6.3.14 Rotate the ICV vent-port-plug removal/pressure relief tool handle clockwise to install the ICV outer vent-port-plug hand tight.

6.3.15 Remove the ICV vent-port-plug removal/pressure relief tool and tighten the ICV outer vent-port-plug to 10 to $13 \mathrm{ft}-\mathrm{lbs}$ (120 to 156 in-lbs) torque with an appropriate torque wrench.

6.3.16 At the end of three minutes, record the leakage rate.

6.3.17 Determine the actual leakage rate by subtracting the background reading (step 6.3.12) from the leakage rate (step 6.3.16). If the ICV main O-ring seal fails to pass the leak-test, isolate the leak path, replace the O-ring seal(s) per WI 4.2 and/or repair the seal surface(s) per WI 4.12, and repeat the leak-test. If the system cannot pass the leak-test, prepare an NCR for disposition by the WID National TRU Programs.

6.3.18 Remove the ICV seal leak check tool and associated leak-test equipment from the ICV seal-test-port.

6.3.19 Install the ICV seal-test-port-plug and tighten to 6 to $8 \mathrm{ft}-\mathrm{lbs}$ (72 to $96 \mathrm{in}-\mathrm{lbs}$ ) torque with an appropriate torque wrench.

6.3.20 Install a clean helium-free ICV vent-port-plug leak check tool (see Figure 1.10) into the ICV vent-port (see Figure 6.2).

6.3.21 Attach the leak detector hose assembly to the ICV vent-port-plug leak check tool.

6.3.22 Evacuate the ICV vent-port-plug leak check tool until the vacuum is sufficient to operate the leak detector per the manufacturer's recommendations.

NOTE: Initial spurious leakage rate readings on the leak detector do NOT necessarily indicate a leak. Some residual helium gas may still be entrapped around the vent-port-plug seal and threaded areas.

6.3.23 When the leak detector reading is within the test range (i.e., less than $2.6 \times 10^{-7} \mathrm{scc} / \mathrm{s}$, helium), begin timing the leak-test. At the end of three minutes, record the leakage rate. If the ICV outer vent-port-plug seal fails to pass the leak-test, isolate the leak path, replace the O-ring seal per WI 4.1 and/or repair the seal surface(s) per WI 4.12, and repeat the leak-test. If the system cannot pass the leak-test, prepare an NCR for disposition by the WID National TRU Programs.

6.3.24 Remove the ICV vent-port-plug leak check tool and associated leak-test equipment from the ICV vent-port.

6.3.25 Install the ICV vent-port cover using the ICV vent-port cover removal tool and tighten to 13 to $16 \mathrm{ft}$-lbs (156 to $192 \mathrm{in}-\mathrm{lbs}$ ) torque with an appropriate torque wrench.

6.3.26 Assemble the OCA lid onto the OCA body following the guidelines of the steps in Section 4.3.17. 
6.3.27 Install the OCV vent-port-plug leak check tool (see Figure 1.5) into the OCV vent-port.

6.3.28 Attach the leak detector hose assembly to the OCV vent-port-plug leak check tool (see Figure 6.5).

6.3.29 Evacuate the OCV annulus until the vacuum is sufficient to operate the leak detector per the manufacturer's recommendations.

NOTE: Initial spurious leakage rate readings on the leak detector do NOT necessarily indicate a leak. Some residual helium gas may still be entrapped around the external ICV structure and threaded areas.

6.3.30 When the leak detector reading is within the test range (i.e., less than $2.6 \times 10^{-7} \mathrm{scc} / \mathrm{s}$, helium), begin timing the leak-test. At the end of 30 minutes, record the leakage rate. If the ICV containment structure fails to pass the leaktest, isolate the leak path, perform necessary repairs, and repeat the leak-test. If, after repeated attempts, the system cannot be made to pass the leak-test, prepare an NCR for disposition by the WID National TRU Programs.

6.3.31 Remove the OCV vent-port-plug leak check tool and associated leak-test equipment from the OCV vent-port, and GO TO step 6.2.23.

\subsection{Assembly Leak-Testing the OCV Containment Seals and Structure}

NOTE: The following leak-test instructions are for reference only. Each user shall develop and qualify procedures to perform this test by qualified personnel by following the guidelines of ANSI N14-5-1997, "Radioactive Materials Leakage-Tests on Packages for Shipment."

\subsubsection{Testing Prerequisites}

- To be acceptable, the containment vessel shall have a leakage rate of $1.0 \times 10^{-7} \mathrm{scc} / \mathrm{s}$ (leaktight), air (i.e., $2.6 \times 10^{-7} \mathrm{scc} / \mathrm{s}$, helium, at an ambient temperature of $40^{\circ} \mathrm{F}$, or above).

- $\quad$ Record the OCA lid and body serial numbers on the "OCV Containment Structure Leakage-Test Data Sheet" found in Attachment B-5.

- $\quad$ Obtain a helium mass spectrometer leak detector capable of detecting a leakage rate of $5.0 \times 10^{-8} \mathrm{scc} / \mathrm{s}$, air (i.e., $1.3 \times 10^{-7} \mathrm{scc} / \mathrm{s}$, helium. Record the leak detector's serial number.

- Obtain a calibrated standard leak and calibrate the leak detector according to the manufacturer's recommendations such that the leak detector's sensitivity is $5.0 \times 10^{-8} \mathrm{scc} / \mathrm{s}$, air (i.e., $1.3 \times 10^{-7} \mathrm{scc} / \mathrm{s}$ ). Record the calibrated standard leak serial number.

- Obtain a calibrated ambient temperature measuring device and record the device serial number and ambient temperature.

6.4.2 Assemble the ICV lid in accordance with the guidelines of the steps in Section 4.3.16. 
6.4.3 Install the OCA lid in accordance with the guidelines of the steps in Section 4.3.17.

6.4.4 Fabricate a close-fitting, sealed, plastic tent around the OCA exterior.

6.4.5 Install a helium gas supply line through the bottom of the plastic tent and seal around the hose. Provide a vent hole through the plastic tent opposite the location of the helium supply line.

6.4.6 Install a clean helium-free OCV vent-port-plug leak check tool (see Figure 1.5) through the plastic tent and into the OCV vent-port. Seal around the OCV ventport-plug leak check tool (see Figure 6.6).

6.4.7 Attach the leak detector to the OCV vent-port-plug leak check tool.

6.4.8 Evacuate the OCV annulus until the vacuum is sufficient to operate the leak detector per the manufacturer's recommendations.

6.4.9 Record the leak detector's background leak rate reading.

NOTE: $\quad$ After helium gas is installed outside the OCA, monitor the leak detector for a period of 30 minutes.

6.4.10 Purge the plastic tent with helium gas for a period of time equal to three times the tent fill time. Record the helium purge time. Begin timing for helium leaktesting of the OCV containment structure.

6.4.11 At the end of 30 minutes, record the leakage rate.

NOTE: The helium gas concentration within the plastic tent is conservatively assumed to be $50 \%$. Therefore, the measured leakage rate must be multiplied by a factor of two to account for less than a pure (100\%) concentration of helium gas.

6.4.12 Determine the actual leakage rate by subtracting the background reading (step 6.4.9) from the leakage rate (step 6.4.11), and multiplying the difference by two. If the OCV containment structure fails to pass the leak-test, isolate the leak path, perform necessary repairs, and repeat the leak-test. If the system cannot pass the leak-test, prepare an NCR for disposition by the WID National TRU Programs.

6.4.13 Remove the OCV vent-port-plug leak check tool and associated leak-test equipment from the OCV vent-port.

6.4.14 Remove the helium gas supply and plastic tent.

6.4.15 Remove the OCV seal-test-port-plug using the OCV seal-test-port-plug removal tool (see Figure 1.6).

6.4.16 Install the OCV seal leak check tool (see Figure 1.7).

6.4.17 Attach the leak detector to the OCV seal leak check tool (see Figure 6.3). 
6.4.18 Evacuate the OCV seal-test-port until the vacuum is sufficient to operate the leak detector per the manufacturer's recommendations.

6.4.19 Install the OCV vent-port-plug removal/pressure relief tool (see Figure 1.4) into the OCV vent-port, with the OCV vent-port-plug retracted into the tool.

6.4.20 Using appropriate fittings, attach in parallel a vacuum pump assembly and helium gas supply assembly to the OCV vent-port-plug removal/pressure relief tool; install an isolation valve into each line to allow independent closure of each line.

6.4.21 Close the valve to the helium gas supply, open the valve to the vacuum pump, and evacuate the OCV annulus to a $90 \%$ vacuum, or better. Record the vacuum pressure level.

6.4.22 Record the leak detector's background leak rate reading.

NOTE: $\quad$ After helium pressure is stabilized within the OCV annulus, monitor the leak detector for a period of three minutes.

6.4.23 Close the isolation valve to the vacuum pump and open the isolation valve to the helium source. Backfill the OCV annulus with helium gas to atmospheric pressure. Record the backfill pressure. Begin timing for helium leak-testing of the OCV main O-ring seal.

6.4.24 Rotate the OCV vent-port-plug removal/pressure relief tool handle clockwise to install the OCV vent-port-plug hand tight.

6.4.25 Remove the OCV vent-port-plug removal/pressure relief tool and tighten the OCV vent-port-plug to 13 to $16 \mathrm{ft}-\mathrm{lbs}$ (156 to 192 in-lbs) torque with an appropriate torque wrench.

6.4.26 At the end of three minutes, record the OCV main O-ring seal leakage rate.

6.4.27 Determine the actual leakage rate by subtracting the background reading (step 6.4.22) from the leakage rate (step 6.4.26). If the OCV main O-ring seal fails to pass the leak-test, isolate the leak path, replace the O-ring seal(s) per WI 4.2 and/or repair the seal surface(s) per Work WI 4.12, and repeat the leaktest. If the system cannot pass the leak-test, prepare an NCR for disposition by the WID National TRU Programs.

6.4.28 Remove the OCV seal leak check tool and associated leak-test equipment from the OCV seal-test-port.

6.4.29 Install a helium-free (clean) OCV vent-port-plug leak check tool (see Figure 1.5) into the OCV vent-port.

6.4.30 Attach the leak detector to the OCV vent-port-plug leak check tool.

6.4.31 Evacuate the OCV vent-port-plug leak check tool until the vacuum is sufficient to operate the leak detector per the manufacturer's recommendations. 
NOTE: Initial spurious leakage rate readings on the leak detector do NOT necessarily indicate a leak. Some residual helium gas may still be entrapped around the vent-port-plug seal and threaded areas.

6.4.32 When the leak detector reading is within the test range (i.e., less than $2.6 \times 10^{-7} \mathrm{scc} / \mathrm{s}$, helium), begin timing the leak-test. At the end of three minutes, record the leakage rate. If the OCV vent-port-plug seal fails to pass the leaktest, isolate the leak path, replace the O-ring seal per WI 4.1 and/or repair the seal surface(s) per WI 4.12, and repeat the leak-test. If the system cannot pass the leak-test, prepare an NCR for disposition by the WID National TRU Programs.

6.4.33 Remove the OCV vent-port-plug leak check tool and associated leak-test equipment from the OCV vent-port. 
Figure 6.1 O-Ring Seal Leak-Test Setup Support Arrangement for Assembled ICV

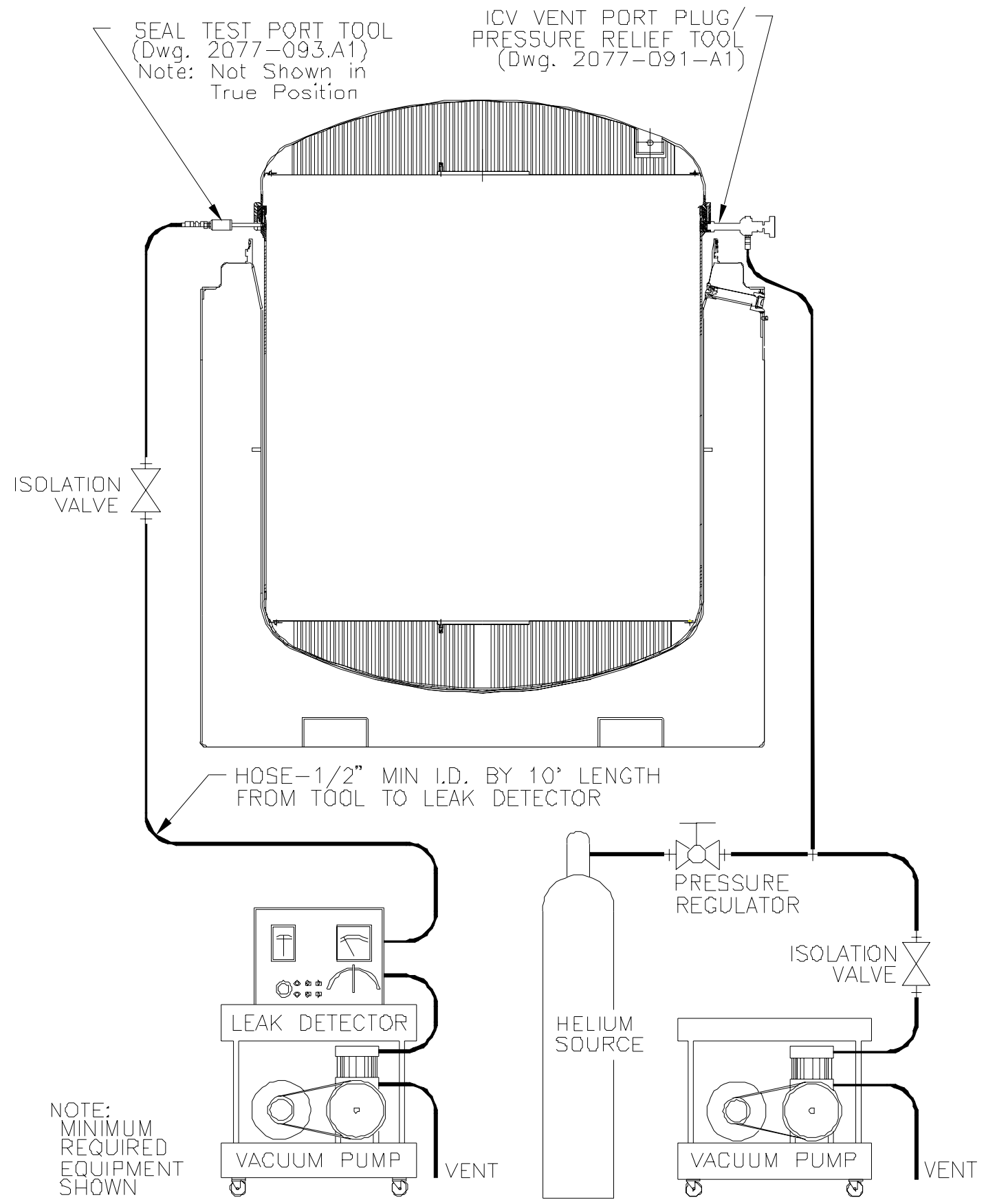

Not to scale 
Figure 6.2 Vent-Port-Plug Seal-Test Setup Support Arrangement for ICV

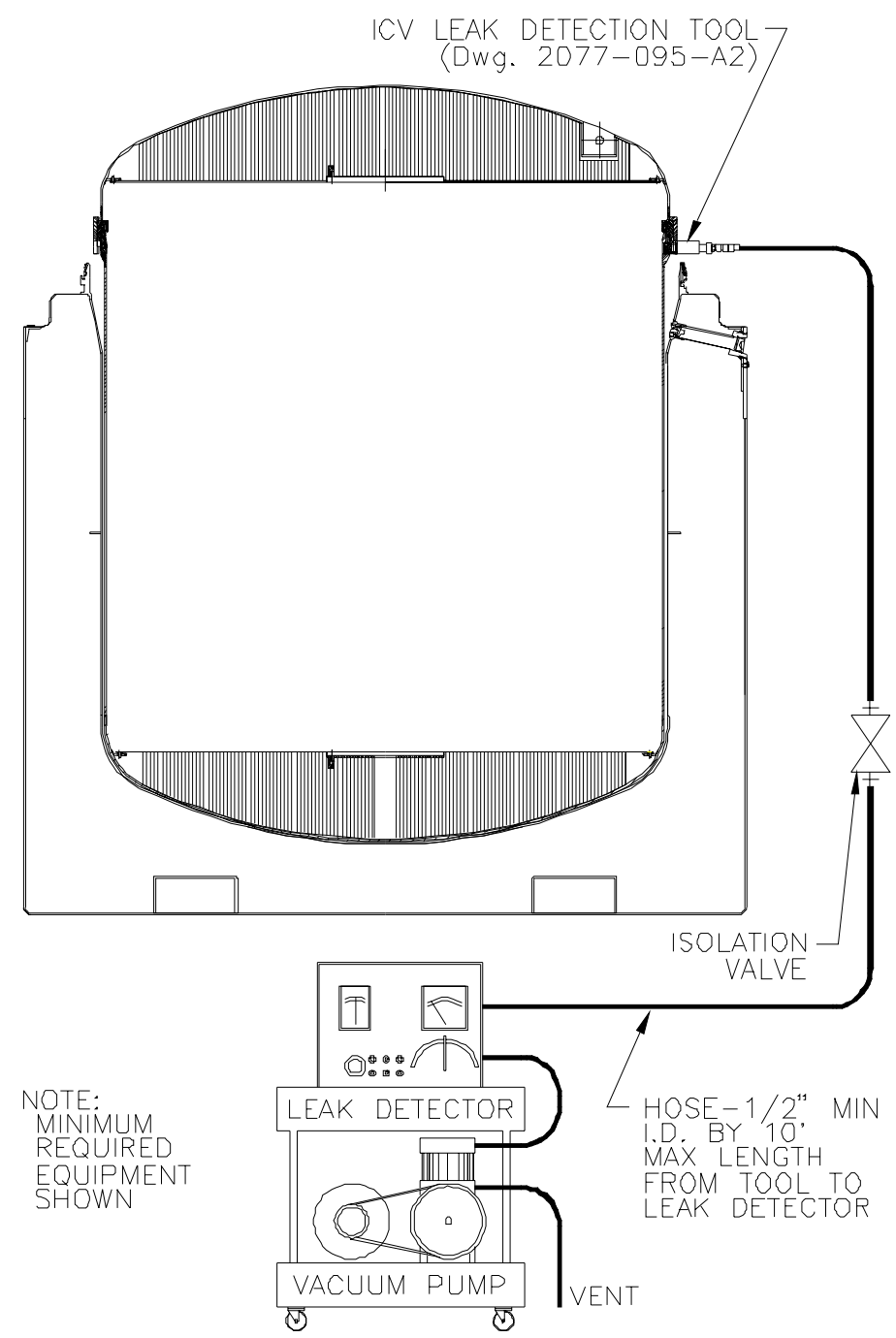

Not to scale 
Figure 6.3 O-ring Seal Leak-Test Setup Support Arrangement for Assembled OCV

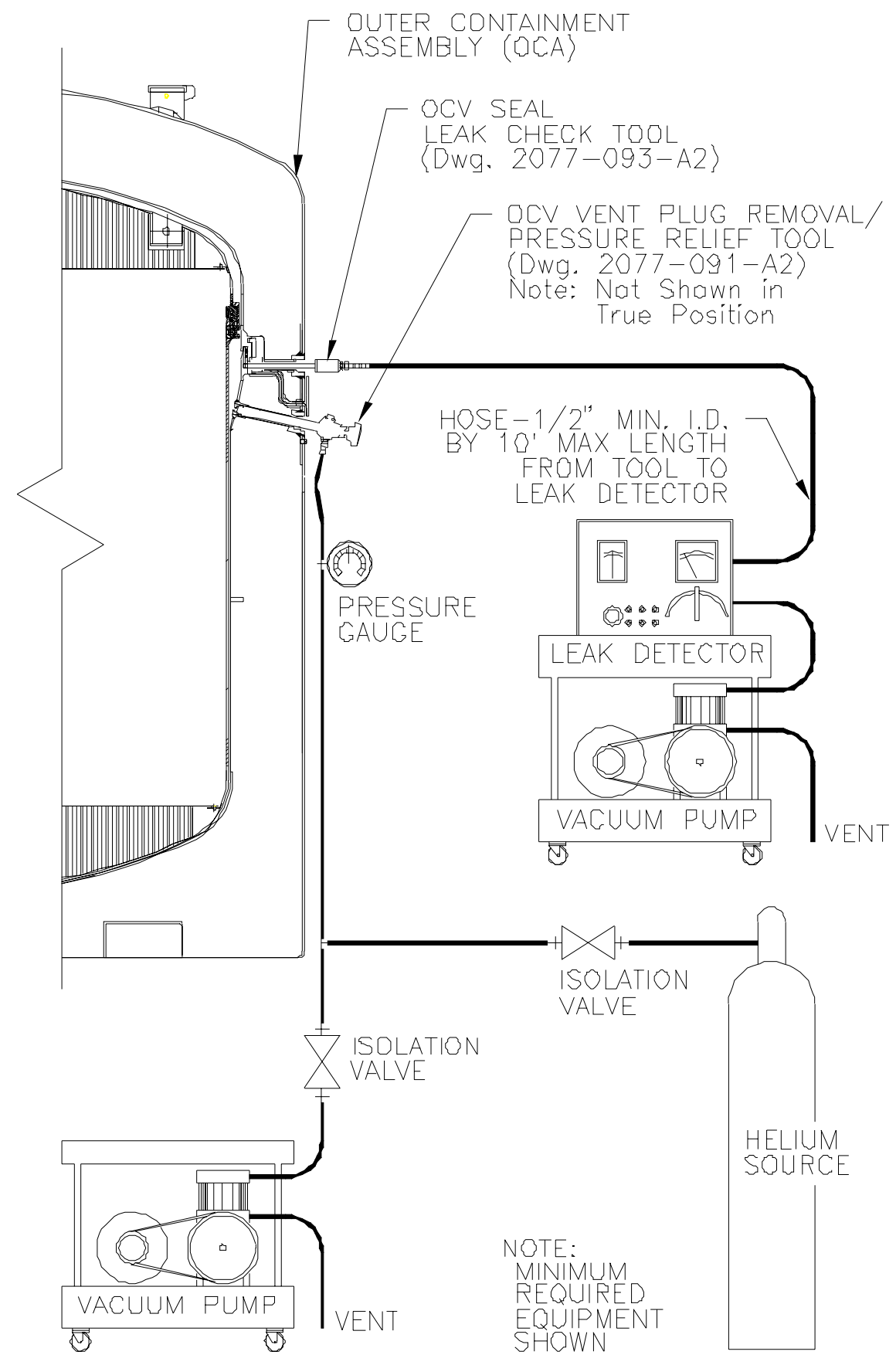

Not to scale 
Figure 6.4 Vent-Port-Plug Seal Test Setup Support Arrangement for OCV

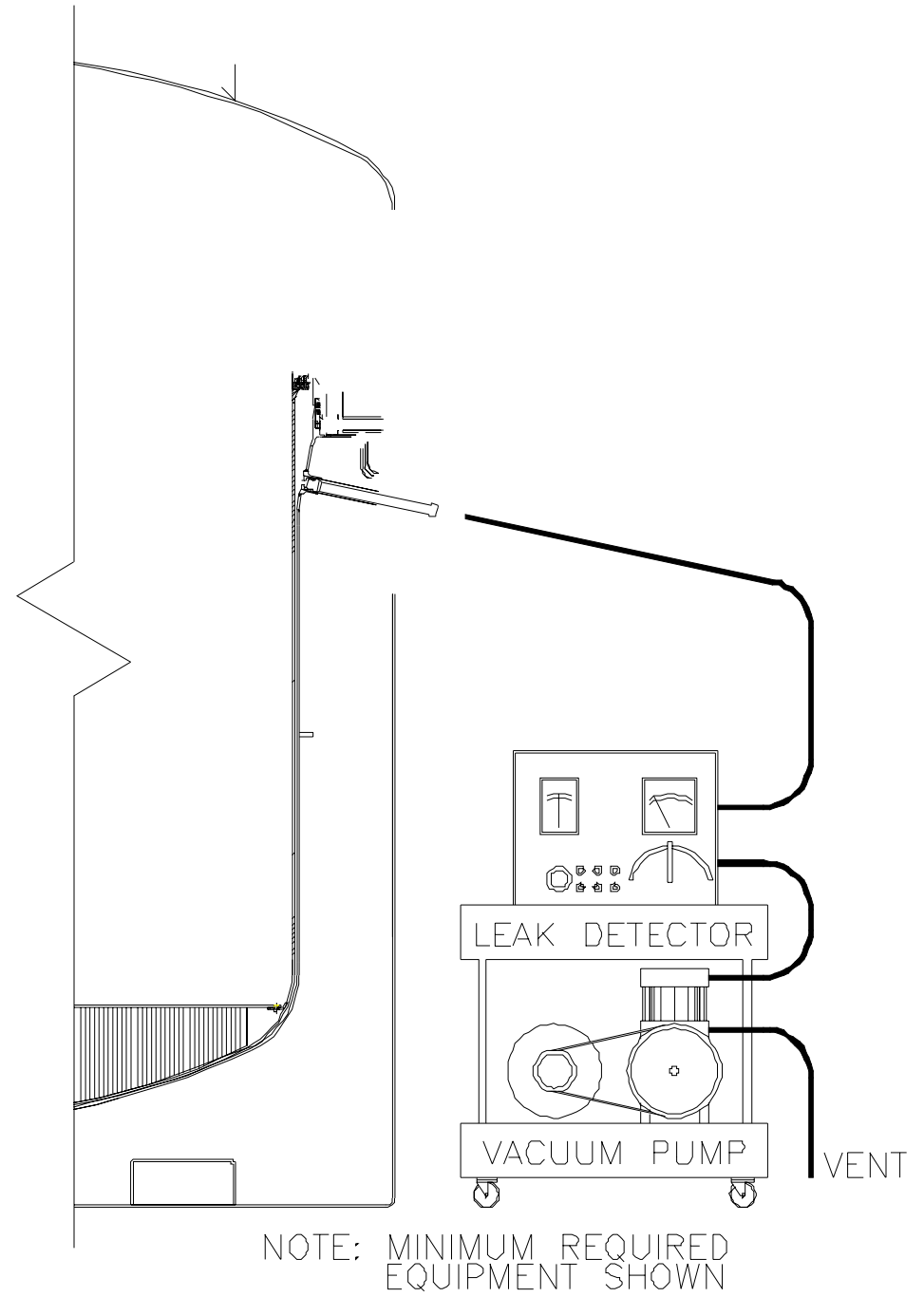

Not to scale 
Figure 6.5 Vessel Weld Leak-Test Setup Support Arrangement for Assembled ICV

ICV Vent Port Plug Leak Check Tool (2077-095-A2)

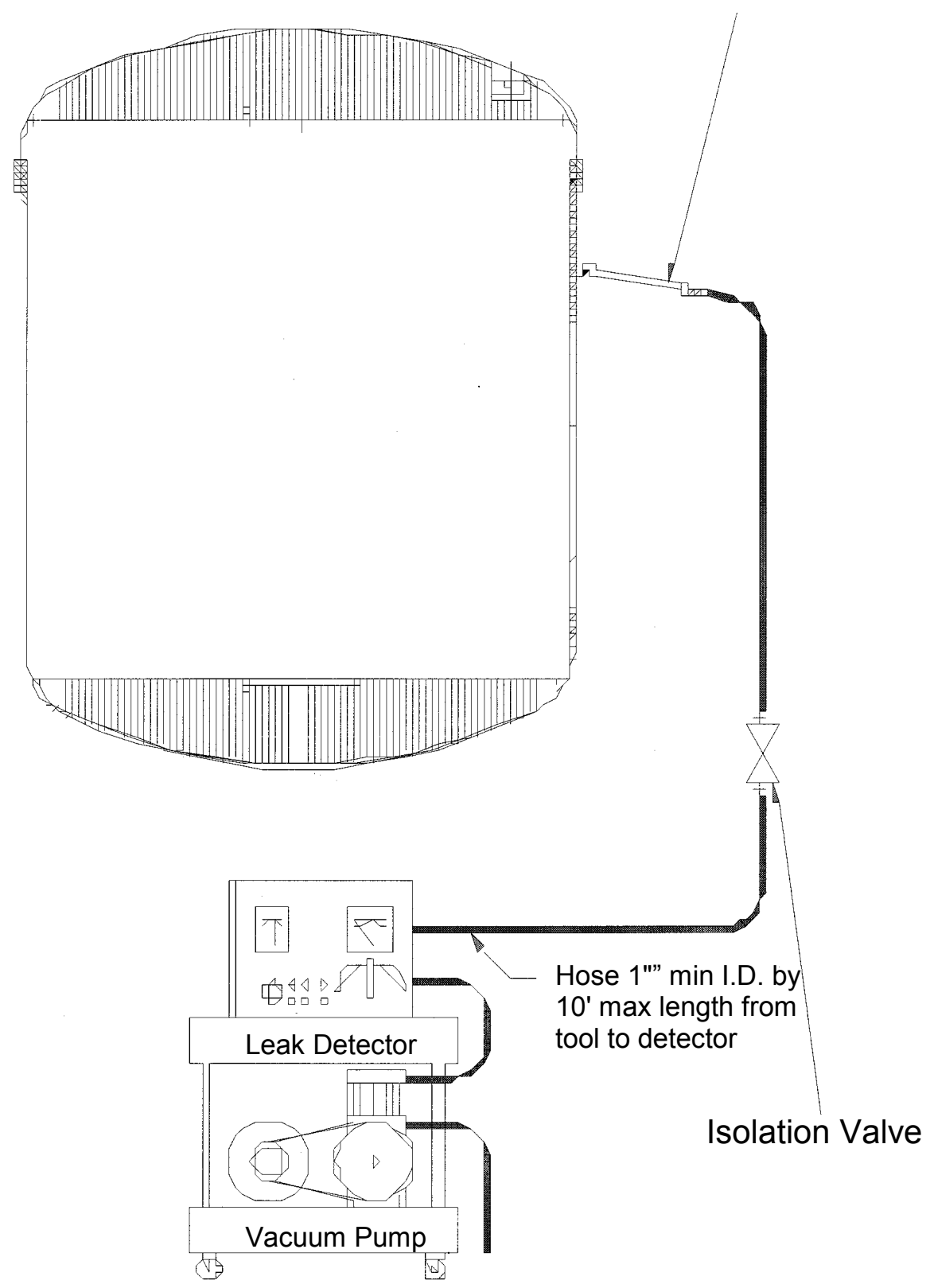

Not to scale 
Figure 6.6 Vessel Weld Leak-Test Setup Support Arrangement for Assembled OCV

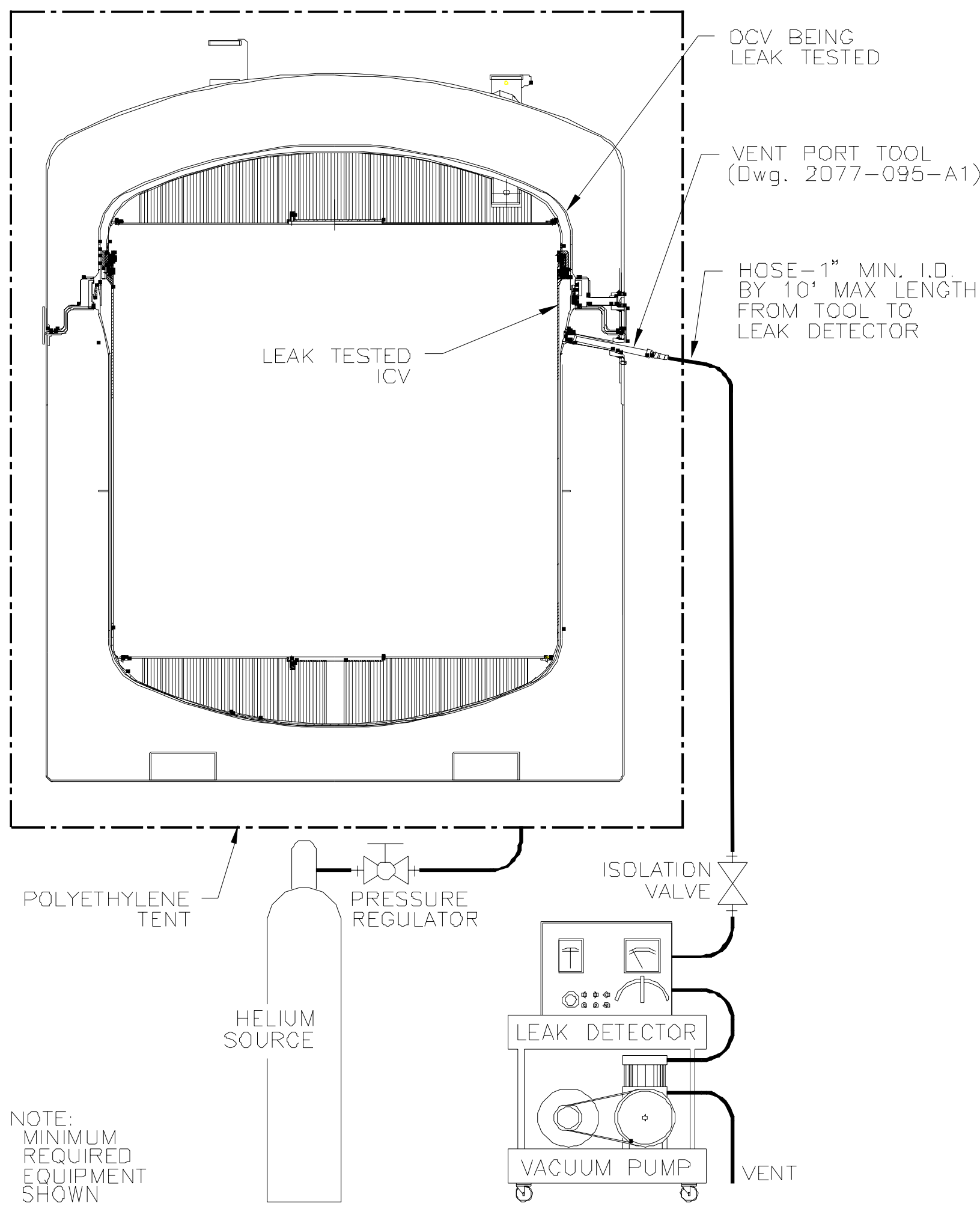

Not to scale 


\subsection{TRUPACT-II PACKAGE STRUCTURAL PRESSURE-TESTING}

\subsection{Structural Pressure-Testing the ICV}

CAUTION: Pneumatic testing of the containment vessel creates a condition where catastrophic failure of the containment vessel, should it occur, would create an explosion of considerable force. Therefore, this test shall be conducted within the confines of a safety enclosure to minimize the possibility of personnel injury or death.

\subsubsection{Testing Prerequisites}

- To be acceptable, the containment vessel shall be pressurized to 75 to $80 \mathrm{psig}$ air, and shall maintain a test pressure of 70 psig or greater for ten minutes.

- $\quad$ Record the ICV lid and body serial numbers on the "ICV Containment Structure Pressure-Test Data Sheet" found in Attachment B-6.

- $\quad$ The ICV Containment Structure Pressure-Test shall be performed every five years after all other preventive maintenance activities have been completed for that year (with exception of the Annual ICV Interior Surfaces Inspection, per Section 5.3 and ICV/OCV leak testing per Sections 6.3 and 6.4). These inspections/tests will be conducted as part of the 5-year structure test. Results will be applied to the annual inspections, as appropriate.

- Obtain primary and secondary calibrated pressure gauges. Record the serial numbers of the calibrated pressure gauges.

7.1.2 Install the ICV lid in accordance with the guidelines of the steps in Section 4.3.16.

7.1.3 Remove the assembled ICV from the OCA and locate the ICV inside a safety enclosure on the ICV work platform.

NOTE: The pressure-test manifold shall be equipped with a valve that can isolate the pressure gauge from the air supply but not from the ICV cavity. A secondary pressure gauge shall be used for primary pressure gauge verification.

7.1.4 Install the ICV vent-port-plug removal/pressure relief tool, with the ICV inner vent-port-plug adapter (see Figure 1.9), and rotate the handle counter-clockwise to remove the ICV inner vent-port-plug. Remove the ICV vent-port-plug removal/pressure relief tool from the ICV vent-port (see Figure 7.1).

7.1.5 Install the ICV vent-port leak check tool (see Figure 1.10) into the ICV vent-port.

7.1.6 Connect the air supply, manifold and the pressure gauges to the ICV vent-port leak check tool.

7.1.7 Pressurize the ICV cavity to $75 \mathrm{psig},+5 /-0$ psig. Isolate the ICV cavity pressure gauges from the air supply after the correct pressure is achieved. Record the primary pressure reading. Begin timing for the containment structure pressuretest. 
7.1.8 After ten minutes, record the secondary pressure reading. If the cavity pressure drops below 70 psig in ten minutes, isolate the leak path, replace the O-ring seal(s) per WI 4.2 and/or repair the seal surface(s) per WI 4.12, and repeat the pressure-test. If the system cannot pass the pressure-test, prepare an NCR for disposition by the WID National TRU Programs.

7.1.9 Depressurize the ICV cavity and remove all pressure-test equipment from the ICV.

NOTE: ICV lid removal does not require the HPT inspections. All actions requiring an HPT may be omitted.

7.1.10 Remove the ICV and work platform from the safety enclosure.

7.1.11 Remove the ICV lid in accordance with the guidelines of the steps in Section 4.3.4.

7.1.12 Perform the Annual ICV Interior Surfaces Inspection per Section 5.3.

\subsection{Structural Pressure-Testing the OCV}

NOTE: The following structural pressure-test instructions are for reference only. Each user shall develop and qualify procedures to perform this test by qualified personnel.

CAUTION: Pneumatic testing of the containment vessel creates a condition where catastrophic failure of the containment vessel, should it occur, would create an explosion of considerable force. Therefore, this test shall be conducted within the confines of a safety enclosure to minimize the possibility of personnel injury or death.

\subsubsection{Testing Prerequisites}

- To be acceptable, the containment vessel shall be pressurized to 75 to 80 psig air, and shall maintain a test pressure of 70 psig or greater for ten minutes.

- $\quad$ Record the OCA lid and body serial numbers on the "OCV Containment Structure Pressure-Test Data Sheet" found in Attachment B-7.

- The OCV Containment Structure Pressure-Test shall be performed every five years after all other preventive maintenance activities have been completed for that year.

- Obtain primary and secondary calibrated pressure gauges. Record the serial numbers of the calibrated pressure gauges.

7.2.2 Install the OCA lid in accordance with the guidelines of the steps in Section 4.12.

7.2.3 Locate the OCA within the safety enclosure. 
NOTE: The pressure-test manifold shall be equipped with a valve that can isolate the pressure gauge from the air supply but not from the ICV cavity. A secondary pressure gauge shall be used for primary pressure gauge verification.

7.2.4 Install the OCV vent-port-plug removal/pressure relief tool (see Figure 1.4), and rotate the handle counter-clockwise to remove the OCV vent-port-plug.

Remove the OCV vent-port-plug removal/pressure relief tool from the OCV ventport (see Figure 7.2).

7.2.5 Install the OCV vent-port leak check tool (see Figure 1.5) into the OCV ventport.

7.2.6 Connect the air supply, manifold and the pressure gauges to the OCV vent-port leak check tool.

7.2.7 Pressurize the OCV cavity to $75 \mathrm{psig},+5 /-0$ psig. Isolate the OCV cavity pressure gauges from the air supply after the correct pressure is achieved. Record the primary pressure reading. Begin timing for the containment structure pressure-test.

7.2.8 After ten minutes, record the secondary pressure reading. If the cavity pressure drops below 70 psig in ten minutes, isolate the leak path, replace the O-ring seal(s) per WI 4.2 and/or repair the seal surface(s) per WI 4.12, and repeat the pressure-test. If the system cannot pass the pressure-test, prepare an NCR for disposition by the WID National TRU Programs.

7.2.9 Depressurize the OCV cavity and remove all pressure-test equipment from the OCV.

NOTE: OCA lid removal does not require the HPT inspections. All actions requiring an HPT may be omitted.

7.2.10 Remove the OCA from the safety enclosure.

7.2.11 Remove the OCA lid in accordance with the guidelines of the steps in Section 4.3.

7.2.12 Perform an inspection of the OCV per Section 5.4.

7.2.13 Reassemble the TRUPACT-II and perform an ICV/OCV leak test per Section 6.0. 
Figure 7.1 Verification Pressure-Test Support Arrangement for Assembled ICV

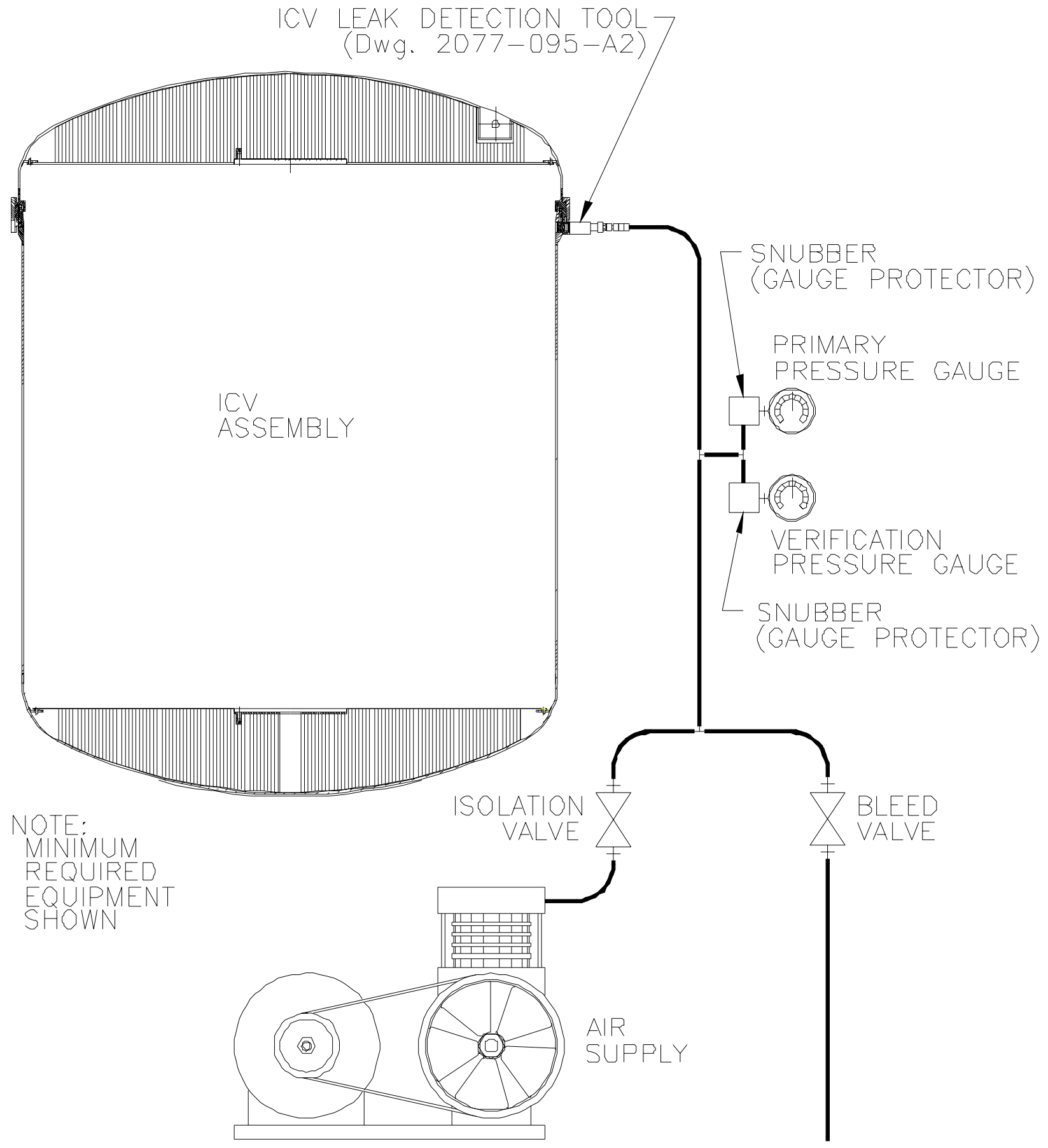

Not to scale 
Figure 7.2 Verification Pressure-Test Support Arrangement for Assembled OCV

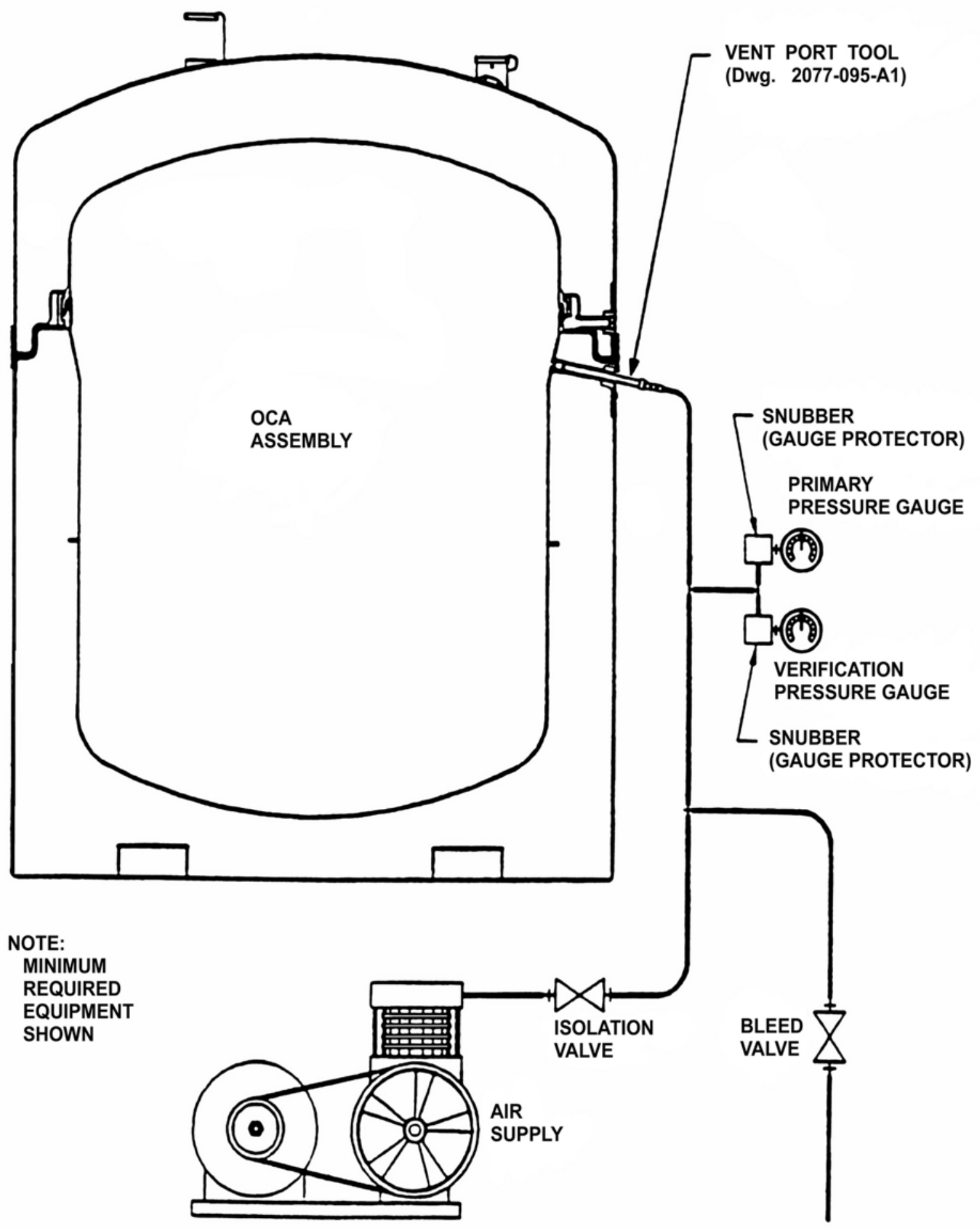




\section{Attachment A - TRUPACT-II Data Sheet}

- $\quad$ Empty TRUPACT-II Receipt and Inspection Data Sheet

- $\quad$ TRUPACT-II Loading Data Sheet

- $\quad$ Loaded TRUPACT-II Trailer Data Sheet

- Loaded TRUPACT-II Receipt and Processing Data Sheet

- Empty TRUPACT-II Shipment Data Sheet

- Empty TRUPACT-II Trailer Data Sheet 


\begin{tabular}{|c|c|c|}
\hline \multicolumn{3}{|c|}{ Empty TRUPACT-II Receipt and Inspection Data Sheet } \\
\hline STEP(S) & DESCRIPTION & INITIALS \\
\hline \multicolumn{3}{|l|}{ Facility: } \\
\hline 4.3.1.1 & TRUPACT-II Serial No: & \\
\hline \multicolumn{3}{|c|}{ PERFORMANCE } \\
\hline 4.3.1.2 & $\begin{array}{l}\text { Shipping documents validated, TRUPACT-II undamaged and released, and } \\
\text { nameplate checked. }\end{array}$ & \\
\hline 4.3.1.3 & TRUPACT-II maintenance labels are present and maintenance is current. & \\
\hline 4.3.6.1 & $\begin{array}{l}\text { Activity on smears is below DOT acceptable limits } \\
\text { Survey No: } \quad \text { Survey Date: }\end{array}$ & \\
\hline 4.3.6.4 & OCA lid components and hardware satisfactory & \\
\hline 4.3.7.1 & $\begin{array}{l}\text { Activity on smears is below DOT acceptable limits } \\
\text { Survey No: } \quad \text { Survey Date: }\end{array}$ & \\
\hline 4.3.7.7 & ICV lid components and hardware satisfactory & \\
\hline 4.3.8.1 & $\begin{array}{l}\text { Activity on smears is below DOT acceptable limits } \\
\text { Survey No: } \quad \text { Survey Date: }\end{array}$ & \\
\hline 4.3.8.5 & OCA body inspection satisfactory & \\
\hline 4.3.9.10 & OCA components and hardware satisfactory & \\
\hline 4.3.10.4 & ICV body inspection satisfactory & \\
\hline 4.3.11.9 & ICV components and hardware satisfactory & \\
\hline 4.3.12.4 & ICV free of water & \\
\hline 4.3 .13 & Pre-loading preparations and inspections complete & \\
\hline
\end{tabular}

Performers, enter printed name, signature, date and initials:

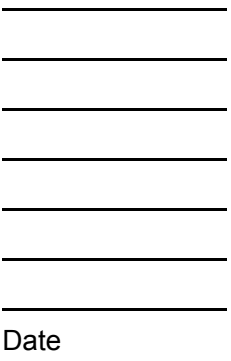

REMARKS: 


\begin{tabular}{|c|c|c|}
\hline \multicolumn{3}{|c|}{ TRUPACT-II Loading Data Sheet } \\
\hline STEP(S) & DESCRIPTION & INITIALS \\
\hline \multicolumn{3}{|l|}{ Facility:_ } \\
\hline 4.3.15.1 & TRUPACT-II Serial No: & \\
\hline \multicolumn{3}{|c|}{ PERFORMANCE } \\
\hline 4.3.15.3 & Payload assembled in accordance with TRAMPAC & \\
\hline 4.3.15.9 & Payload assembly weight: & \\
\hline 4.3.15.11 & Empty TRUPACT-II weight: & \\
\hline 4.3.15.12 & $\begin{array}{l}\text { Loaded TRUPACT-II total weight: } \\
\text { Not to exceed } 19,250 \text { lbs. }\end{array}$ & \\
\hline 4.3.16.1 & ICV Body serial number & \\
\hline 4.3.16.12 & ICV inner vent port plug installed and torqued to specified value & \\
\hline 4.3.16.13 & ICV lock ring bolts installed and torqued to specified values & \\
\hline 4.3.16.14 & Assembly verification leak test performed for ICV containment seals & \\
\hline 4.3.17.11 & OCA Body serial number: & \\
\hline 4.3.17.7 & OCA lock ring bolts installed and torqued to specified values & \\
\hline 4.3.17.8 & Assembly verification leak test performed for OCV containment seals & \\
\hline 4.3.17.11 & $\begin{array}{l}\text { Tamper indicating security seals installed and numbers recorded } \\
\text { Survey No: } \quad \text { Survey Date: }\end{array}$ & \\
\hline
\end{tabular}

Performers, enter printed name, signature, date and initials:

Printed Name
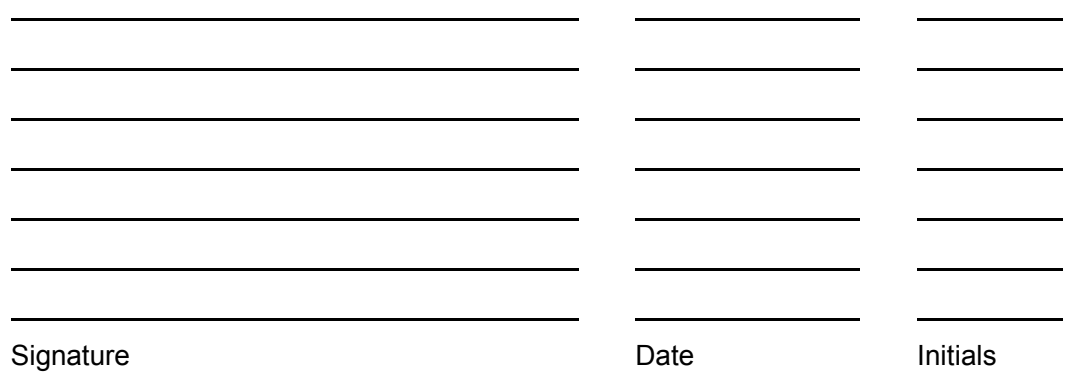

REMARKS:

REVIEW/VALIDATIONS: 


\begin{tabular}{|c|c|c|c|}
\hline \multicolumn{4}{|c|}{ Loaded TRUPACT-II Trailer Data Sheet } \\
\hline STEP(S) & \multicolumn{2}{|c|}{ DESCRIPTION } & Initials \\
\hline \multicolumn{4}{|l|}{ Facility: } \\
\hline \multicolumn{4}{|c|}{ PERFORMANCE } \\
\hline 4.3.18.1 & $\begin{array}{l}\text { Shipment No. } \\
\text { Trailer No. } \\
\text { TRUPACT-II Nos.: }\end{array}$ & & \\
\hline 4.3.18.3 & Trailer Inspection Date: & & \\
\hline 4.3.18.7 & $\begin{array}{l}\text { Position \# } 1 \text { TRUPACT-II S/N: } \\
\text { Position \# } 2 \text { TRUPACT-II S/N: } \\
\text { Position \# } 3 \text { TRUPACT-II S/N: }\end{array}$ & $\begin{array}{ll}\text { Weight: } & \text { lbs. } \\
\text { Weight: } & \text { lbs. } \\
\text { Weight: } & \text { lbs. }\end{array}$ & \\
\hline 4.3.18.8 & Net Payload Weight: (Cannot exceed 52,00c & 0 lbs.) & \\
\hline 4.3.18.9 & TRUPACT-II Shipment complies with 49 CF & R 172, Subparts D, E, and F & \\
\hline 4.3.18.11 & Shipping papers are in accordance with $49 \mathrm{C}$ & CFR 172, Subpart C & \\
\hline 4.3.18.12 & Trailer Loading Complete & & \\
\hline
\end{tabular}

Performers, enter printed name, signature, date and initials:

Printed Name
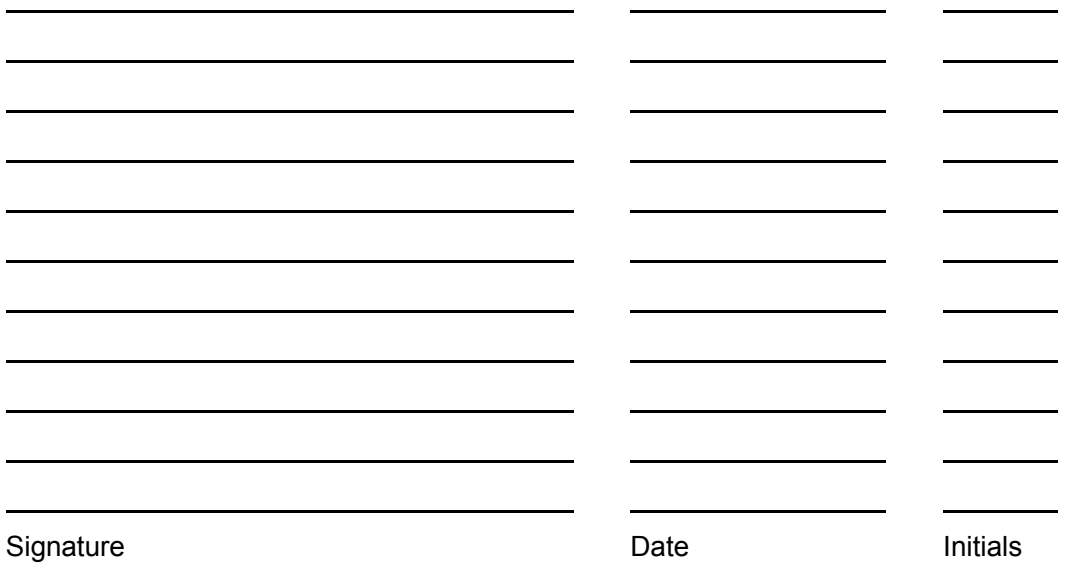

REMARKS:

REVIEW/VALIDATIONS: 


\begin{tabular}{|c|c|c|}
\hline \multicolumn{3}{|c|}{ Loaded TRUPACT-II Receipt and Processing Data Sheet } \\
\hline STEP(S) & DESCRIPTION & Initials \\
\hline \multicolumn{3}{|l|}{ Facility: } \\
\hline \multicolumn{3}{|c|}{ PERFORMANCE } \\
\hline 4.3.19.1 & TRUPACT-II Serial No: & \\
\hline 4.3.19.2 & Shipping documents validated. TRUPACT-II undamaged and released. & \\
\hline 4.3.19.3 & TRUPACT-II external survey complete and below DOT acceptable limits. & \\
\hline 4.3.21.13 & Activity on smears at or below acceptable limits & \\
\hline 4.3.22.13 & Activity on Radiation assessment Filter at or below acceptable limits. & \\
\hline 4.3.22.17 & Activity on smears at or below acceptable limits. & \\
\hline 4.3.23.8 & Payload visually inspected for damage. & \\
\hline 4.3.23.9 & Activity on smears at or below acceptable limits. & \\
\hline
\end{tabular}

Performers, enter printed name, signature, date and initials:

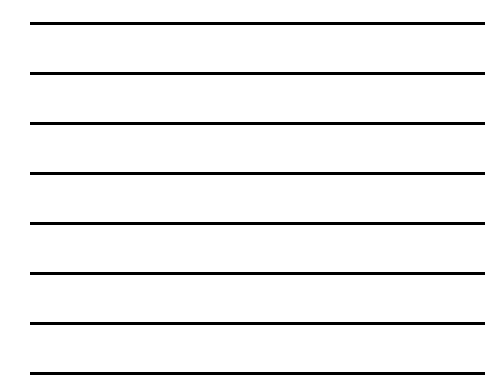

Printed Name

REMARKS:

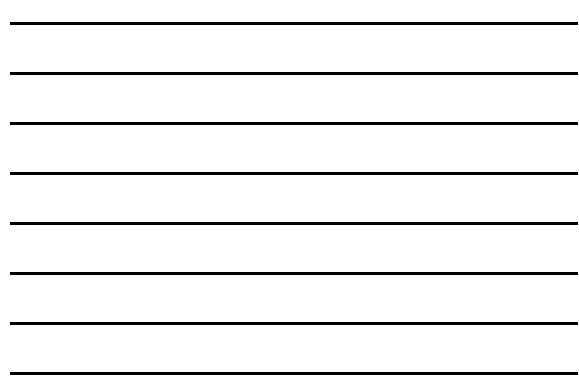

Signature

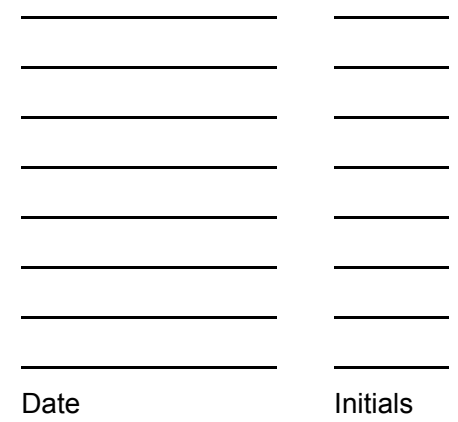

REVIEW/VALIDATIONS:

Supervisor: (Print Name)

Signature

Date 


\begin{tabular}{|c|c|c|}
\hline \multicolumn{3}{|c|}{ Empty TRUPACT-II Shipment Data Sheet } \\
\hline STEP(S) & DESCRIPTION & Initials \\
\hline \multicolumn{3}{|c|}{ Facility: } \\
\hline \multicolumn{3}{|c|}{$\begin{array}{ll}\text { PERFORMANCE } \\
\end{array}$} \\
\hline 4.3.24.1 & TRUPACT-II serial number: & \\
\hline 4.3.24.2 & TRUPACT-II maintenance is current. & \\
\hline 4.3.25.1 & $\begin{array}{l}\text { OCA lid interior and exterior survey complete and below DOT acceptable } \\
\text { limits: } \\
\text { Survey No: }\end{array}$ & \\
\hline 4.3.25.5 & OCA lid components and hardware satisfactory. & \\
\hline 4.3.26.1 & $\begin{array}{l}\text { ICV lid interior and exterior survey complete and below DOT acceptable limits: } \\
\text { Survey No: }\end{array}$ & \\
\hline 4.3.26.7 & ICV Lid components and hardware satisfactory. & \\
\hline 4.3.27.1 & $\begin{array}{l}\text { OCA body exterior and ICV body interior surveys complete and below DOT } \\
\text { acceptable limits } \\
\text { Survey No: }\end{array}$ & \\
\hline 4.3.27.5 & OCA body inspection satisfactory & \\
\hline 4.3.28.10 & OCA components and hardware satisfactory & \\
\hline 4.3.29.4 & ICV body inspection satisfactory & \\
\hline 4.3.30.9 & ICV components and hardware satisfactory & \\
\hline 4.3.31.4 & ICV free of water & \\
\hline 4.3.31.5 & Pre-shipment inspections complete & \\
\hline 4.3.32.2 & ICV body Serial Number: & \\
\hline 4.3.33.2 & OCA body Serial Number: & \\
\hline 4.3.33.15 & Pre-shipment preparations complete. Unit ready for transport. & \\
\hline
\end{tabular}

Performers, enter printed name, signature, date and initials:

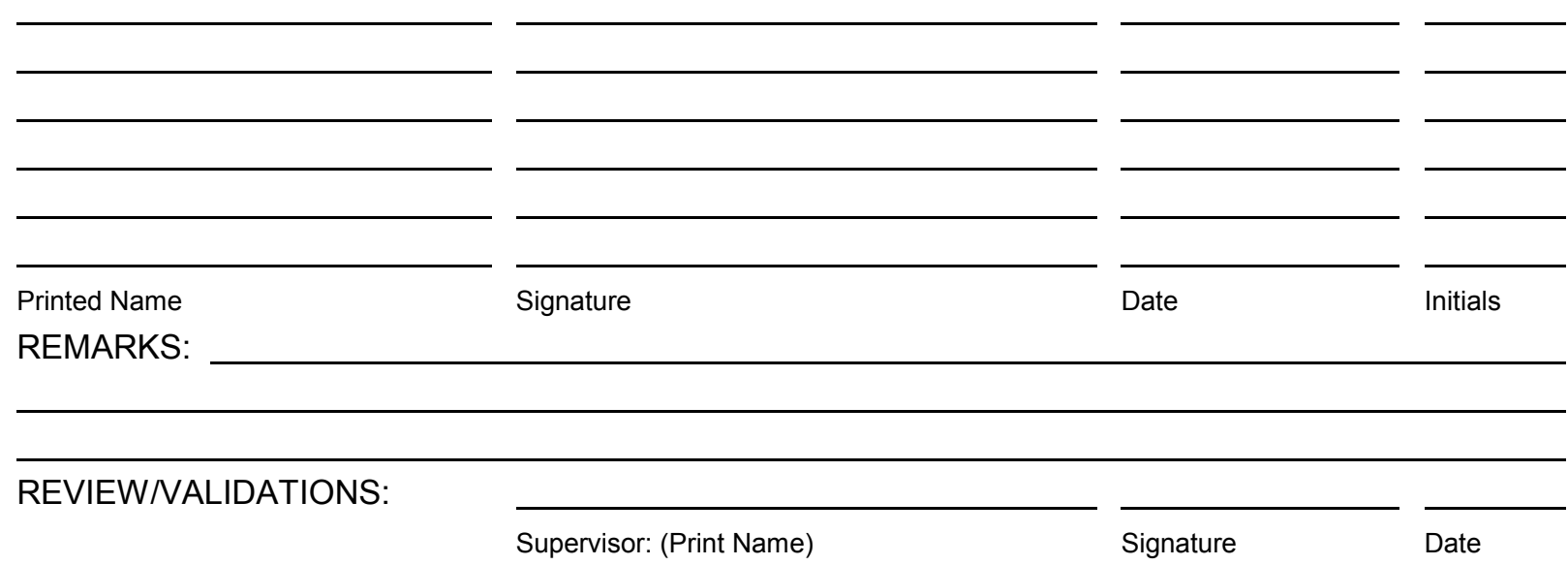




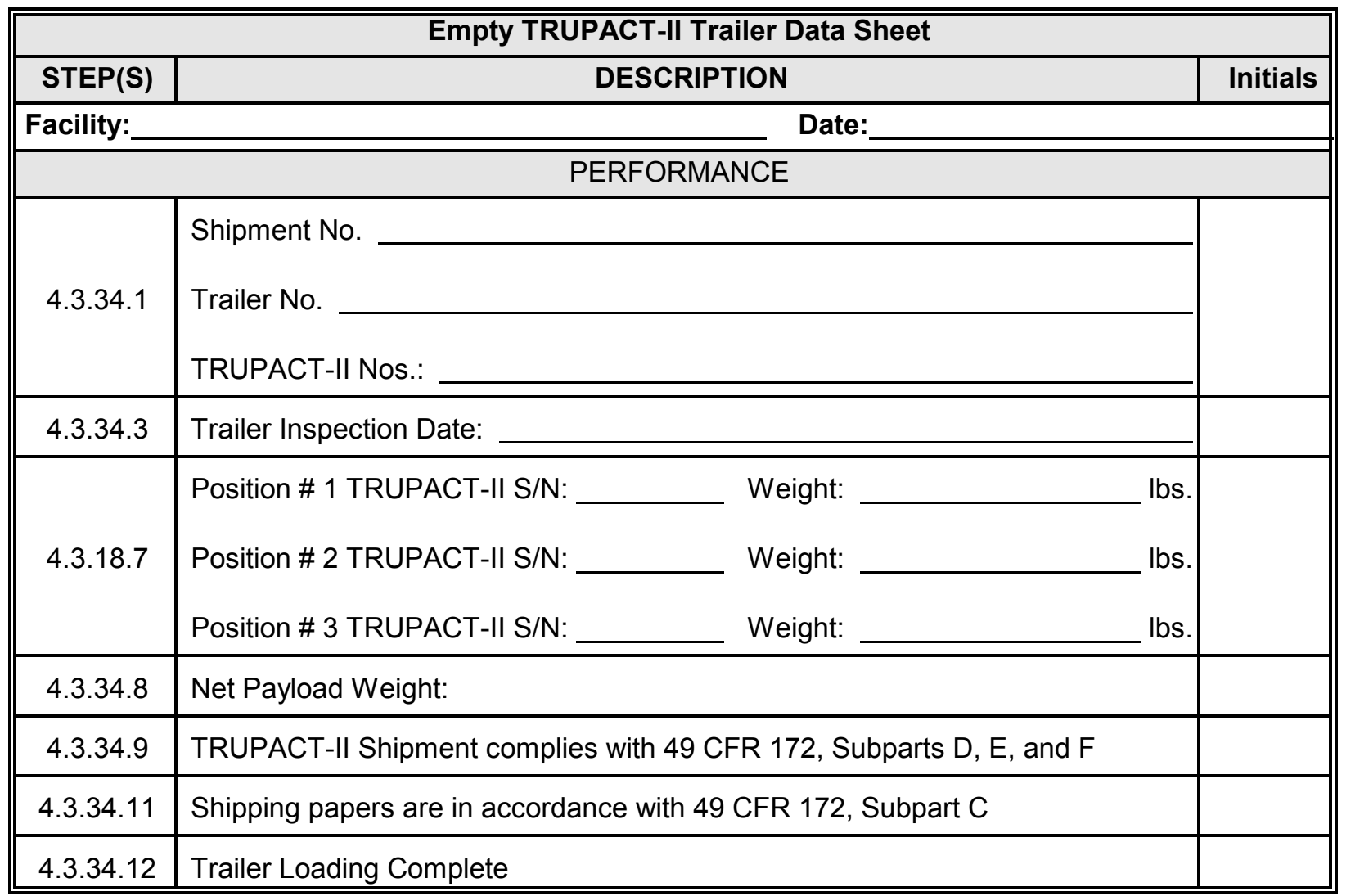

Performers, enter printed name, signature, date and initials:

REMARKS:

REVIEW/VALIDATIONS: 


\section{Attachment B - TRUPACT-II Leakage and Pressure-Test Data Sheets}

- $\quad$ TRUPACT-II ICV Containment Seals Leakage-Test Data Sheet

- $\quad$ TRUPACT-II OCV Containment Seals Leakage-Test Data Sheet

- $\quad$ TRUPACT-II ICV Containment Structure Leakage-Test Data Sheet

- $\quad$ TRUPACT-II OCV Containment Structure Leakage-Test Data Sheet

- $\quad$ TRUPACT-II ICV Containment Structure Pressure-Test Data Sheet

- $\quad$ TRUPACT-II OCV Containment Structure Pressure-Test Data Sheet 


\begin{tabular}{|c|c|}
\hline \multicolumn{2}{|r|}{ TRUPACT-II ICV Containment Seals Leakage-Test Data Sheet } \\
\hline Facility: & Date: \\
\hline STEP & DESCRIPTION \\
\hline 6.1 .1 & $\begin{array}{l}\text { ICV lid serial number: } \\
\text { ICV body serial number: }\end{array}$ \\
\hline 6.1.1 & $\begin{array}{l}\text { Leak detector serial number: } \\
\text { Calibrated standard leak serial number: } \\
\text { Temperature instrument serial number: }\end{array}$ \\
\hline 6.1 .1 & Ambient temperature: \\
\hline 6.1 .1 & Leak detector calibrated \\
\hline 6.1 .2 & Verify ICV lid installed per steps \\
\hline 6.1 .10 & Vacuum pressure level: \\
\hline 6.1 .11 & Leak detector background leak rate reading: \\
\hline 6.1 .12 & Helium pressure level: \\
\hline 6.1 .14 & ICV outer vent-port-plug at 10 to $13 \mathrm{ft}-\mathrm{lbs}$ (120 to $156 \mathrm{in}-\mathrm{lbs}$ ) torque \\
\hline 6.1 .15 & Leak detector test reading: \\
\hline 6.1 .16 & ICV main O-ring seal leakage rate: \\
\hline 6.1 .18 & ICV seal-test-port-plug at 6 to $8 \mathrm{ft}-$-lbs (72 to 96 in-lbs) torque \\
\hline 6.1 .22 & ICV vent-port-plug seal leakage rate: __ He-cc/s \\
\hline 6.1 .24 & ICV vent-port cover at 13 to $16 \mathrm{ft}$-lbs ( 156 to 192 in-lbs) torque \\
\hline
\end{tabular}

Performed by: 


\begin{tabular}{|c|c|}
\hline \multicolumn{2}{|r|}{ TRUPACT-II OCV Containment Seals Leakage-Test Data Sheet } \\
\hline Facility: & Date: \\
\hline STEP & DESCRIPTION \\
\hline 6.2.1 & $\begin{array}{l}\text { OCA lid serial number: } \\
\text { OCA body serial number: }\end{array}$ \\
\hline 6.2 .1 & $\begin{array}{l}\text { Leak detector serial number: } \\
\text { Calibrated standard leak serial number: } \\
\text { Temperature instrument serial number: }\end{array}$ \\
\hline 6.2 .1 & Ambient temperature: \\
\hline 6.2 .1 & Leak detector calibrated \\
\hline 6.2 .2 & Verify OCA lid installed per steps \\
\hline 6.2 .8 & Vacuum pressure level: \\
\hline 6.2 .9 & Leak detector background leak rate reading: \\
\hline 6.2 .10 & Helium pressure level: \\
\hline 6.2 .12 & OCV outer vent-port-plug at 10 to $13 \mathrm{ft}-\mathrm{lbs}$ (120 to $156 \mathrm{in}-\mathrm{lbs}$ ) torque \\
\hline 6.2 .13 & Leak detector test reading: \\
\hline 6.2 .14 & OCV main O-ring seal leakage rate: \\
\hline 6.2 .16 & OCV seal-test-port-plug at 6 to $8 \mathrm{ft}-\mathrm{lbs}$ (72 to 96 in-lbs) torque \\
\hline 6.2 .20 & OCV vent-port-plug seal leakage rate: __ He-cc/s \\
\hline 6.2 .22 & OCV vent-port cover at 13 to $16 \mathrm{ft}-\mathrm{lbs}$ (156 to $192 \mathrm{in}$-lbs) torque \\
\hline 6.2 .23 & $\begin{array}{l}\text { OCV seal-test-port access cover at } 13 \text { to } 16 \mathrm{ft}-\mathrm{lbs} \text { (156 to } 192 \text { ) in-lbs } \\
\text { torque }\end{array}$ \\
\hline 6.2 .24 & OCV vent-port access cover at 35 to $45 \mathrm{ft}-\mathrm{lbs}$ torque \\
\hline
\end{tabular}

Performed by: 


\begin{tabular}{|c|c|}
\hline \multicolumn{2}{|r|}{ TRUPACT-II ICV Containment Structure Leakage-Test Data Sheet } \\
\hline Facility: & Date: \\
\hline STEP & DESCRIPTION \\
\hline 6.3.1 & $\begin{array}{l}\text { ICV lid serial number: } \\
\text { ICV body serial number: }\end{array}$ \\
\hline & Leak detector serial number: \\
\hline 6.3.1 & $\begin{array}{l}\text { Calibrated standard leak serial number: } \\
\text { Temperature instrument serial number: }\end{array}$ \\
\hline 6.3 .1 & Ambient temperature: \\
\hline 6.3 .1 & Leak detector calibrated \\
\hline 6.3 .2 & ICV honey comb spacers removed per WI 4.13 \\
\hline 6.3 .3 & ICV lid installed per steps \\
\hline 6.3 .4 & ICV inner vent-port-plug removed \\
\hline 6.3 .11 & Vacuum pressure level: \\
\hline 6.3 .12 & Leak detector background leak rate reading: __ He-cc/s \\
\hline 6.3 .13 & Helium pressure level: \\
\hline 6.3 .15 & ICV outer vent-port-plug at 10 to $13 \mathrm{ft}-\mathrm{lbs}(120$ to 156$)$ in-lbs torque \\
\hline 6.3 .16 & Leak detector test reading: \\
\hline 6.3 .17 & ICV main O-ring seal leakage rate: \\
\hline 6.3 .19 & ICV seal-test-port-plug at 6 to $8 \mathrm{ft}-\mathrm{lbs}$ ( 72 to 96 in-lbs) torque \\
\hline 6.3 .23 & ICV vent-port-plug seal leakage rate: \\
\hline 6.3 .25 & ICV vent-port cover at 10 to $13 \mathrm{ft}-$ Ibs (156 to 192 in-lbs) torque \\
\hline 6.3 .26 & OCA lid installed per steps \\
\hline 6.3 .30 & ICV containment structure leakage rate: \\
\hline
\end{tabular}

Performed by: 


\begin{tabular}{|c|c|}
\hline \multicolumn{2}{|r|}{ TRUPACT-II OCV Containment Structure Leakage-Test Data Sheet } \\
\hline Facility: & Date: \\
\hline STEP & DESCRIPTION \\
\hline 6.4 .1 & $\begin{array}{l}\text { OCA lid serial number: } \\
\text { OCA body serial number: }\end{array}$ \\
\hline 6.4 .1 & $\begin{array}{l}\text { Leak detector serial number: } \\
\text { Calibrated standard leak serial number: } \\
\text { Temperature instrument serial number: }\end{array}$ \\
\hline 6.4 .1 & Ambient temperature: \\
\hline 6.4.1 & Leak detector calibrated \\
\hline 6.4 .2 & ICV lid installed per Section 4.11 \\
\hline 6.4 .2 & ICV seal and O-ring leak-tested per Section 6.1 \\
\hline 6.4 .3 & OCA lid installed per Section 4.12 \\
\hline 6.4 .9 & Leak detector background reading: \\
\hline 6.4 .10 & Helium purge time: \\
\hline 6.4 .11 & Leak detector test reading: \\
\hline 6.4 .12 & $\begin{array}{l}\text { OCV containment structure leakage rate: } \\
\text { ([step 6.4.11-step 6.4.9] x2) } \mathrm{He-cc/s}\end{array}$ \\
\hline 6.4 .21 & Vacuum pressure level: \\
\hline 6.4 .22 & Leak detector background reading: \\
\hline 6.4 .23 & Helium backfill pressure level: \\
\hline 6.4 .25 & OCV vent-port cover at 10 to $13 \mathrm{ft}-\mathrm{lbs}$ (156 to $192 \mathrm{in}$-lbs) torque \\
\hline 6.4 .26 & OCV main O-ring seal leakage rate: \\
\hline 6.4 .27 & $\begin{array}{l}\text { OCV main O-ring seal leakage rate: } \\
\text { (the value in step } 6.4 .26 \text { minus the value in step } 6.4 .22 \text { ) }\end{array}$ \\
\hline 6.4 .32 & OCV vent-port-plug seal leakage rate: \\
\hline
\end{tabular}

Performed by: 


\begin{tabular}{|c|c|}
\hline \multicolumn{2}{|r|}{ TRUPACT-II ICV Containment Structure Pressure-Test Data Sheet } \\
\hline Facility: & $\begin{array}{l}\text { Date: } \\
\end{array}$ \\
\hline STEP & DESCRIPTION \\
\hline 7.1 .1 & $\begin{array}{l}\text { ICV lid serial number: } \\
\text { ICV body serial number: }\end{array}$ \\
\hline 7.1.1 & All annual preventive maintenance activities completed \\
\hline 7.1.1 & $\begin{array}{l}\text { Primary pressure gauge serial number: } \\
\text { Secondary pressure gauge serial number: }\end{array}$ \\
\hline 7.1.2 & Verify ICV lid installed per Section 4.11 \\
\hline 7.1 .4 & ICV inner vent-port-plug removed \\
\hline 7.1 .7 & Initial primary pressure gauge reading: \\
\hline 7.1.8 & Initial secondary pressure gauge reading: \\
\hline 7.1.7 & Final primary pressure gauge reading: \\
\hline 7.1 .8 & Final secondary pressure gauge reading: \\
\hline
\end{tabular}

Performed by:

Printed Name 


\begin{tabular}{|c|c|}
\hline \multicolumn{2}{|r|}{ TRUPACT-II OCV Containment Structure Pressure-Test Data Sheet } \\
\hline Facility: & Date: \\
\hline STEP & DESCRIPTION \\
\hline 7.2 .1 & $\begin{array}{l}\text { OCA lid serial number: } \\
\text { OCA body serial number: }\end{array}$ \\
\hline 7.2 .1 & All annual preventive maintenance activities completed \\
\hline 7.2 .1 & $\begin{array}{l}\text { Primary pressure gauge serial number: } \\
\text { Secondary pressure gauge serial number: }\end{array}$ \\
\hline 7.2.2 & Verify OCA is installed per Section 4.12 \\
\hline 7.2 .4 & OCV vent-port-plug removed \\
\hline 7.2 .7 & Initial primary pressure gauge reading: \\
\hline 7.2.8 & Initial secondary pressure gauge reading: \\
\hline 7.2 .7 & Final primary pressure gauge reading: \\
\hline 7.2.8 & Final secondary pressure gauge reading: \\
\hline
\end{tabular}

Performed by: 


\section{Attachment C - TRUPACT-II Work Instruction Format}

\section{C.1 Preparing Work Instructions for Periodic Maintenance or Initial Release}

All packaging work/periodic maintenance instructions will be written using "TRUPACT-II Work Instruction Format." The following descriptions and examples will aid in writing work instructions. The spaces listed in the examples may be increased or decreased as required.

- Title

The title will be a short description of the work or periodic maintenance to be performed.

- Instruction Number

The instruction number will be assigned by the WID National TRU Programs. After the instruction number, enter the revision number.

- TRUPACT-II Serial Number

Insert the appropriate serial number at the time of performance.

- Page Of

Insert form page numbering information here.

- $\quad$ Applicable Drawings

Drawings that apply to the work instruction may be SARP drawings or additional shop drawings required to complete the task.

- $\quad$ SARP Requirements

Provide a short narrative of the SARP requirement, reference the appropriate SARP section(s), and applicable SARP section revision number.

- $\quad$ Special Tools Required

List special tools required to complete the task.

- $\quad$ Spare Parts Required

List all TRUPACT-II Packaging spare parts required to complete the task.

- Materials Required

List all materials required to complete the task.

- $\quad$ Safety Requirements

List safety precautions needed to complete the task.

- $\quad$ Prerequisite Conditions

List any required prerequisite conditions 
- Instruction steps

List the detailed procedural steps to follow to complete the task.

- Verification Requirements

List the verification requirements (i.e., leak-tests, material certification, etc.) required to complete the test.

- $\quad$ Signature

Appropriate signatures shall be provided for all signature blocks.

\section{C.2 Revising Existing Work Instructions}

The revision will require the same approval as the original instruction. Revisions may be initiated by telephone or in writing from a user to the WID National TRU Programs. The WID National TRU Programs will approve tentative revisions by telephone, if necessary, and initiate the written revision.

The WID National TRU Programs can be reached during normal hours at (505) 234-7500. After business hours, call the WIPP Central Monitoring Room (CMR) at (505) 234-8125/8457 for communication of relevant items.

\section{C.3 Cancellation of Existing Work Instructions}

Approvals for cancellation will be made by the WID National TRU Programs. The cancellation letter shall be attached to the original Work Instruction and dispositioned per DOE Order 1324.2. The canceled work instruction and all references to the canceled Work Instruction shall be deleted from this document through the normal change and revision procedure, and changes will be distributed to all user sites. 


\section{Page 1 of 4}

\begin{tabular}{|l|l||}
\hline \multicolumn{2}{|c|}{ TRUPACT-II WORK INSTRUCTION } \\
\hline \hline \multirow{2}{*}{ Title: } & Instruction No.: \\
\cline { 2 - 2 } & TRUPACT-II SN: \\
\hline Applicable Drawings: & Page of \\
\hline SARP Requirements: \\
\hline Special Tools Required: \\
\hline Spare Parts Required: \\
\hline Materials Required: \\
\hline Safety Requirements: \\
\hline
\end{tabular}


Page 2 of 4

\begin{tabular}{||ll||}
\hline \multicolumn{1}{||}{ TRUPACT-II WORK INSTRUCTION } \\
\hline \hline Instruction No. Continued \\
\hline Instruction Steps: \\
\hline
\end{tabular}


Page 3 of 4

\begin{tabular}{||l||}
\hline TRUPACT-II WORK INSTRUCTION \\
\hline \hline Instruction No. Continued \\
\hline Instruction Steps Continued: \\
\hline \\
\hline
\end{tabular}


Page 4 of 4

\begin{tabular}{||lc||}
\hline \multicolumn{2}{|c|}{ TRUPACT-II WORK INSTRUCTION } \\
\hline \hline Instruction No. Continued & Page of \\
\hline Instruction Steps Continued: & \\
& \\
\hline Verification Requirements: & \\
\hline \hline Written by: & Date: \\
\hline Approved by: -QA & Date: \\
\hline Approved by: -Engineering & Date: \\
\hline \hline
\end{tabular}


Attachment D - TRUPACT-II Approved Work Instructions

NOTE: $\quad$ Working copies must be made of these Work Instructions, but originals must be returned to this document for future additional copies. All work instructions listed below can be performed by the TRUPACT-II maintenance vendor. Work Instructions 4.1 - 4.6, 4.12, and 4.14 are considered to be within the capabilities of a user to perform. Additionally, steps from 4.13 that pertain to the replacement of spacer fasteners, washers and screws and steps 8 and 9 of 4.7 for installation of OCV Locking Z-Flange Screws are considered withing the capabilities of users to perform.

- WI 4.1, Rev. 6, Replacement of ICV/OCV Small Plugs, O-rings, Gaskets

- WI 4.2, Rev. 6, Replacement of ICV/OCV Upper and Lower Main O-rings, ICV Wiper O-Ring, OCA Fiber Gasket and ICV Debris Seal

- WI 4.3, Rev. 6, Replacement of Misc. Parts Not Requiring Detailed Instructions

- WI 4.4, Rev. 6, Cleaning Flange Threads for OCV Seal-Test-Port/Vent-Port Access Covers

- WI 4.5, Rev. 6, Replacement of Polyethylene Filter in ICV Seal Flange

- WI 4.6, Rev. 6, Replacement of Threaded Inserts/Fasteners for TRUPACT-II

- WI 4.7, Rev. 6, Replacement of OCV Lock-ring Actuator

- WI 4.8, Rev. 6, Axial Play Measurement (OCV Lid-to-Body) (ICV Lid-to-Body) and Wear Pad Replacement

- WI 4.9, Rev. 6, ICV/OCV Lid and Body Seal Flange Tab Widths

- WI 4.10, Rev. 6, ICV/OCV Lid and Body Flange Groove Widths

- $\quad$ WI 4.11, Rev. 6, ICV/OCV Upper Main O-Ring Seal Groove Depth Measurement and Surface Finish

- WI 4.12, Rev. 6, Minor Repair of Vessel O-Ring Sealing Surface ICV/OCV, Minor Repair of Wall Surface ICV/OCA (Exposed Surfaces)

- WI 4.13, Rev. 6, Replacement/Inspection/Measurements ICV Honeycomb Spacers

- $\quad$ WI 4.14, Rev. 1, Minor Repair of ICV/OCV O-Ring Locking Surfaces (burrs, dings, and nicks)

- WI 4.15, Rev. 0, Chg. 1, Annual and 5-Year Maintenance Inspections

WI 4.16, Rev. 0, Repair of ICV/OCV Locking Ring Stop Plate(s)

WI 4.17, Rev. 0, Repair of ICV Upper/Lower Spacer Bracket(s) 
Attachment E - Miscellaneous System Interface and Tool Drawings

- Drawing No. 2077-300, Rev. B , TRUPACT-II Interface Control Drawings

- TRUPACT-II Leak-Test and Vent-Port Tool Drawings:

- $\quad$ Drawing No. 2077-091, Rev. E, TRUPACT-II ICV and OCV Vent Plug Removal/Pressure Relief Tools

- $\quad$ Drawing No. 2077-092, Rev. C, TRUPACT- II OCV and ICV Outer Vent Plug Removal and Installation Tool

- $\quad$ Drawing No. 2077-093, Rev. C, TRUPACT- II ICV/OCV Seal Leak Check Tools

- $\quad$ Drawing No. 2077-094, Rev. D, TRUPACT- II ICV and OCV Seal Check Port-plug Installation/Removal Tools

- $\quad$ Drawing No. 2077-095, Rev. F, TRUPACT- II ICV/OCV Leak Detection Tool

- $\quad$ Drawing No. SK-1104, Spacer Removal Sling

- ACGLF drawings:

- Drawing No. 2014-060, Rev. 0, (ACG) Lift Fixture Top Assembly

- $\quad$ Drawing No. 2014-061, Rev. 0, (ACG) Lift Fixture Frame Weldment

- $\quad$ Drawing No. 2014-062, Rev. 0, (ACG) Lift Fixture Upper Structure Turntable Weldment

- $\quad$ Drawing No. 2014-063, Rev. 0, (ACG) Lift Fixture Counterweight Fabrication and Assembly

- $\quad$ Drawing No. 2014-064, Rev. 0, (ACG) Lift Fixture Leg Weldment and Miscellaneous Details

- $\quad$ Drawing Nos. 2014-400-AB, Rev. 0; 2014-410- AB, Rev. 0; 2014-420-AB, Rev. 0; and 2014-430

- $\quad$ Drawing No. 2077-022, Rev. M, TRUPACT-II Tie-down Assembly 
Attachment F - TRUPACT-II Certificate of Compliance (NRC Docket No. 71-9218) 
Attachment G - TRUPACT- II Safety Analysis Report for Packaging (SARP General Arrangement Drawings)

NOTE: $\quad$ The drawings listed in this section are the design drawings that were approved by the Nuclear Regulatory Commission (NRC). With the exception of Drawing No. 2077-1120, no changes shall be made to these drawings without acquiring NRC approval.

- $\quad$ Drawing No. 2077-007-SNP, Rev. C, TRUPACT-II Payload Assembly Design

- Drawing No.2077-008-SNP, Rev. C, TRUPACT-II Pallet and Alignment Guide Tube Design

- $\quad$ Drawing No.2077-500-SNP, Rev. M, TRUPACT-II Packaging 
Attachment H - TRUPACT- II Qualification Requirements

The following guidelines establish the minimum training requirements for TRUPACT-II Operations. User site qualification cards SHALL include these items as a minimum. Users may separate the requirements to address different skills used to load a TRUPACT-II per site requirements as long as all areas are addressed by each site.

I. References

A. ADJUSTABLE CENTER OF GRAVITY LIFT FIXTURE

1. ACGLF Operation and Maintenance Manual

2. Drawing \#41-J-513 W

B. TRUPACT-II OPERATIONS

1. TRUPACT-II Operating and Maintenance Instructions DOE/WIPP 93-1001

2. TRUPACT-II SARP

3. DOE/WIPP Hoisting and Rigging Standard DOE-STD-1090-99

C. TRUPACT-II MAINTENANCE

1. TRUPACT-II Operating and Maintenance Instructions DOE/WIPP 93-1001

2. TRUPACT-II SARP, Sections 1.0 through 1.2 .3 .1 and Chapters 7 and 8

D. TRAILER LOADING AND UNLOADING TRUPACT-II

1. TRUPACT-II Operating and Maintenance Instructions DOE/WIPP 93-1001

2. TRUPACT-II SARP

3. DOE Hoisting and Rigging Standard DOE-STD-1090-99

II. Knowledge

A. ACGLF

1. State the rated capacity of the ACGLF. (Ref. A.1, 2)

2. Describe the precaution that should be taken before the ACGLF is lifted without a load. (Ref. A.1, ACGLF Operating and Maintenance Instructions)

3. State what to look for when performing a pre-operational check on the ACGLF (Ref. A.1)

4. State what to inspect for on the SWB adapter. (Ref. A.1, ACGLF Operating and Maintenance Instructions)

5. State how to determine if lift clip assemblies are locked in the proper position. (Ref. A.1, ACGLF Operating and Maintenance Instructions)

B. TRUPACT-II OPERATIONS

1. Discuss the ICV/OCV lid removal process. (Ref. B.1)

2. Describe the purpose and identify the type of seals used on the TRUPACT-II. (Ref. B. 1, 2)

3. Describe the physical construction of the TRUPACT-II assembly. (Ref. B.1, 2) 
4. Describe the OCV Locking Ring Assembly. (Ref. B.1)

5. State the lubrication requirements for the O-ring seals. (Ref. B.1, 2)

6. Identify the different special tools required for TRUPACT-II operation and discuss the function of each tool. (Ref. B.1, 2)

7. Explain the purpose of the following TRUPACT-II components. (Ref. B.1, B.2)
a. Seals
b. Lids
c. Pallet
d. Pick points
e. Closure ring lock points
f. Vent and test ports

8. Discuss the limits associated with TRUPACT-II operation (i.e., pressure, radiation levels). (Ref B.1,2)

9. State the locations of the security seals on the TRUPACT-II. (Ref. B.1).

10. Describe the precautions that should be taken when removing the OCV/ICV lids. (Ref. A.1, B.1, 2)

11. Describe the precautions that should be taken when installing the lids. (Ref. B.1)

12. Describe the precautions when removing the ACGLF from the OCV/ICV lids and the waste packages. (Ref. A.1, B.1)

13. State the TRUPACT-II inspection process for the ICV and OCV. (Ref. B.1)

14. Describe the stuck lid removal process. (Ref. B.1)

\section{TRUPACT-II MAINTENANCE}

1. Describe the method of cleaning the port threads. (Ref C.1)

2. Discuss the three different types of leak testing required for the TRUPACT-II and when each must be performed. (Ref. C.1, 2)

3. Identify the materials needed to clean the sealing surfaces. (Ref. C.1)

4. State the hazards associated with improper drill depth setting when replacing threaded inserts. (Ref. C.1)

5. Identify materials required to replace ICV Lid Debris Seal. (Ref. C.1)

6. State how to replace ICV Lid Debris Seal. (Ref. C.1)

7. Describe how to complete a TRUPACT-II maintenance record.

8. State the record retention requirement for TRUPACT-II Maintenance Records.

\section{TRAILER LOADING AND UNLOADING ${ }^{1}$}

1. Describe the use and/or purpose of proper time position for handling TRUPACT-Ils. (Ref. D.1, 2,3)

2. Describe the process of removing the TRUPACT-II from the trailer. (Ref. D.1,3)

3. Discuss what is inspected on the Trailer Tie-down Assembly. (Ref. D.1)

4. State how to re-work/clean tie-downs. (Ref. D.1)

5. State how to lubricate tie-downs. (Ref D.1)

6. State the maximum load limit for the TRUPACT-II AND TRUPACT-II Trailer. (Ref. D.1, 2)

7. State the process of installing TRUPACT-II Tie-downs. (Ref. D.1) 
III. Operations

\section{A. ACGLF}

1. Perform a pre-operational check of the ACGLF. (Ref. A.1)

2. Operate ACGLF. (Ref. A.1, B.1,3)

3. Perform Standard Waste Box Adaptor Pre-operational Checks. (Ref. A.1)

4. Operate Standard Waste Box Adapter. (Ref. A.1, B.1, 3)

B. TRUPACT-II OPERATION

1. Perform Outer Containment Vessel (OCV) Upper Assembly Removal. (Ref. B.1, B.3)

2. Perform Inner Containment Vessel (ICV) Lid Removal. (Ref. B.1, 3)

3. Load a Standard Waste Box (SWB) Payload. (Ref. B.1, 3)

4. Load a Drum Payload. (Ref. B.1,3)

5. Inspect Outer Containment Assembly. (Ref. B.1)

6. Inspect OCV Lower Assembly. (Ref. B.1)

7. Inspect Inner Containment Vessel Lid. (Ref. B.1)

8. Inspect Inner Containment Vessel Lower Assembly. (Ref. B.1)

9. Perform ICV Lid Installation. (Ref. B.1)

10.Perform OCA Upper Assembly Lid Installation. (Ref. B.1)

11. Prepare TRUPACT-II for Trailer Loading. (Ref. B.1)

C. TRUPACT-II MAINTENANCE

1. Replace a Small O-ring. (Ref. C.1)

2. Replace ICV/OCV Lock Ring Bolt Threaded Inserts. (Ref. C.1)

3. Replace ICV Lid Debris Seal. (Ref. C.1)

4. Complete WP Form 1709. (Ref. C.1)

D. TRAILER LOADING AND UNLOADING ${ }^{1}$

1. Transport a TRUPACT-II from the trailer to the dock. (Ref D.1,3)

2. Load a TRUPACT-II on the Trailer. (Ref. D.1,3)

3. Install TRUPACT-II Trailer Tie-downs. (Ref. D.1)

4. Perform Trailer Tie-down Assembly Inspections. (Ref. D.1)

5. Unload a TRUPACT-II from a trailer. (Ref. D.1,3)

${ }^{1}$ This section applies only to those sites that remove the TRUPACT-Ils from trailer for TRUPACT-II operations. 